Technological University Dublin

DƯBLIN

ARROW@TU Dublin

Articles

Crest: Centre for Research in Engineering

Surface Technology

2015-8

\title{
Visible-Light Activation of TiO2 Photocatalysts: Advances in Theory and Experiments
}

\author{
Vinodkumar Etacheri \\ Technological University Dublin \\ Cristiana di Valentin \\ University di milano Bicocca \\ Jenny Schneider \\ University of Hanover
}

See next page for additional authors

Follow this and additional works at: https://arrow.tudublin.ie/cenresart

\section{Recommended Citation}

Etacheri, V. et al (2015) Visible-light activation of TiO2 photocatalysts: Advances in theory and experiments. iJournal of photochemistry and photobiology C: photochemistry reviews. 25 (2015) 1-29. doi:10.1016/j.jphotochemrev.2015.08.003 1389-5567

This Article is brought to you for free and open access by the Crest: Centre for Research in Engineering Surface Technology at ARROW@TU Dublin. It has been accepted for inclusion in Articles by an authorized administrator of ARROW@TU Dublin. For more information, please contact arrow.admin@tudublin.ie, aisling.coyne@tudublin.ie,gerard.connolly@tudublin.ie.

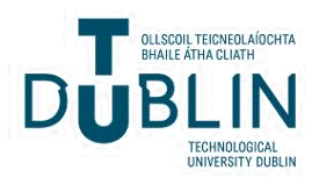


Authors

Vinodkumar Etacheri, Cristiana di Valentin, Jenny Schneider, Detlef Bahnemann, and Suresh Pillai

This article is available at ARROW@TU Dublin: https://arrow.tudublin.ie/cenresart/51 


\section{Visible-Light Activation of $\mathrm{TiO}_{2}$ Photocatalysts: Advances in Theory and Experiments}

Vinodkumar Etacheri, ${ }^{1,2}$ Cristiana Di Valentin, ${ }^{3}$ Jenny Schneider, ${ }^{4}$ Detlef Bahnemann, ${ }^{4,5}$ and Suresh C. Pillai ${ }^{6,7} *$

In this review, advances in the strategies for improving the photocatalytic activity of $\mathrm{TiO}_{2}$ under visible-light irradiation are discussed in detail. Effects of various techniques on the electronic structure and photocatalytic activities have been systematically investigated. Several theoretical insights and future recommendations are presented to enhance the performance of existing visible-light active $\mathrm{TiO}_{2}$.

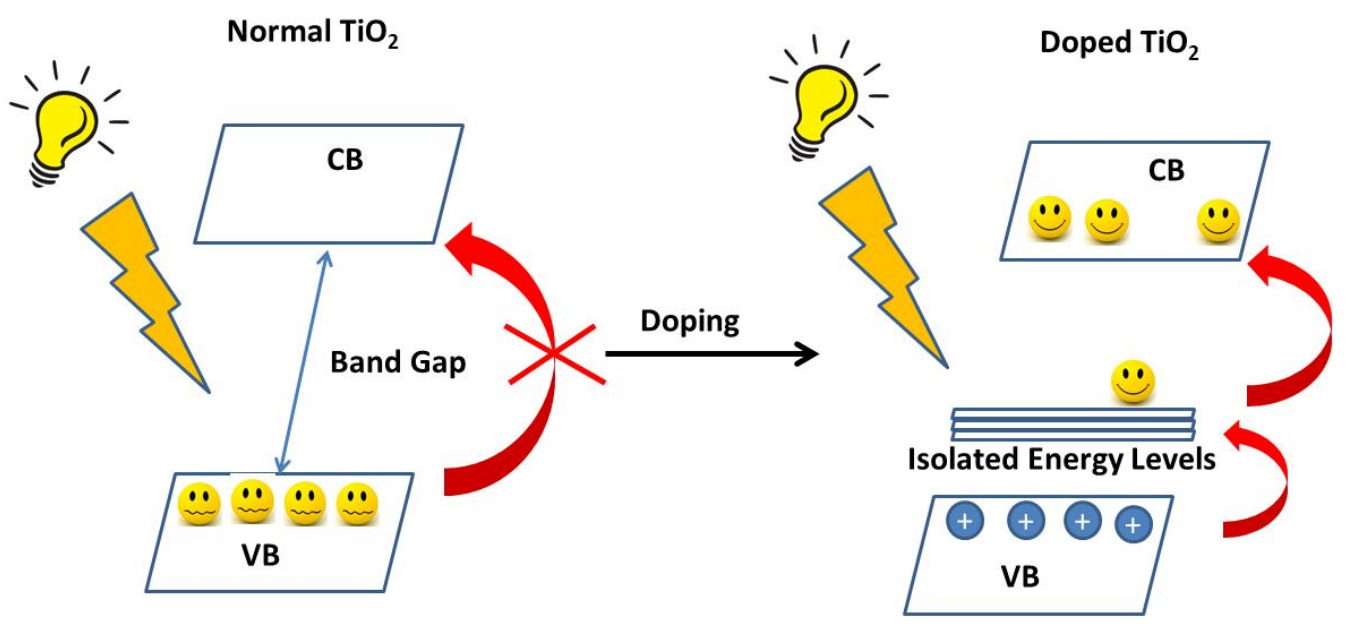

Journal of Photochemistry and Photobiology C: Photochemistry Reviews, Volume 25, December 2015, Pages 1-29: doi:10.1016/j.jphotochemrev.2015.08.003 


\title{
Visible-Light Activation of $\mathrm{TiO}_{2}$ Photocatalysts: Advances in Theory and Experiments
}

Vinodkumar Etacheri, ${ }^{1,2}$ Cristiana Di Valentin, ${ }^{3}$ Jenny Schneider, ${ }^{4}$ Detlef Bahnemann, ${ }^{4,5}$ and Suresh C. Pillai ${ }^{6,7}$ *

${ }^{1}$ School of Chemical Engineering, Purdue University, 480 Stadium Mall Drive West Lafayette, Indiana 47907, United States

${ }^{2}$ Centre for Research in Engineering Surface Technology (CREST), FOCAS Institute, Dublin Institute of Technology, Kevin Street, Dublin 8, Ireland

${ }^{3}$ Dipartimento di Scienza dei Materiali, Università di Milano Bicocca, via Cozzi 55, 20125 Milano, Italy

${ }^{4}$ Institut fuer Technische Chemie, Gottfried Wilhelm Leibniz Universitaet Hannover, Callinstrasse 3, D-30167 Hannover, Germany

${ }^{5}$ Laboratory for Nanocomposite Materials, Department of Photonics, Faculty of Physics, Saint-Petersburg State University, Ulianovskaia str. 3, Peterhof, Saint-Petersburg, 198504, Russia

${ }^{6}$ Nanotechnology Research Group, Department of Environmental Science, Institute of Technology Sligo, Sligo, Ireland

${ }^{7}$ Centre for Precision Engineering, Materials and Manufacturing Research (PEM), Institute of Technology, Sligo, Sligo, Ireland

*Email pillai.suresh@itsligo.ie; Phone +353 719305816

Keywords: Photo-induced reactions, solar energy, mechanism, fundamentals, doping, graphene, energy and environmental, hydrogen production, tutorial review.

\begin{abstract}
The remarkable achievement by Fujishima and Honda (1972) in the photoelectrochemical water splitting results in the extensive use of $\mathrm{TiO}_{2}$ nanomaterials for environmental purification and energy storage/conversion applications. Though there are many advantages for the $\mathrm{TiO}_{2}$ compared to other semiconductor photocatalysts, its
\end{abstract}


band gap of $3.2 \mathrm{eV}$ restrains application to the UV-region of the electromagnetic spectrum $(\lambda \leq 387.5 \mathrm{~nm})$. As a result, development of visible-light active titanium dioxide is one of the key challenges in the field of semiconductor photocatalysis. In this review, advances in the strategies for the visible light activation, origin of visiblelight activity, and electronic structure of various visible-light active $\mathrm{TiO}_{2}$ photocatalysts are discussed in detail. It has also been showed that if appropriate models are used, the theoretical insights can successfully be employed to develop novel catalysts to enhance the photocatalytic performance in the visible region. Recent developments in the theory and experiments in visible-light induced water splitting, degradation of environmental pollutants, water and air purification and antibacterial applications are also reviewed. Various strategies to identify appropriate dopants for improved visible-light absorption and electron-hole separation to enhance the photocatalytic activity are discussed in detail, and a number of recommendations are also presented.

\section{Introduction}

Photocatalysis refers to the acceleration of a chemical reaction in the presence of substances called photocatalysts, which can absorb light quanta of appropriate wavelengths depending on the band structure [1-4]. Usually semiconductors including $\mathrm{TiO}_{2}, \mathrm{Fe}_{2} \mathrm{O}_{3}, \mathrm{WO}_{3}, \mathrm{ZnO}, \mathrm{CeO}_{2}, \mathrm{CdS}, \mathrm{Fe}_{2} \mathrm{O}_{3}, \mathrm{ZnS}, \mathrm{MoO}_{3}, \mathrm{ZrO}_{2}$, and $\mathrm{SnO}_{2}$ are selected as photocatalysts due to their narrow band gap and distinct electronic structure (unoccupied conduction band and occupied valence band) [5-24]. In semiconductor photocatalysis, electrons from the valence band of a semiconductor are excited to the conduction band by light of higher energy matching the band gap, resulting in $\mathrm{e}^{-}{ }_{\mathrm{CB}} /$ $\mathrm{h}^{+}$vB pairs (Figure 1). Conduction band electrons are good reducing agents $(+0.5$ to $1.5 \mathrm{~V}$ vs. NHE) whereas the valence band holes $\left(\mathrm{h}^{+}{ }_{\mathrm{VB}}\right)$ are strong oxidising agents 
$(+1.0$ to $+3.5 \mathrm{~V}$ vs. NHE) [25]. The lack of a continuum of inter-band states in semiconductors assures an adequately extended lifetime for photogenerated $\mathrm{e}_{\mathrm{CB}}^{-} / \mathrm{h}^{+}{ }_{\mathrm{VB}}$ pairs to initiate a redox reaction on the catalyst surface. Electrons in the conduction band can reduce $\mathrm{O}_{2}$ to form superoxide radicals $\left(\mathrm{O}_{2}{ }^{-}\right)$. Additional reaction of $\mathrm{O}_{2} \bullet^{-}$ with holes on the valence band produce singlet oxygen $\left({ }^{1} \mathrm{O}_{2}\right)[26,27]$. Subsequent reaction of valence band holes with surface adsorbed $\mathrm{H}_{2} \mathrm{O}$ or $\mathrm{HO}^{-}$result in the formation of hydroxyl radicals $(\mathrm{HO} \bullet)$, hydrogen peroxide $\left(\mathrm{H}_{2} \mathrm{O}_{2}\right)$, and protonated superoxide radical (HOO•). $\mathrm{H}_{2} \mathrm{O}_{2}$ in the valence band is reported to be resulting from the coupling of two $\mathrm{HOO} \cdot[28,29]$. Further reaction of $\mathrm{H}_{2} \mathrm{O}_{2}$ with $\mathrm{HO} \cdot$ to form protonated superoxide radical $(\mathrm{HOO} \bullet)[4,30]$.

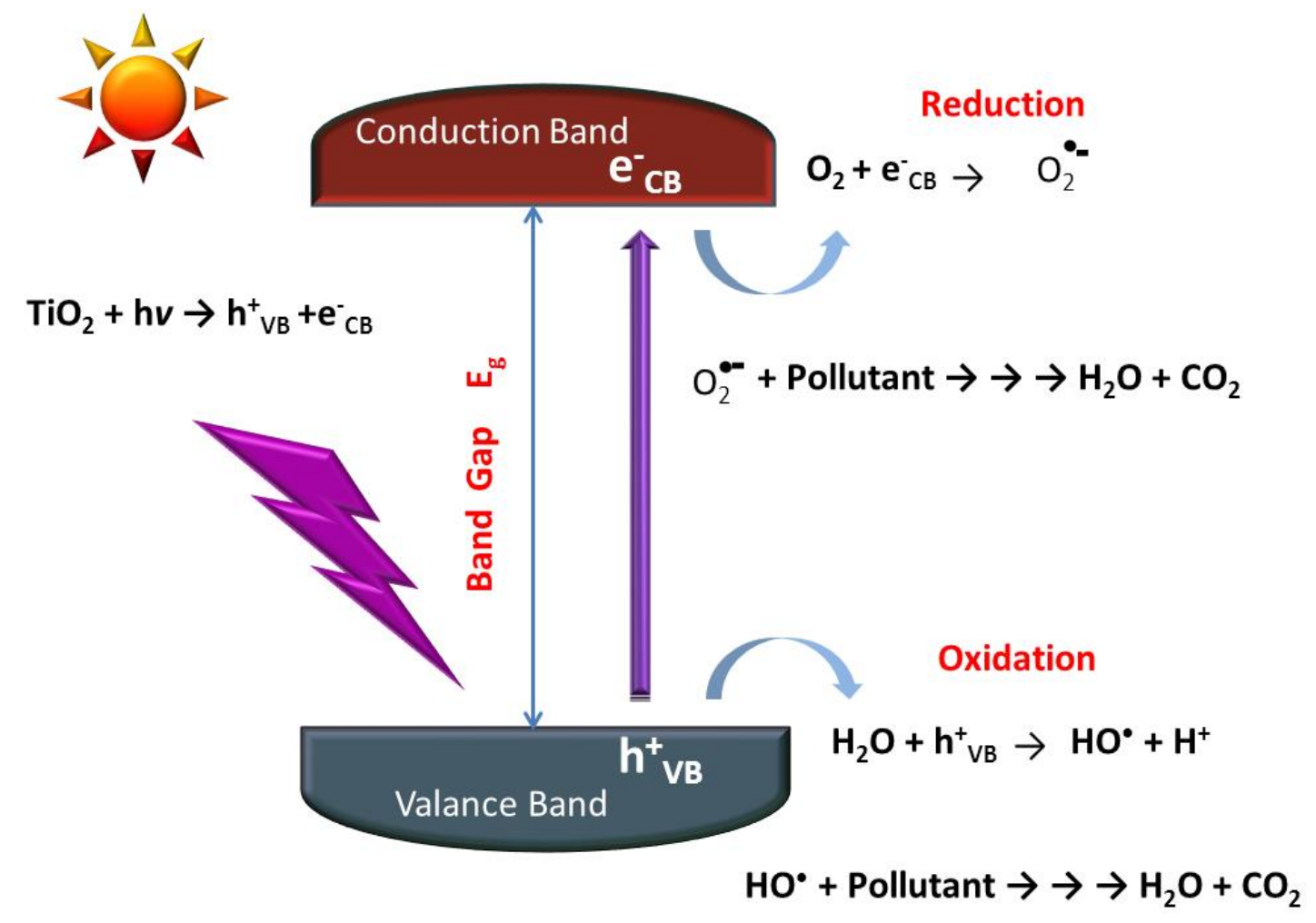

Figure 1. Mechanism of semiconductor photocatalysis. Reproduced with permission from ref.

[4] Copyright 2015 Elsevier Science 
During the photocatalytic process, free electrons/holes, and reactive oxidizing species (ROS) such as $\mathrm{HO}_{2} \bullet, \mathrm{HO} \bullet$ and $\mathrm{O}_{2}{ }^{-}$react with the surface adsorbed impurities including inorganic, organic compounds, and biological species (bacteria, virus etc.) leading to their decomposition. The efficiency of a photocatalytic reaction mainly depends on the capability of the photocatalyst to generate longer-lived electrons and holes that result in the formation of reactive free radicals. Usually, the crucial aspect is the creation and efficient utilization of the reactive oxidizing species (ROS). Semiconductor nanomaterials, especially $\mathrm{TiO}_{2}$ find wide range of applications in the area of photocatalysis, pigments, dye sensitized solar cells, air/water sanitization, initiation of chemical reactions, optoelectronics, cancer therapy, cathodic protection of metals from corrosion, electrochromic displays, and light-activated antibacterial surfaces $[6-8,10,11,13,17,19,31-46]$. Currently, researchers all over the world are trying to improve the efficiency and selectivity of $\mathrm{TiO}_{2}$ photocatalysts for various applications. Although a number of review papers and feature articles are published recently on the advances of $\mathrm{TiO}_{2}$ photocatalysis [1-4, 7, 47-50], theoretical and experimental strategies for visible light activation have not been described comprehensively. To gain further insights into the development of next generation photocatalysts, it is highly desirable to condense the advances in experimental as well as theoretical approaches. Aim of this review is to summarize the progress in the experimental methods, theoretical approaches, and electronic structure modelling of $\mathrm{TiO}_{2}$ for the visible-light activation. Several recommendations are also presented for improving the visible-light absorption and electron-hole separation of current generation $\mathrm{TiO}_{2}$ photocatalysts.

\section{Basic principles and mechanism of photocatalysis}

\subsection{Structural and electronic properties}


The initial work of water decomposition using electrodes composed of $\mathrm{TiO}_{2}$ was done by Fujishima and Honda [5]. They found that the photolysis of water into their individual constituents $\left(\mathrm{H}_{2}\right.$ and $\left.\mathrm{O}_{2}\right)$ is greatly affected by the nature of surface defects. However, the quantum efficiencies of $\mathrm{TiO}_{2}$ in solar energy conversions are rather poor due to faster recombination of electron-hole pairs $[13,51]$. Since its invention in 1972 , light-induced decomposition of organic species is the most vigorously investigated application of $\mathrm{TiO}_{2}$ photocatalyst. For the first time, photocatalytic reduction of $\mathrm{CN}^{-}$in aqueous solution was reported in 1977 by Frank and Bard [52, 53]. This investigation triggered the use of $\mathrm{TiO}_{2}$ photocatalyst for water purification by exploiting solar irradiations $[18,54,55]$. Other noteworthy advances include the invention of dye sensitized solar cells by Gratzel et al, which is composed of titanium dioxide anodes and the discovery of anti-fogging abilities of $\mathrm{TiO}_{2}$ surfaces by Wang et al. $[33,56]$ The extensive use of titanium dioxide for a wide range of applications over other photocatalysts results from its non-toxicity, abundance (inexpensiveness), thermal/chemical stability, and high redox potential $[18,57,58]$. Anatase (tetragonal), rutile (tetragonal), and brookite (orthorhombic) are three polymorphs of $\mathrm{TiO}_{2}$. Band gaps of anatase, rutile and brookite phases are 3.2, 3.0 and 3.4 eV respectively [59-61]. Wider band gaps are common for poorly crystallized nanoparticles and thin films, and a band gap narrowing up to $0.2 \mathrm{eV}$ was observed for $\mathrm{TiO}_{2}$ nanomaterials having 5-10 nm particle size. Anatase and brookite are meta-stable phases, and rutile is thermodynamically stable. Anatase and brookite $\mathrm{TiO}_{2}$ irreversibly and exothermically converts to rutile at temperatures exceeding $600{ }^{\circ} \mathrm{C}[8,10,62,63]$. Due to superior mobility of electron-hole pairs, and improved surface hydroxyl density, anatase $\mathrm{TiO}_{2}$ exists as the photocatalytically most active polymorph of $\mathrm{TiO}_{2}[54,64,65]$. In contrast, photocatalytic performance of rutile $\mathrm{TiO}_{2}$ is not promising, and the activity of brookite 
phase is not systematically investigated $[19,66]$. A number of factors, such as surface area, particle size, ratio of polymorphs, type of dopants, defect concentration, synthesis method, and phase purity, strongly affect the photocatalytic activity of $\mathrm{TiO}_{2}$ [67-69].

The crystal structure of $\mathrm{TiO}_{2}$ polymorphs can be explained by the different spatial arrangements of $\mathrm{TiO}_{6}$ octahedra $\left(\mathrm{Ti}^{4+}\right.$ ions bordered by six $\mathrm{O}^{2-}$ ions). The differences between three crystal structures are the various degrees of distortion and 3D assembly of $\mathrm{TiO}_{6}$ octahedra (Figure 2). In the anatase tetragonal crystal structure ( $a$ $=b=3.78 \AA, c=9.50 \AA$ ) each octahedron share corners to form (001) plane. Whereas tetragonal structure of rutile ( $a=b=4.58 \AA, c=2.95 \AA$ ) consists of edge sharing octahedron (001) plane. Orthorhombic structure of brookite phase ( $a=5.43 \AA$, b = 9.16 $\AA, c=5.13 \AA$ ) is made up of both corner and edge sharing octahedra. These different crystal structures result in various densities and electronic structure of the three $\mathrm{TiO}_{2}$ polymorphs. Titanium dioxide usually exists as an n-type type semiconductor due to the presence of oxygen vacancies [70]. Photocatalytic activity of amorphous $\mathrm{TiO}_{2}$ is negligible compared to that of crystalline $\mathrm{TiO}_{2}[71,72]$. This is because the crystalline structure minimizes the photo excited electron hole recombination.

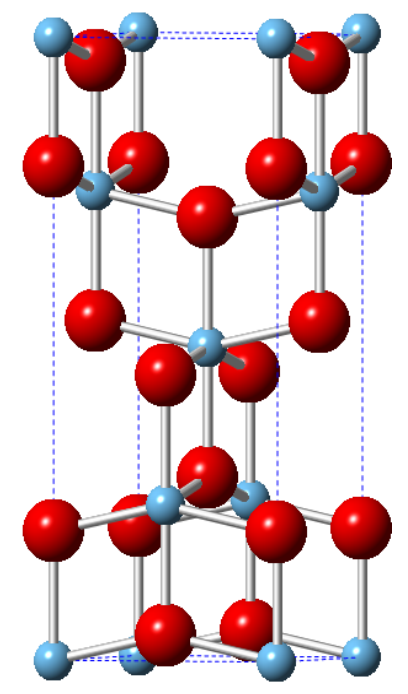

Anatase

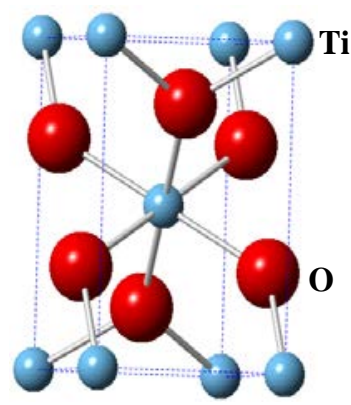

Rutile

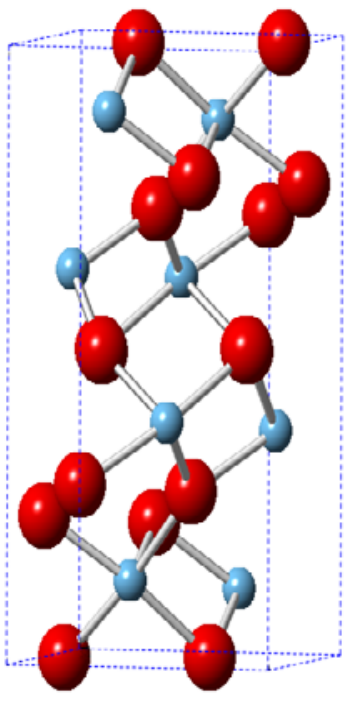

Brookite 
Figure 2. Crystal structure of anatase, rutile and brookite

\subsection{Mechanism of photocatalysis}

As described in the introduction part, illumination of $\mathrm{TiO}_{2}$ with light waves of energy greater than its band gap results in the formation of electron-hole pairs. Hoffmann et al. proposed a general mechanism for $\mathrm{TiO}_{2}$ photocatalysis based on the laser flash photolysis measurements [18]. Various steps in the mechanism with corresponding reaction times are presented in scheme 1 . According to this mechanism, there exists nanosecond to picosecond competition between trapping and recombination of photogenerated electron-hole pairs. 


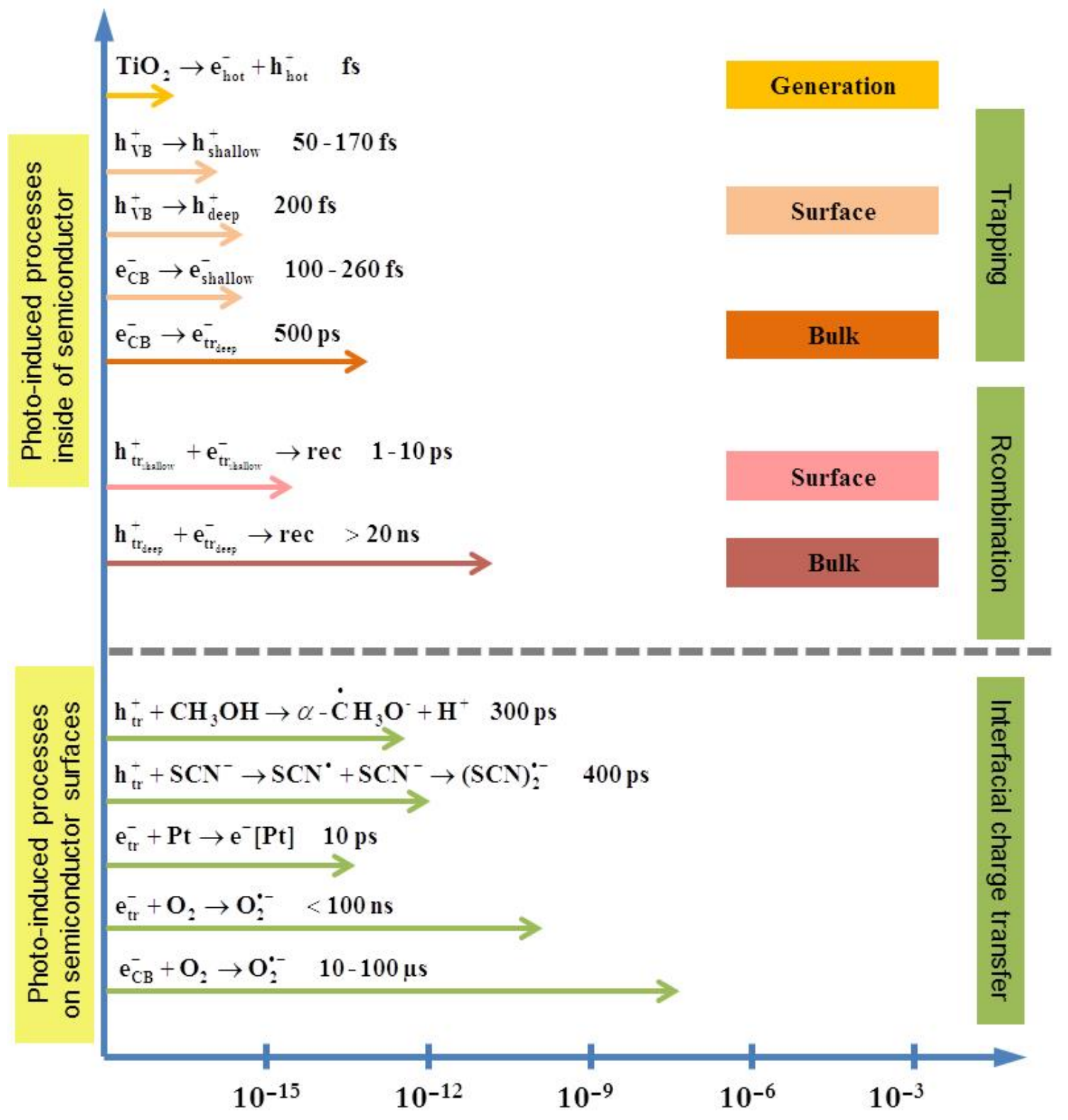

Scheme 1. Various steps involved in $\mathrm{TiO}_{2}$ photocatalysis. Reproduced with permission from ref. [3] Copyright 2014 American Chemical Society

The second type of competition (millisecond to microsecond) is between interfacial charge transfer and recombination of trapped species. The overall quantum efficiency of the photocatalytic process depends on the net effect of these competitions. The quantum efficiency of a photocatalytic reaction is expected to increase by increasing 
the lifetime of electron-hole pairs and the interfacial charge transfer. This mechanism does not consider direct transfer of photogenerated holes.

However, it was assumed that hole-transfer occurs only through a surface trapped hole species or through the hydroxyl radical. This hypothesis was proved by the identification of hydroxylated compounds during the photocatalytic decomposition of halogenated aromatic compounds. Additionally, this study has provided evidence for the fact that hydroxyl radicals are the primary oxidizing species in photo-activated $\mathrm{TiO}_{2}$ [73-75]. Electron paramagnetic resonance (EPR) spectroscopy also confirmed the formation of hydroperoxy $\left({ }^{\circ} \mathrm{O}_{2} \mathrm{H}\right)$ and hydroxyl radicals $\left({ }^{\circ} \mathrm{OH}\right)$ during the illumination of aqueous $\mathrm{TiO}_{2}$ suspensions [76-80]. Mao et al. investigated the kinetics of the hydroxyl radical mediated oxidation of chlorinated hydrocarbons. The strong dependence of the $\mathrm{C}-\mathrm{H}$ bond strengths and the rate of oxidation confirmed the abstraction of $\mathrm{H}$ atom by ${ }^{\circ} \mathrm{OH}$ as the rate-determining step [81].

The rate of decomposition of pollutants were found to be highly dependent on its adsorbed concentration, which also implies that the hydroxyl radical concentration on the catalyst surface determines the reaction kinetics [82, 83]. On the other hand, the direct oxidation mechanism using valence band hole prior to trapping is also reported in the literature. Mao et al. reported the photo-Kolbe type oxidation of oxalic acid and trichloroacetic acid using $\mathrm{TiO}_{2}$ valence band holes [81]. During the $\mathrm{TiO}_{2}$ sensitized decomposition of potassium iodide, 2, 4, 5 trichlorophenol and thianthrene, products of the direct electron transfer oxidation reaction were observed, and they were unable to find evidence for hydroxyl radical reaction [84]. In addition, Experimental evidence for the hole-mediated decomposition of organic moieties such as acetate, glyoxylate, and formate on $\mathrm{TiO}_{2}$ surface were also reported [85]. However, $\mathrm{OH}$ radicals and holes exhibited different regioselectivities in the photocatalytic oxidation of 4- 
hydroxybenzyl alcohol (HBA) on $\mathrm{ZnO}$ and $\mathrm{TiO}_{2}$ [86]. In addition to hole's and hydroxyl radical's, involvement of $\mathrm{H}_{2} \mathrm{O}_{2}$ in the photocatalytic decomposition of various inorganic and organic compounds was also found [87]. In this mechanism, highly reactive ${ }^{\circ} \mathrm{OH}$ species are generated as a result of homolytic scission, or $\mathrm{H}_{2} \mathrm{O}_{2}$ act as an electron acceptor. In most of the photocatalytic reactions, two-electron reduction of oxygen results in the formation of $\mathrm{H}_{2} \mathrm{O}_{2}$.

Similarly, Gerischer et al. identified oxygen reduction as the rate-determining step in semiconductor photocatalysis $[88,89]$. Through ${ }^{18} \mathrm{O}$ isotopic studies, Hoffman et al. proved that all hydrogen peroxide arises from dioxygen reduction using conduction band electrons and in the absence of oxygen, no $\mathrm{H}_{2} \mathrm{O}_{2}$ was detected [90]. They also proposed that hydroxyl radical bound on $\mathrm{TiO}_{2}$ surface $\left(\mathrm{TiOH}^{\circ+}\right)$ acts as the principal oxidizing agent in the absence of $\mathrm{O}_{2}$. Because of the more negative conduction band level of $\mathrm{TiO}_{2}$ compared to hydrogen production level, $\left(\mathrm{E}_{\mathrm{H} 2 / \mathrm{H} 2 \mathrm{O}}\right)$, photo-excited electrons can result in the water splitting to generate hydrogen. Photo-excited electron-hole pairs in $\mathrm{TiO}_{2}$ can also destroy bacteria and other microorganisms. This happens due to strong redox reactions of the electron-hole pairs with proteins and amino acids, which are the building blocks of micro-organisms. Hashimoto and coworkers explained the mechanism of photokilling of $E$. Coli bacteria on nanocrystalline $\mathrm{TiO}_{2}$ coatings [91]. They observed photodecomposition of bacterial cell wall due to the decay of lipopolysaccharide (LPS), which is the major constituent of the cell wall [92]. Recently, Pillai and co-workers reported the photocatalytic antimicrobial properties of partially crystalline nanotube $\mathrm{TiO}_{2}$ bundles [93]. These nanotube materials were found to be highly effective in disinfecting both E. coli (97.53\%) and S. aureus (99.94\%). The high-aspect ratios of nanotubes (Figure 3) and presence of a large number of surface hydroxyl groups were reported as the reasons for high antibacterial activity. 
It is thus clear that the antibacterial effect of $\mathrm{TiO}_{2}$ is a bactericidal action (which involves decomposition of the cell wall), and not a simple bacteriostatic action. Photoinduced bacterial-killing mechanism on titanium dioxide surface has been also demonstrated by other studies [94-96]. In the first step, electron-hole pairs are created by the irradiation of light on the semiconductor surface. The reactive oxygen species (ROS), such as $\mathrm{O}_{2}{ }^{-},{ }^{1} \mathrm{O}_{2}, \mathrm{HO} \bullet, \mathrm{H}_{2} \mathrm{O}_{2}$, and $\mathrm{HO}_{2} \bullet$ formed by the reaction between electron-hole pairs and surface adsorbed $\mathrm{H}_{2} \mathrm{O}, \mathrm{HO}^{-}$and $\mathrm{O}_{2}$. Further reaction of these species results in the bacterial decomposition. Initially the reactive oxygen species attack the weak points of bacterial cell wall to leak the internal components, followed by the total decomposition of the damaged cells [93, 94, 96]. Observed rate of photokilling was low for micro-organisms having a cell wall. Those without a cell wall undergo fast photo-degradation due to direct attack of electron hole pairs on cytoplasmic membrane. Thus, photocatalysis can be used as a powerful tool for the destruction of micro-organisms [91, 92, 97].

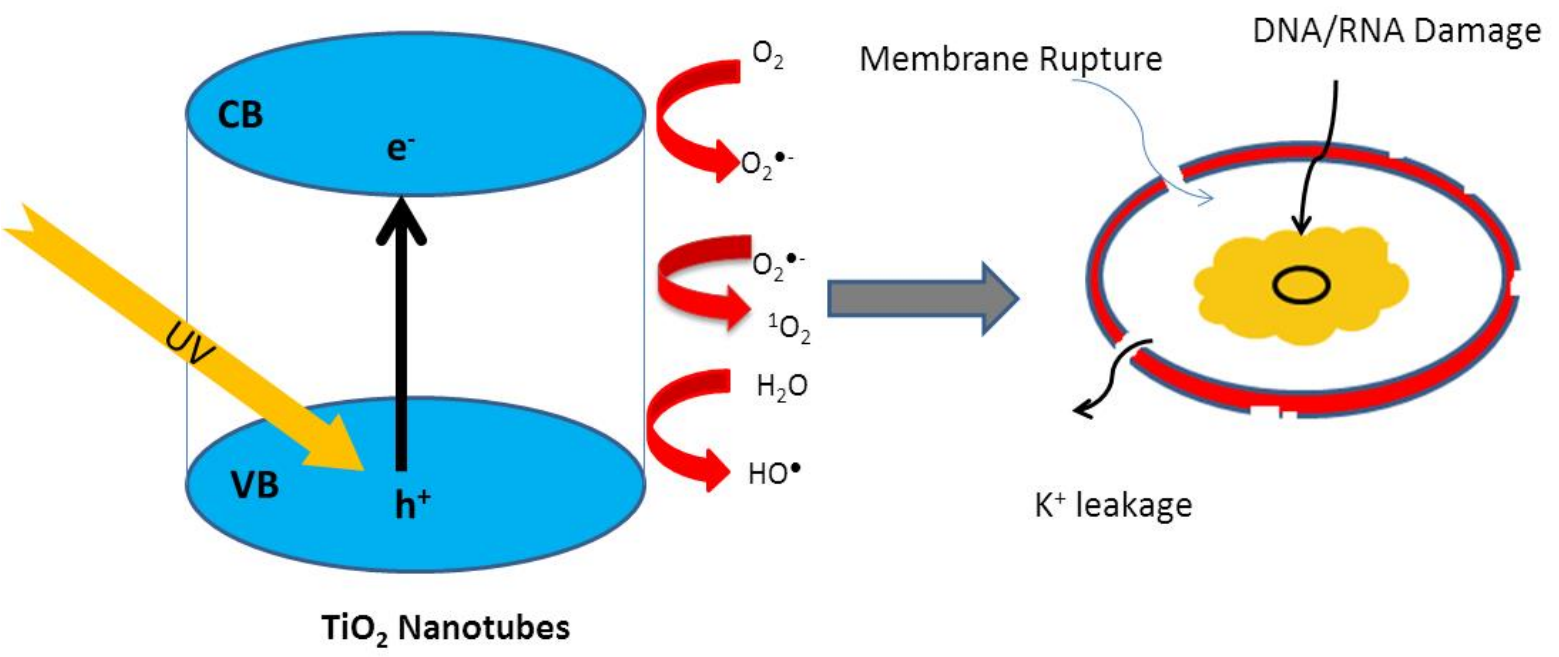

Figure 3. Schematic representation of bacterial photokilling using $\mathrm{TiO}_{2}$. Reproduced with permission from ref. [93] Copyright 2015 Elsevier Science.

Zhang et al studied the mechanism of the $\mathrm{OH}$ radical production in anatase and rutile photocatalysts by employing two different probe molecules such as coumarin and coumarin- 
3-carboxilic acid [98]. Rutile $\mathrm{TiO}_{2}$ was found to produce smaller amount of $\mathrm{OH}$ radicals compared to anatase crystals (Figure 4). Hydroxyl radical formation on anatase $\mathrm{TiO}_{2}$ surface was explained by the conversion of trapped holes. Whereas on rutile $\mathrm{TiO}_{2}$ surface, Ti-peroxo (Ti-OO-Ti) formed by the combination of two trapped holes act as a catalyst to generate $\mathrm{OH}$ radical from water. They also concluded that conduction band reduction of $\mathrm{H}_{2} \mathrm{O}_{2}$ doesnot contribute towards $\mathrm{OH}$ radical generation [98]. These findings are very significant towards optimizing the photocatalytic activity of $\mathrm{TiO}_{2}$ polymorphs for various applications.

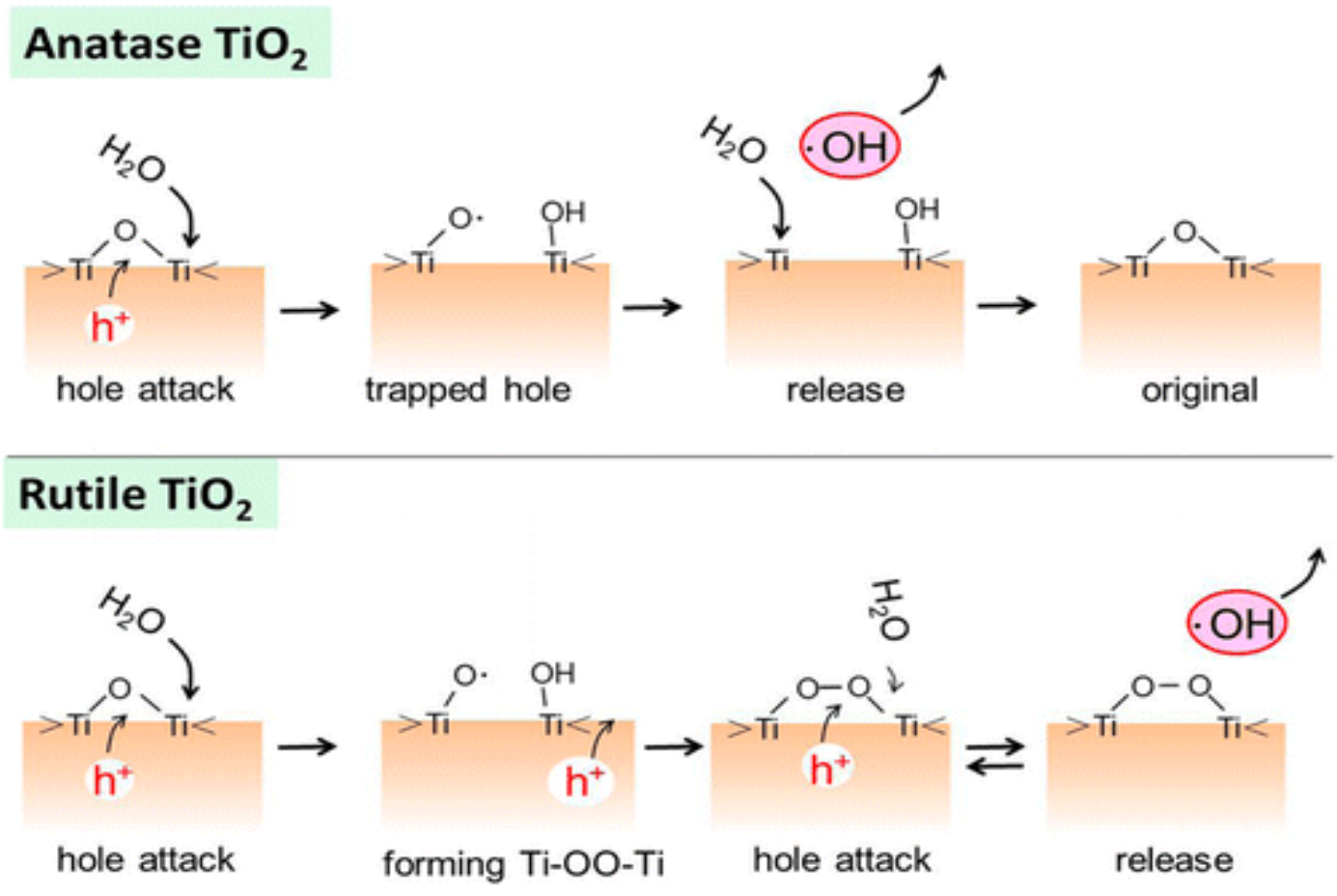

Figure 4. Scheme showing the mechanism of $\mathrm{OH}$ radical production with anatase and rutile. Reproduced with permission from ref. [98]. Copyright 2014 American Chemical Society

\subsection{Limitations of $\mathrm{TiO}_{2}$ photocatalyst}

One of the main shortcomings of $\mathrm{TiO}_{2}$ photocatalyst is the recombination of photogenerated charge carriers, which decreases the quantum efficiency of the overall 
reaction [40]. Photo-excited electron come back to the valence band radiatively or nonradiatively during the recombination process [99-101]. This can occur either in the bulk or on the surface, which are normally induced by defects, impurities and other crystal bulk/surface imperfections [40, 102]. Trapping of the photo-generated electrons by the reduction of surface $\mathrm{Ti}^{4+}$ ions to $\mathrm{Ti}^{3+}$ species happens in $\sim 30 \mathrm{ps}$, while the recombination occurs within 10 ns [102]. Many methods including heterojunction formation, doping with ions, and nanosized crystals have been demonstrated to reduce photo-excited charge carrier recombination [103-110]. For example, $\mathrm{TiO}_{2}$ doped with Ag and Au exhibited superior photocatalytic activities [63, 111]. This was due to the fact that the metal nanoparticles act as electron traps during the photocatalytic reaction, and thereby decreasing the rate of electron-hole recombination. Additionally, the industrial $\mathrm{TiO}_{2}$ Evonik Degussa P-25 is a mixture of $30 \%$ rutile and $70 \%$ anatase, which exhibited notably higher photocatalytic activities compared to other phase-pure $\mathrm{TiO}_{2}$ samples [112]. Superior photocatalytic activities of these biphasic $\mathrm{TiO}_{2}$ resulted from the efficient transfer of electron from the conduction band of anatase to those of rutile $\mathrm{TiO}_{2}$. Notably, higher visible-light induced photocatalytic activities of N-doped, and S, N-codoped anatase-rutile nanoheterojunctions are reported by Etacheri et al [11, 17]. They explained details of electronic structure of these heterostructure photocatalysts, and attributed superior photocatalytic activities to the efficient transfer of photogenerated electrons from the conduction band of anatase to that of rutile. In conclusion, any factor increasing the life-time of electron-hole pairs can substantially increase the photocatalytic performance and quantum efficiency of $\mathrm{TiO}_{2}$ photocatalysts.

Poor thermal stability of the photocatalytically most active anatase phase is another main disadvantage of $\mathrm{TiO}_{2}$ photocatalyst. Anatase $\mathrm{TiO}_{2}$, the most 
photocatalytically active polymorph, is thermally less stable and undergoes irreversible transformation to the less active rutile phase occurs above $600{ }^{\circ} \mathrm{C}[10,113]$. This confines the high temperature $\left(\geq 700{ }^{\circ} \mathrm{C}\right)$ applications including ceramic materials. The anatase to rutile transformation (ART) is slow below $600{ }^{\circ} \mathrm{C}$ and extremely rapid above $700{ }^{\circ} \mathrm{C}$. The transformation involves co-operative movement of the individual $\mathrm{O}^{2-}$ and $\mathrm{Ti}^{4+}$ ions. During ART, two Ti-O bonds of the anatase crystal structure (edgeshared) to form a corner shared rutile structure (Figure 5) [113-116]. As mentioned in the introduction part (section 1), both rutile and anatase have tetragonal crystal structure and previous reports proved that the kinetic stability of anatase is higher than that of rutile under ambient conditions.

Rutile is a thermodynamically more stable phase than anatase. The thermodynamic phase stability calculation by Banfield and co-workers demonstrated that a critical particle-size of around $14 \mathrm{~nm}$ is required to initiate anatase to rutile transformation [117, 118]. Anatase phase is more stable below this critical size [10]. Activation energy of $90 \mathrm{Kcal} / \mathrm{mol}$ is required for the transformation, which follows first order kinetics. Creation of lattice vacancies through removal of oxygen ions accelerates ART. The transformation temperature depends on several factors such as (a) impurity content (b) reaction atmosphere (c) particle size and its morphology (d) degree of agglomeration and (e) synthesis method of anatase $\mathrm{TiO}_{2}$. Another serious drawback of the $\mathrm{TiO}_{2}$ photocatalyst is the wide band gap of anatase $\mathrm{TiO}_{2}\left(E_{\mathrm{bg}} \sim 3.2 \mathrm{eV}\right)$, which restrains its use to UV light $(\lambda \leq 390 \mathrm{~nm})$ [8]. Because of this, $\mathrm{TiO}_{2}$ displays a high photocatalytic activity only when it is irradiated by UV light. Even though the absorption onset of high temperature stable rutile phase $\left(E_{\mathrm{bg}} \sim 3.0 \mathrm{eV}\right)$ occurs around $413 \mathrm{~nm}$, its performance is restricted due to mediocre redox potential, and faster recombination of electron-hole pairs [66]. This means that only $\sim 5 \%$ of the solar 
radiations can be utilized by the conventional $\mathrm{TiO}_{2}$ photocatalyst, which adversely affect the commercialization of $\mathrm{TiO}_{2}$ based photocatalysts $[17,119]$. It is crucial to develop visible-light active $\mathrm{TiO}_{2}$ to effectively exploit solar-radiations or other artificial lights. Studies begin in the 1980s to synthesize narrow band-gap titanium dioxide that can absorb and efficiently utilize both UV (290-400 nm) and visible (400$700 \mathrm{~nm})$ light. Various techniques employed for the visible light activation are explained in detail in the following sections.

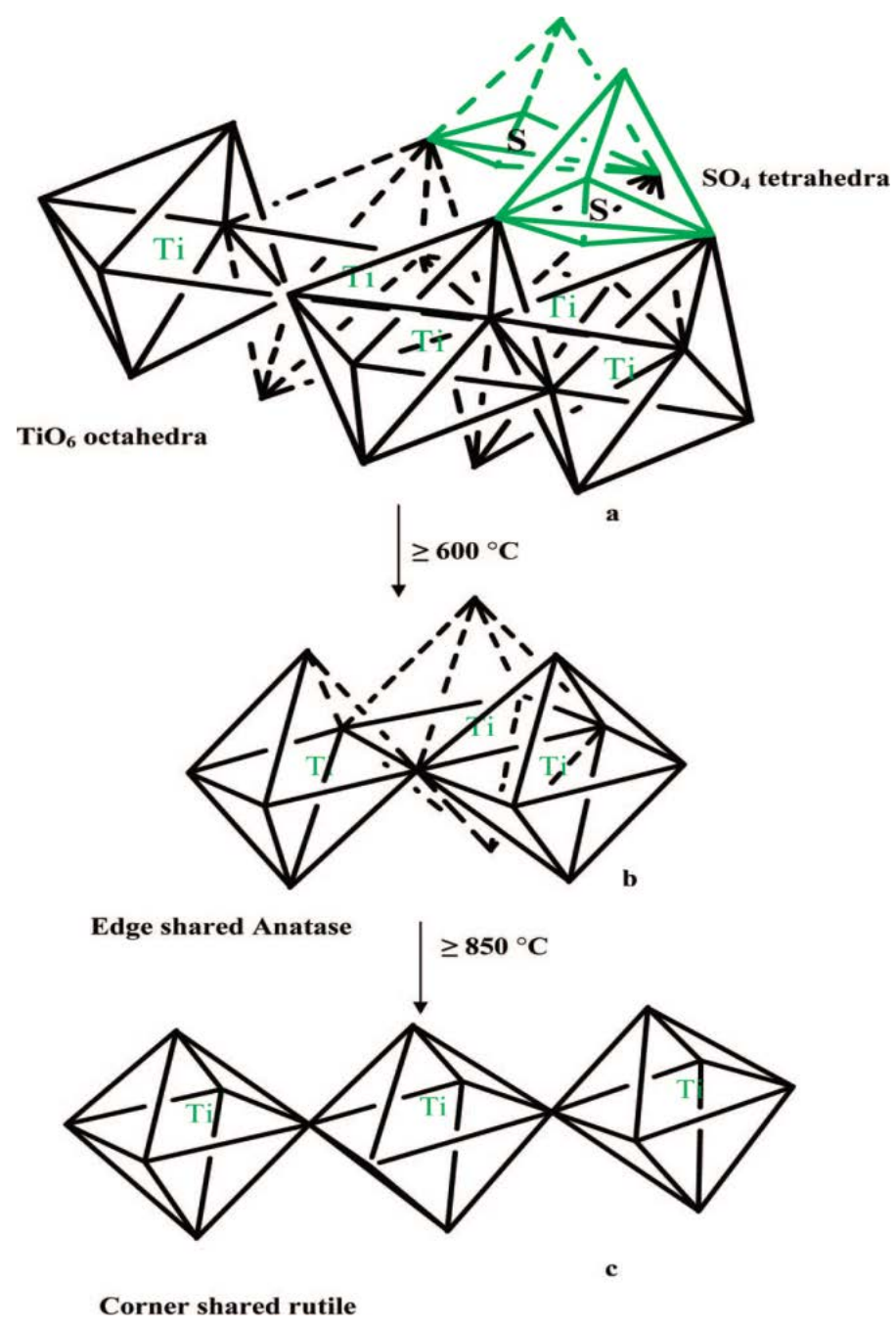

Figure 5. The schematic representation of transformation of edge shared anatase photocatalysts to corner shared rutile from a titanyl oxysulfate precursor. Reproduced with permission from ref. [113] Copyright 2008 American Chemical Society 


\section{Advances in the theoretical approaches to model photocatalysts and their photoactivity}

Theory can be applied to investigate various aspects of the photocatalytic cycle; in particular, the light absorption process, the electron/hole transport in the bulk and their migration to the surface, the band edge alignments of semiconductors, and surface photo-redox chemistry, just to cite the most relevant ones. If accurate methods and models are used, the theoretical insights can be fruitfully used to improve the photocatalytic performance, especially in the range of visible-light.

\subsection{Photocatalysts electronic structure}

Density functional theory (DFT) has gained a prominent position in the general scenario of computational materials science thanks to its rather high accuracy at a relatively low cost. This applies also to the case of materials for photocatalysis (e.g. $\mathrm{TiO}_{2}$ ), where the accurate description of the electronic structure is crucial in order to correctly understand and foresee their interaction with light and the photo-response. However, standard DFT approaches, such as LDA and GGA methods, suffer of the residual electron self-interaction and an improper description of electron correlations causing the well-known underestimation of the band gap and excessive delocalization of the dopant induced states. Two pragmatic approaches for the correction of self-interaction are the hybrid density functional methods, which include a fraction of exact (Hartree-Fock type) exchange, and the DFT+U methods, where an on-site Hubbard $U$ electron repulsion is added on selected localized orbitals. These methods presented a better explanation of the fundamental gap but also of the location of the impuritystates induced by the presence of the dopants in the band-gap of $\mathrm{TiO}_{2}$, which is critical for the in the visible light absorption process.

Hybrid density functionals, with a typical $20-25 \%$ contribution of exact exchange, overestimate the $\mathrm{TiO}_{2}$ band gap. A reduction of this contribution to $12-15 \%$ makes the Kohn- 
Sham gap match the experimental fundamental gap. With the DFT+U method, very large and unphysical $\mathrm{U}$ values $(\mathrm{U}=6 \mathrm{eV})$ for the on-site correction on $\mathrm{Ti} 3 \mathrm{~d}$ states are required to reproduce the experimental band gap, whereas the use of the self-consistent linear response derived $\mathrm{U}$ values ( $\mathrm{U}=3.23 \mathrm{eV}$ for anatase and $\mathrm{U}=3.25$ for rutile) only slightly improves the GGA band gap [120]. Such values are anyhow better suitable for the correct description of the electronic modifications induced by the dopants.

\subsection{Doped and Defective Photocatalysts}

The visible light activation of photocatalysts is often the result of electronic structure engineering of materials through doping or defectivity. These approaches cause the modification of the band structure or the introduction of new defect states in the photocatalyst band gap, whose correct position and description are not easily obtained by the ground state DFT calculations. It is common practice to estimate the semiconductor band gap and the energy levels introduced in the gap by defect centers using single-particle Kohn-Sham eigenvalues. This approach, however, is not well justified and can be used only for qualitative comparisons with optical or photoemission experimental data. The problem of the position of defect states in the gap can be partly solved by the calculation of the "transition energy levels" between different charge states of the (intrinsic or extrinsic) defect under investigation. These quantities (commonly referred to as $\varepsilon^{\text {opt }}$ or $\varepsilon^{\text {therm }}$, for optical and adiabatic transitions, respectively) are obtained from total energy calculations and converted into formation energy of the defect in a specific charge state. This approach is analogous to the delta-selfconsistent-field method which allows to compute electronic excitations in finite systems from total energy differences. The transition energy levels (Figure 6) formalism provides a rigorous framework for computing then excitation and emission energies in doped or defective semiconductors that can be directly compared with experiments [121, 122]. Many successful 
examples of the use of transition energy levels to rationalize optical and photocatalytic properties of materials already exist in the literature [123-131].

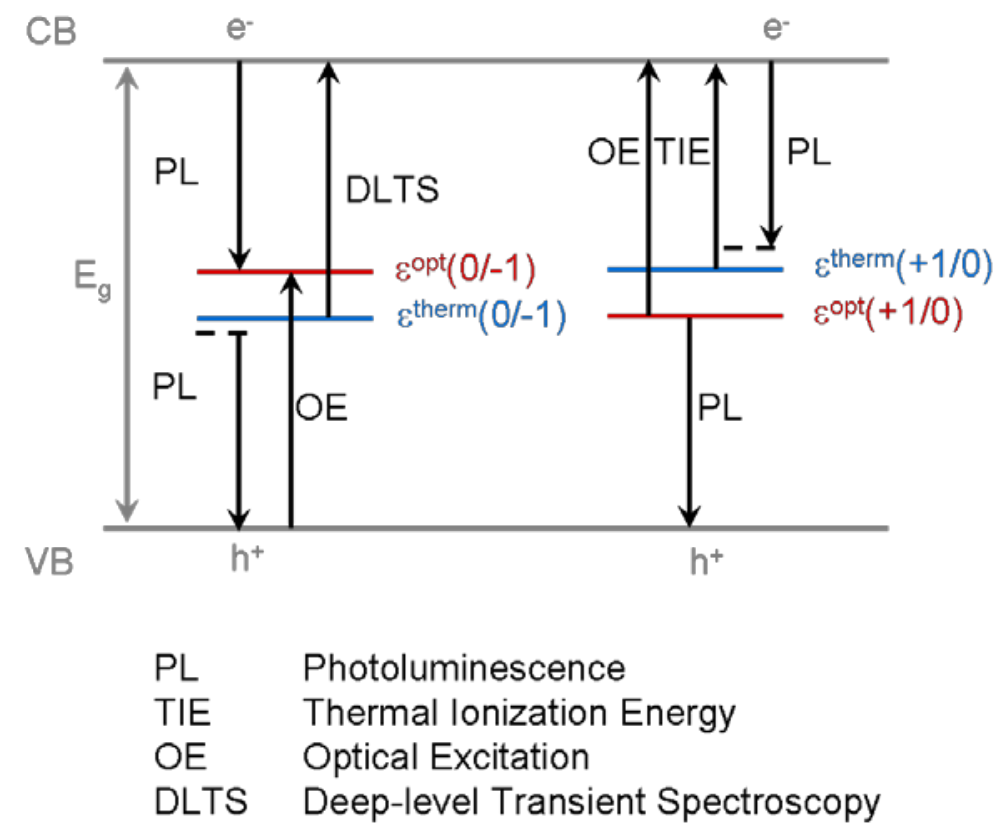

Figure 6. Schematic representation of electronic transitions in doped or defective semiconductors in relation with the spectroscopic techniques which can probe them. The $\uparrow$ arrows indicate an electron excitation, the $\downarrow$ arrows indicate an electron decay. $\varepsilon^{\text {therm }}$ and $\varepsilon^{\text {opt }}$ are defined with respect to the valence band maximum for $(0,-1)$ and $(+1,0)$ charge state transitions. Reproduced with permission from ref. [121] Copyright 2014 American Chemical Society

\subsection{Photocatalysts light-induced excitation}

To compute excitation energies, one should go beyond DFT, either through many-body perturbation theory (MBPT), in the GW approximation and the Bethe-Salpeter equation, or the time-dependent DFT (TD-DFT) method. A number of studies on bulk $\mathrm{TiO}_{2}$ have recently appeared in the literature [123, 124, 132-134]. However, these approaches are still either too costly or not sufficiently accurate for extended systems, particularly if exposing surfaces. A more simplified approach to simulate the photoexcited $\mathrm{TiO}_{2}$ is based on spin-constrained DFT, 
where the first excited state is obtained by imposing a triplet spin state configuration to the model system [135]. Structural relaxation in the excited state is then achievable (not possible with any other more sophisticated method), which allows one to compute the emission energy from a self-trapped exciton. Comparison of the computed with the experimental luminescence values is excellent (2.6 vs. $2.3 \mathrm{eV}$ ), especially considering the inherent approximations [136]. The same approach can be used to describe separated electron/hole pairs, travelling from the bulk to the surface where they become self-trapped. Self-trapping energies are interesting quantities since they define how surface traps are competitive with respect to electron or hole transfers to chemical adsorbates, which are the first chemical step of any redox process in the photocatalytic cycle.

\subsection{Redox processes at the photocatalysts surface}

Photoinduced electrons and holes are generally considered to travel from the bulk to the surface. Recently, the driving force for this migration has been determined to be the larger trapping energy at a surface rather than a bulk regular site [135]. Chemical species adsorbed on the surface are excellent scavengers for electrons and holes. The $\mathrm{O}_{2}$ molecule is found to very easily remove the electron from the catalyst to form first superoxo and then peroxo species (Figure 7) [137].

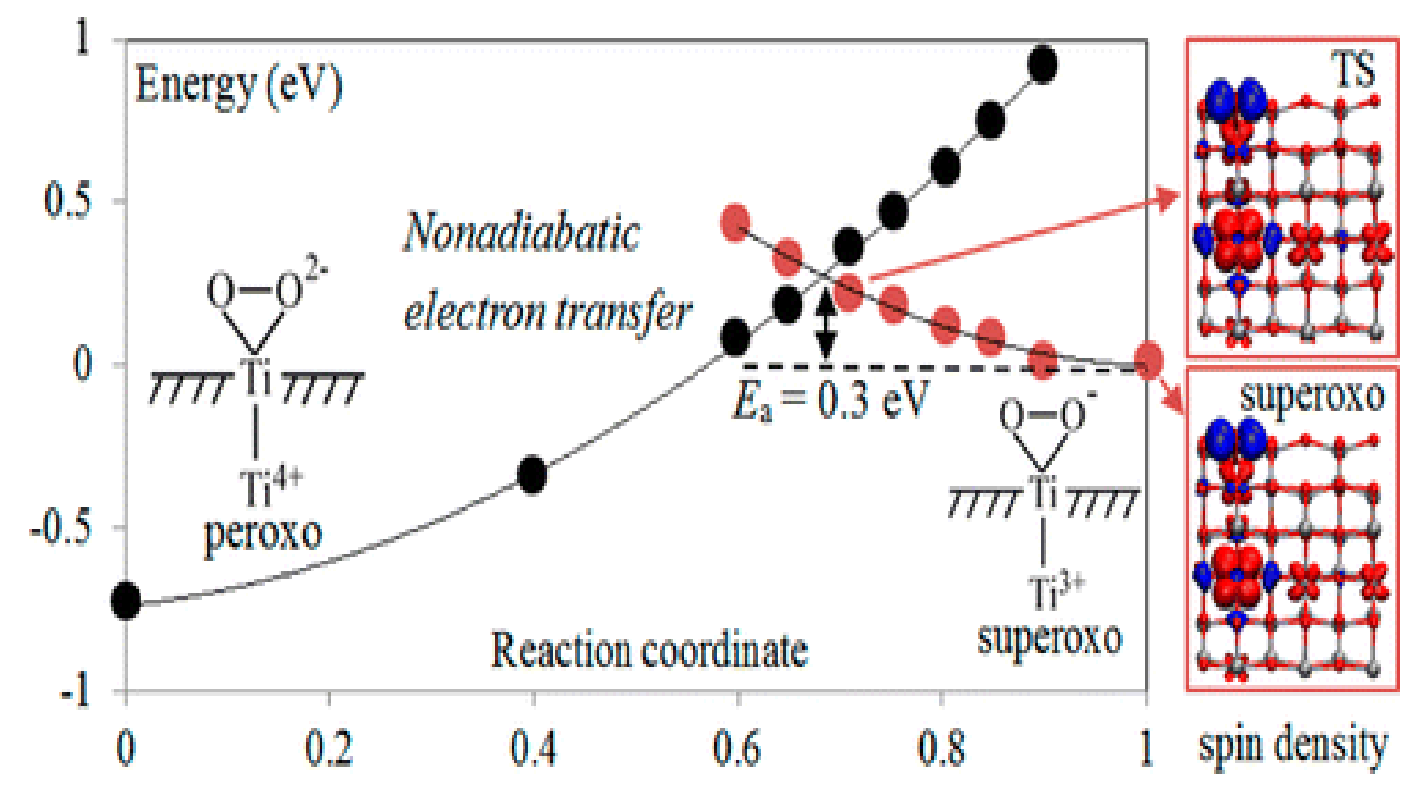


Figure 7. Schematic diagram showing the transfer of electron from a reduced $\mathrm{TiO}_{2}$ surface to oxygen molecule. Reproduced with permission from ref. [137] Copyright 2013 American Chemical Society

Organic acids and alcohols were also computed to be excellent hole scavengers, which is a hint that the direct oxidation mechanisms is a viable path for certain chemical species [138]. Hydroxyl species are found to facilitate photo-oxidation reaction of methyl chloride on rutile (110) surface [139].

\section{Historical developments of visible-light active $\mathrm{TiO}_{2}$ photocatalysts}

As discussed earlier, one of the major drawbacks of pure $\mathrm{TiO}_{2}$ is the large band gap implying that this material can only be activated using an irradiation with photons in the UV region $(\lambda \leq 387 \mathrm{~nm})$. In order to obtain activity in the visible region, it is essential to modify the semiconductor materials by using dye sensitisation, noble metal doping, transition metal addition and non-metal doping. Modification with transition metal ions was the first method reported for their visible-light activation of $\mathrm{TiO}_{2}$ [140]. The main drawback of these catalysts is the formation of recombination sites for photogenerated charge carriers and thus lowering the quantum efficiency. Transition metals also block the active surface reaction sites. In 1986 Sato discovered that modification of $\mathrm{TiO}_{2}$ with $\mathrm{NH}_{4} \mathrm{OH}$ resulted in their visible light absorption [141]. Later Asahi et al for the first time investigated the photocatalytic activity of N-doped $\mathrm{TiO}_{2}$ [142]. After this report, significant efforts have been devoted for the development of various anion doped $\mathrm{TiO}_{2}$ photocatalysts [143, 144].

\subsection{Dye-sensitization}


This is one of the widely used techniques for the utilization of visible-light in photocatalytic and photovoltaic systems [145-148]. During visible-light irradiation, excited electrons are transferred from the dyes to the conduction band of the semiconductor (Figure 8). Some dyes are even capable of producing electrons by absorbing visible-light in the absence of semiconductors. Nevertheless, in the absence of semiconductor charge separators, photocatalytic activities of these dyes are too low. Visible-light absorption and electron transfer to the conduction band of $\mathrm{TiO}_{2}$ often resulted in a superior photocatalytic activity. Degradation of the dye itself is one of the main issues in the dye-sensitization of semiconductors. This was usually overcome by dye regeneration by using sacrificial agents, or redox systems like EDTA and $\mathrm{I}_{3}{ }^{-} / \mathrm{I}^{-}$pair [149]. Optimum conditions to obtain higher photocatalytic efficiencies are fast electron transfer to the semiconductor and slow recombination. In the case of dye-sensitization, electron injections occur in a femtosecond scale compared to the recombination of electron-hole pairs in nanoseconds to milliseconds scale [150-154]. Advantages of the dye-sensitized photocatalytic reactions are the fast injection of electrons to the semiconductor and slow backward reaction. Visible-light induced hydrogen generation through dye-sensitized water splitting was reported by previous researchers $[155,156]$. These studies illustrated that the electron injection occurs only from the dye molecules adsorbed on the surface of the photocatalyst. Dye-sensitization was also identified as highly effective for the degradation of a number of pollutants under visible irradiation [157, 158].

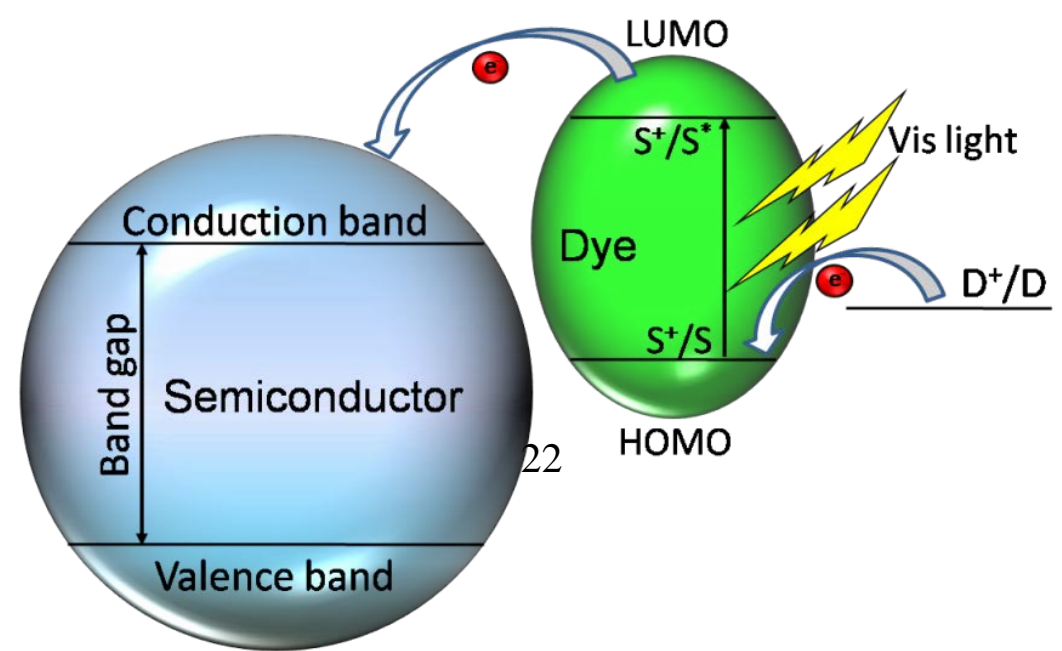


Figure 8. Mechanism of dye sensitized semiconductor photocatalysis

\subsection{Noble metal loading}

Noble metals for instance $\mathrm{Au}, \mathrm{Ag}, \mathrm{Pt}, \mathrm{Pd}$, and Rh have been reported as very efficient dopants for the visible-light activation and thereby improving the performance of $\mathrm{TiO}_{2}$ photocatalysts [159-164]. Fermi levels of these noble metals are lower than that of $\mathrm{TiO}_{2}$, which results in the effective transfer of the photogenerated electrons from the conduction band of $\mathrm{TiO}_{2}$ to metal particles (Figure 9) [165]. This electron trapping process significantly reduces the electron-hole recombination rate, which results in stronger photocatalytic reactions. Electron spin resonance (ESR) spectroscopy was used by previous researchers to investigate the charge transfer mechanism in these metals doped $\mathrm{TiO}_{2}$ [166]. Anpo and Takeuchi employed electron paramagnetic resonance (EPR) spectroscopy to establish electron transfer between Pt nanoparticles and $\mathrm{TiO}_{2}$ [167]. Bamwenda et al. investigated the effect of $\mathrm{Au}$ and Pt nanoparticles on the photocatalytic activity of $\mathrm{TiO}_{2}$ materials through the photocatalytic splitting of water-ethanol mixture [160]. Seery et al. improved the visible-light photocatalytic activity of $\mathrm{TiO}_{2}$ by silver doping. They observed superior UV, and Vis-light absorption due to silver plasmon [168]. 
Figure 9. Electron transfer mechanism in silver loaded $\mathrm{TiO}_{2}$. Reproduced with permission from ref. [165] Copyright 2011 American Chemical Society

A number of synthetic methods including sol-gel process, hydrothermal method, impregnation, and photo-deposition were reported for the fabrication of noble metal modified $\mathrm{TiO}_{2}$ [168-170]. Photocatalytic activities of these modified samples were highly dependent on both the synthesis method and work function of the noble metal. Among the various noble metal modified $\mathrm{TiO}_{2}$ samples, $\mathrm{Pt}$ and $\mathrm{Au}$ loaded were found to be most effective and less sensitive to the synthesis methods. The higher effectiveness resulted from the higher work-functions and optimum electron-affinity associated with Pt and Au. Sakthivel et al. studied the photocatalytic activities of Au, Pt, and Pd modified $\mathrm{TiO}_{2}$ through photo-oxidation of acid green-16 and determined the optimum loading for each metal [161]. Reduced photocatalytic performance was identified above an optimum metal content, which was proven to be as a result of reduced photon absorption by $\mathrm{TiO}_{2}$ and action of excess metal as electron-hole recombination centers. The noble metal loaded $\mathrm{TiO}_{2}$ photocatalysts shows also different photocatalytic activities for hydrogen production depending on the noble metal and sacrificial regent.

Recently, $\mathrm{TiO}_{2}$ loaded with metallic nanoparticles possessing unique properties, such as localized surface plasmon resonance (LSPR), are widely used for 
photocatalytic reactions in visible wavelengths [165, 171]. Modification of semiconductor nanostructures with plasmonic metal-nanoparticles improved the efficiency of water splitting, decomposition of organic compounds, and photovoltaic devices (by 10-15 \%) [171-175]. For instance, Tian et al. reported superior visiblelight photocatalytic decomposition of methanol and ethanol on Au-nanoparticles loaded $\mathrm{TiO}_{2}$ films [176, 177]. Furube et al. used transient absorption spectroscopy for the investigation of charge separation/recombination dynamics in Au-nanoparticles loaded $\mathrm{TiO}_{2}$ [178]. Their results proved plasmon induced electron transfer to $\mathrm{TiO}_{2}$. Efficient utilization of the near IR radiations and photoelectric conversion by Aunanorod arrays modified $\mathrm{TiO}_{2}$ single crystals were reported by Nishijima et al. [179] It was found that a thin coating of silica on Au nanoparticles (Figure 10) significantly improved the photocatalytic rate by reducing the carrier recombination [180].

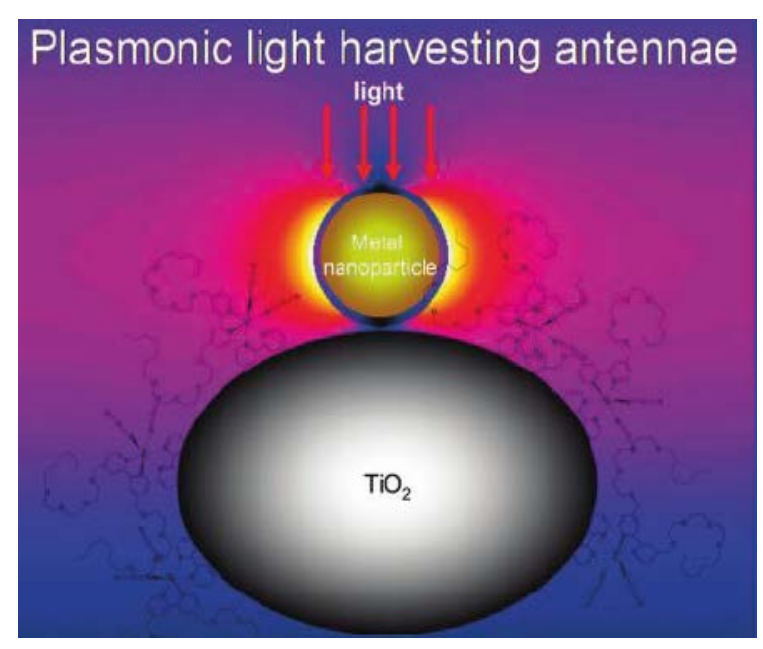

Figure 10. Plasmonic light harvesting using core-shell metal-insulator nanoparticles. Reproduced with permission from ref. [180] Copyright 2011 American Chemical Society

Plasmon sensitization was also used in combination with dye sensitization. For instance, addition of Ag nanoparticles increased the absorption coefficient and efficiency of dye-sensitized solar cells [180, 181]. Similarly, Rand et al modified the tandem solar cells with Ag-nanoparticles and observed an unexpected improvement in 
the charge generation and visible-light absorption [182]. They attributed the surface plasmon modes of Ag-nanoparticles to the increased photocurrent generation. In addition, a number of studies demonstrated the superior plasmon-sensitized visiblelight photocatalytic activities of $\mathrm{TiO}_{2}$ loaded with $\mathrm{Au}$ and Ag nanoparticles [183-185]. Several methods for silver nanoparticle deposition on $\mathrm{TiO}_{2}$ such as thermal evaporation, magnetron sputtering, electrochemical deposition, hydrothermal treatment and photocatalytic reduction have been demonstrated by previous researchers [186191]. In addition to $\mathrm{Au}$ and $\mathrm{Ag}$ nanoparticles, $\mathrm{TiO}_{2}$ nanotube arrays sensitized with $\mathrm{Pd}$ nanoparticles were highly efficient towards the visible-light induced photoelectrocatalytic water splitting [192].

LSPR improves the photocatalytic activity in three different ways by; (1) extending light absorption of semiconductor to longer wavelengths, (2) increasing the scattering of visible-light, and (3) creating electron-hole pairs by transferring the electrons from the metal nanoparticles to the conduction band of semiconductors. When the semiconductor and plasmonic metal nanoparticles are in direct contact, direct electron transfer (DET) results from the metal to the conduction band of the semiconductor [183, 193, 194]. The critical factor deciding the feasibility of DET is the arrangement of the plasmonic metal Fermi level and semiconductor band levels. Consequently, if the electronic energy levels match, metal to semiconductor transfer of holes or electrons can occur even at energies below the band gap. Previous researchers confirmed LSPR mediated transfer of electrons from gold nanoparticles to the conduction band of $\mathrm{TiO}_{2}$ [185]. Recent studies proved that the photocatalytic activity improvement was unchanged even after an insulating layer was added between the semiconductor and plasmonic metal [183]. As a result, it was concluded that electron- 
hole pairs are created on the semiconductor by a radiative contribution of the LSPRmediated local electromagnetic field (LEMF) [172, 174, 195].

\subsection{Transition metal doping}

Improved visible-light photocatalytic activities of various transition metal doped $\mathrm{TiO}_{2}$ has been comprehensively investigated [196-202]. These studies proved that doping results in the increased visible-light absorption. As a result of transition metal doping, impurity energy levels are created in the band gap, which results in visible-light absorption. Photocatalytic activities are also improved by electron transfer between $\mathrm{TiO}_{2}$ and transition metal ions [203]. Choi et al. doped $\mathrm{TiO}_{2}$ with 21 transition metal ions and investigated their photocatalytic activities [196]. Visible-light photo-responses were observed for $\mathrm{TiO}_{2}$ photocatalyst as a result of most of these metal ion doping. Extensive research on the enhancement of $\mathrm{TiO}_{2}$ photocatalytic activities has been performed through doping of transition and rare earth metal ions, especially for air and water sanitization applications [196-198]. Among the various metal ions studied by Choi et al., increased photocatalytic activity was identified for Mo, V, Re, Ru, Fe, Rh, and Os ions doped $\mathrm{TiO}_{2}$ [196]. Whereas $\mathrm{Al}$ and Co ions reduced the activity. Fe and $\mathrm{Cu}$ ions create additional energy levels near the valence band as well as conduction band of $\mathrm{TiO}_{2}$, which result in the trapping of both electrons and holes. Consequently, it is highly recommended to dope $\mathrm{TiO}_{2}$ with either $\mathrm{Fe}$ or $\mathrm{Cu}$ ions to obtain superior photocatalytic activity [196, 197].

Hashimoto et al. designed and fabricated $\mathrm{Cu}(\mathrm{II})$ and $\mathrm{Fe}$ (III) grafted $\mathrm{TiO}_{2}$ photocatalysts for efficient visible-light induced decomposition of 2-propanol to $\mathrm{CO}_{2}$ via acetone [204, 205]. In this case, visible-light activation was caused by the interfacial charge transfer from the valence band holes to $\mathrm{Cu}(\mathrm{II})$ ions. $\mathrm{Cu}(\mathrm{I})$ ions formed by the reduction of $\mathrm{Cu}(\mathrm{II})$ also act as a multi-electron oxygen reduction 
catalyst. Reaction rates of $\mathrm{Cu}(\mathrm{II}) / \mathrm{TiO}_{2}$ catalyst was 2.1 fold higher than those of $\mathrm{N}$ doped $\mathrm{TiO}_{2}$ under similar experimental conditions [204]. Fe(III)-grafted rutile $\mathrm{TiO}_{2}$ displayed optical absorption in the visible region above $400 \mathrm{~nm}$, which resulted from the interfacial charge transfer from the valence band of $\mathrm{TiO}_{2}$ to the surface $\mathrm{Fe}(\mathrm{III})$ species [205]. Superior quantum efficiency of $22 \%$ was observed for $\mathrm{Fe}(\mathrm{III}) / \mathrm{TiO}_{2}$ in the visible-light region (400-530 nm), and photocatalytic activity can be maintained up to $580 \mathrm{~nm}$ with a quantum efficiency of $10 \%$. High performance of $\mathrm{Fe}(\mathrm{III}) / \mathrm{TiO}_{2}$ was attributed to the accumulation of photogenerated holes in the valence band of $\mathrm{TiO}_{2}$ and the catalytic reduction of oxygen by photoreduced $\mathrm{Fe}(\mathrm{II})$ species on $\mathrm{TiO}_{2}$ surface (Figure 11). Morikawa et al. loaded $\mathrm{N}$-doped $\mathrm{TiO}_{2}$ with $\mathrm{Fe}, \mathrm{Cu}$ and $\mathrm{Pt}$ to improve the visible-light response [206]. It was found that Pt, Fe and Cu loading resulted in similar rate enhancement towards acetaldehyde oxidation, while $\mathrm{Pt}$, and $\mathrm{Cu}$ gave the highest rate for toluene and acetic acid oxidation. Rate of formic acid oxidation was enhanced by factors of 5 and 22 on loading $\mathrm{Fe}$ and $\mathrm{Pt}$ respectively. Extremely high rate enhancement of formic acid oxidation was attributed to the combined effect of photocatalysis and thermal catalysis. Such transition metal loading of $\mathrm{N}$-doped $\mathrm{TiO}_{2}$ was also reported by other researchers for the improved visible-light activation of $\mathrm{TiO}_{2}$ [207].

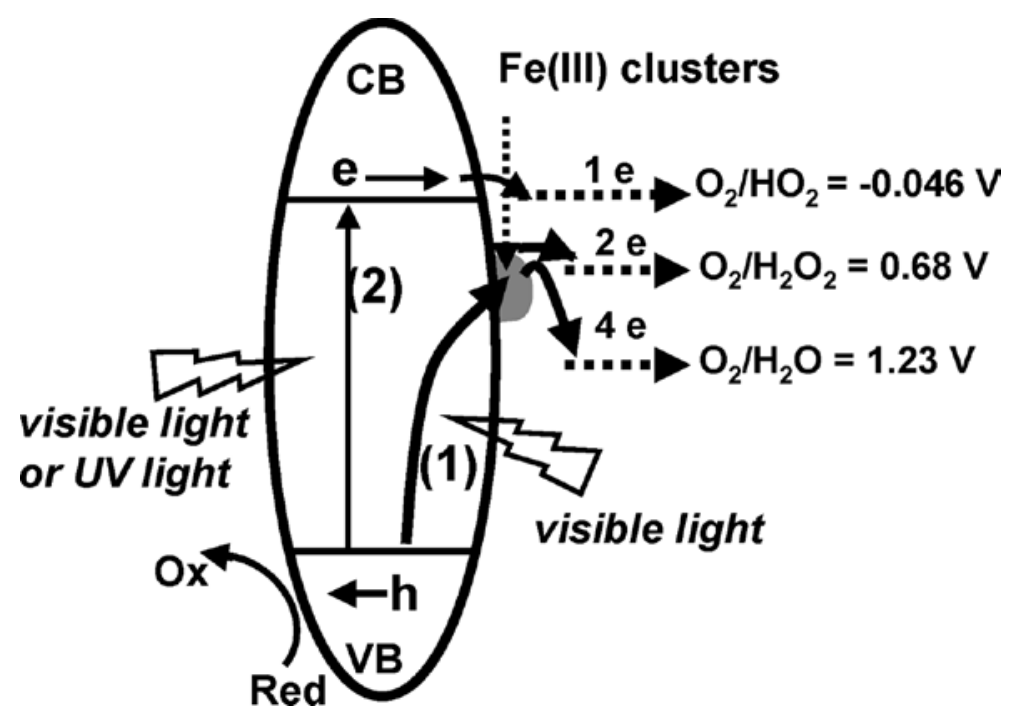


Figure 11. Schematic diagram illustrating the possible photocatalytic mechanism of $\mathrm{Fe}(\mathrm{III}) / \mathrm{TiO}_{2}$ involving interfacial electron transfer and multielectron oxygen reduction. Reproduced with permission from ref. [205] Copyright 2010 American Chemical Society

Peng et al. investigated the photocatalytic activity of Be doped $\mathrm{TiO}_{2}$ [208]. They found that metal ion doping close to the surface improve charge carrier separation, whereas deep doping accelerate carrier recombination. These findings were in good agreement with the results of Choi et al. [196]. Wu et al. investigated the effects of transitional metal ions ( $\mathrm{Cr}, \mathrm{Mn}, \mathrm{Fe}, \mathrm{Co}, \mathrm{Ni}$ and $\mathrm{Cu}$ ) doping on the photocatalytic activity of $\mathrm{TiO}_{2}$ through the photocatalytic oxidation of acetic acid [201]. Enhanced photocatalytic activities were observed for $\mathrm{Cu}, \mathrm{Mn}$ and $\mathrm{Fe}$ ions doped $\mathrm{TiO}_{2}$ as they can trap electrons as well as holes, whereas $\mathrm{Cr}$, Co and $\mathrm{Ni}$ ions doped samples were not much active as they can trap only one charge carrier. Dhanalakshimi et al. investigated the dye sensitized hydrogen production efficiency of $\mathrm{Cu}$-modified $\mathrm{TiO}_{2}$ and compared with that of Pt-doped compositions and the enhancing effect was found to be comparable [146]. Hydrogen production efficiency of $\mathrm{Cu}$-modified $\mathrm{TiO}_{2}$ particles from methanol solution were also investigated by $\mathrm{Wu}$ and Lee [209]. A ten-fold enhancement in the hydrogen production efficiency was demonstrated at an optimum Cu-loading. Xu et al compared photocatalytic activities of various ( $\mathrm{La}, \mathrm{Ce}, \mathrm{Er}, \mathrm{Pr}, \mathrm{Gd}$, Nd and Sm) rare earth metal ion doped $\mathrm{TiO}_{2}$ [199]. $\mathrm{TiO}_{2}$ loaded with optimum dopant content demonstrated superior band-gap narrowing and visible-light photocatalytic activities. As a result of its ability to transfer both electrons and holes to the surface Gd-ions doped $\mathrm{TiO}_{2}$ was found to be the most photoactive.

Another efficient method for improving the visible-light response is metal ion implantation [167, 210, 211]. This process involves bombarding a semiconductor with 
high-energy transition metal ions. During the collision, metal ions penetrate into the semiconductor crystal structure and improve the visible-light absorption by creating additional energy levels. A visible-light response up to $600 \mathrm{~nm}$ has been reported for metal ions implanted $\mathrm{TiO}_{2}$. Takeuchi et al. employed this method to implant Cr ions in $\mathrm{TiO}_{2}$ thin films for the visible-light induced degradation of nitric oxide (NO) [210]. For this implantation, they used an ionized cluster beam (ICB). The UV-Vis absorption studies revealed the band gap narrowing in these $\mathrm{TiO}_{2}$ samples and the extent of band gap narrowing was found to be directly proportional to the Cr-ion loading. Visiblelight photocatalytic activities of these Cr-doped $\mathrm{TiO}_{2}$ were highly promising for $\mathrm{NO}$ degradation. This high activity compared to the chemically Cr-doped $\mathrm{TiO}_{2}$ point towards the fact that metal ion implantation did not create recombination centers. A wide range of ions of metals ( $\mathrm{V}, \mathrm{Cr}, \mathrm{Mn}, \mathrm{Ni}, \mathrm{Mg}, \mathrm{Ti}$ and $\mathrm{Fe}$ ) has been implanted for visible-light activation of $\mathrm{TiO}_{2}[167,211]$. Visible-light absorption was observed for all ions except $\mathrm{Mg}$ and $\mathrm{Ti}$ ions. The effectiveness of dopant ions in the band gap narrowing was found to be in the following order: $\mathrm{V}>\mathrm{Cr}>\mathrm{Mn}>\mathrm{Fe}>\mathrm{Ni}$. In the case of ion implanted $\mathrm{TiO}_{2}$ no sacrificial agents and electron mediators are necessary to maintain the reaction cycles. For improved carrier transferring and photocatalytic activity, metal ions should be doped close to the $\mathrm{TiO}_{2}$ surface. In the case of deep doping, carrier (electrons and holes) transfer to the interface is more difficult and metal ions act as recombination centers. Similarly, photocatalytic activity decreases above an optimum metal ion doping due to increased carrier recombination.

Metal doping of $\mathrm{TiO}_{2}$ has been investigated theoretically in order to establish how the doping element effectively modifies the semiconducting oxide electronic structure for the absorption in the visible and the molecular adsorption properties at the surface [212-215]. In most of the cases the dopant is a transition metal in a 
substitutional lattice cationic site. The correct description of the metal $d$ states, especially when these are partially occupied, requires the use of methods, which reduce the electron self-interaction problem. For the case of Cr-doped $\mathrm{TiO}_{2}$, GGA calculations indicate a spurious half-metallic character of the system (no splitting of the partially occupied $\mathrm{Cr} \mathrm{t}_{2 \mathrm{~g}} \mathrm{~d}$ states), contrarily to the semiconducting properties (splitting of the occupied-unoccupied $\mathrm{Cr} \mathrm{t}_{2 \mathrm{~g}} 3 d$ states) by hybrid functional methods [216]. The presence of transition metal d states in the $\mathrm{TiO}_{2}$ band gap is clearly the origin of the experimentally observed red-shift in the absorption properties of metal doped $\mathrm{TiO}_{2}$ [217].

\subsection{Heterojunction semiconductors}

Coupling of semiconductors having different band gap values is another method to efficiently utilize visible-light and enhancing the photocatalytic activity. The necessary condition for coupling is that the conduction band level of at least one of the semiconductors must have a more negative value compared to the other. The electron injection mechanism in composite semiconductors can occur through the following mechanism (Figure 12). In the case of semiconductor heterojunctions, photogenerated electrons can be effectively transferred from the conduction band of one semiconductor to that of the other. The electron injection always occurs from the more negative conduction band to the less negative one. This electron transfer is identical to the dye sensitization of $\mathrm{TiO}_{2}$, except the difference being the electron injection happens between two semiconductors. Coupling of $\mathrm{TiO}_{2}$ with CdS (band gap $2.4 \mathrm{eV}$ ) and $\mathrm{SnO}_{2}$ (band gap $3.5 \mathrm{eV}$ ) for visible-light induced water splitting and purification were previously investigated [145, 218, 219]. 


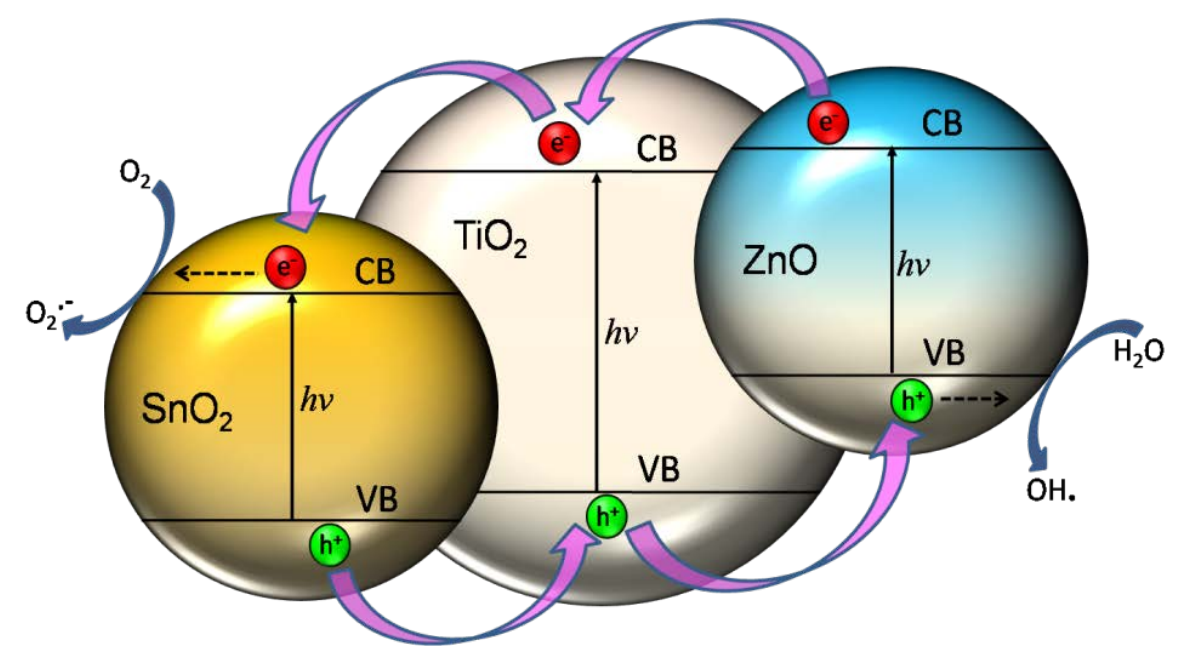

Figure 12. Electron transfer mechanism in composite semiconductor

In this case, the small band gap $\mathrm{CdS}(\mathrm{CB}=-0.76 \mathrm{eV})$ cause visible-light sensitization, and inject electrons to the conduction band of $\mathrm{SnO}_{2}(\mathrm{CB}=-0.34 \mathrm{eV})$, which results in an efficient electron-hole separation and an increase of photocatalytic activity. EDTA was used as a hole scavenger to prevent the photo-corrosion of CdS. Doong et al. reported very high photocatalytic activity of CdS coupled $\mathrm{TiO}_{2}$ towards the photocatalytic decomposition of 2-chlorophenol [220]. The better photocatalytic activity resulted from the electron injection from $\mathrm{CdS}$ to $\mathrm{TiO}_{2}$ and hole injection from $\mathrm{TiO}_{2}$ to CdS, which results in better charge separation. Kang et al. demonstrated the photodegradation of 4-chlorophenol using $\mathrm{CdS}-\mathrm{TiO}_{2}$ composite semiconductor [221]. The photocatalytic activities of the composite were found to be very high in comparison to that of $\mathrm{CdS}$ and $\mathrm{TiO}_{2}$ used separately.

$\mathrm{TiO}_{2}$ coupled with CdS can also be utilized for photocatalytic water splitting due to the more negative conduction band of $\mathrm{TiO}_{2}$ compared to $\mathrm{E}_{\mathrm{H} 2 / \mathrm{H} 2 \mathrm{O}}$. So et al . prevented the photo-corrosion of $\mathrm{CdS}$ with the help of $\mathrm{Na}_{2} \mathrm{~S}$ during photocatalytic hydrogen generation from water [222]. While the optical absorption of CdS- $\mathrm{TiO}_{2}$ 
extends up to $520 \mathrm{~nm}$, this can be utilized for the visible-light induced photocatalytic reactions. Compared to pure CdS and $\mathrm{TiO}_{2}$, a higher rate of hydrogen production was observed for $\mathrm{CdS}-\mathrm{TiO}_{2}$ under visible-light illumination. De et al. proved the improved visible-light activity of CdS-ZnS composite semiconductor for the photocatalytic water splitting [223]. Similar enhancements in the photocatalytic water splitting reactions using CdS-ZnS were also reported by Koca et al. [224] $\mathrm{TiO}_{2}$ coupled with wide band gap semiconductors were found to be highly photocatalytic under UV light. Superior photocatalytic activities of $\mathrm{TiO}_{2}-\mathrm{WO}_{3}$ and $\mathrm{TiO}_{2}-\mathrm{SiC}$ composite semiconductors were observed by Keller and Garin [225]. In the case of $\mathrm{TiO}_{2}-\mathrm{SiC}$ composite, the efficient electron injection occurs from the more negative conduction band of $\mathrm{SiC}$ to the less negative conduction band of $\mathrm{TiO}_{2}$. On the other hand, excited electrons transfer from the conduction band of $\mathrm{TiO}_{2}$ to the less negative conduction band of $\mathrm{WO}_{3}$ in $\mathrm{TiO}_{2}-$ $\mathrm{WO}_{3}$ composite. As a result of improved electron-hole separation, these composite semiconductors were more efficient for the photochemical decomposition of methyl ethyl ketone (MEK). Recently, Li et al. synthesized a series of highly visible-light efficient semiconductors by combining $\mathrm{N}$-doped $\mathrm{ZnO}$ with $\mathrm{WO}_{3}, \mathrm{~V}_{2} \mathrm{O}_{5}$ and $\mathrm{Fe}_{2} \mathrm{O}_{3}$ [226]. In these composite semiconductors, visible-light activation was achieved through nitrogen doping and the small band gap semiconductors such as $\mathrm{WO}_{3}, \mathrm{~V}_{2} \mathrm{O}_{5}$ and $\mathrm{Fe}_{2} \mathrm{O}_{3}$ were responsible for effective electron-hole separation. Coupling of $\mathrm{TiO}_{2}$ with $\mathrm{WO}_{3}$ and $\mathrm{V}_{2} \mathrm{O}_{5}$ were found to be more effective compared to $\mathrm{Fe}_{2} \mathrm{O}_{3}$ due to carrier recombination on $\mathrm{Fe}_{2} \mathrm{O}_{3}$. However, these composites were not suitable for hydrogen production due to the less negative position of $\mathrm{WO}_{3}$ and $\mathrm{V}_{2} \mathrm{O}_{5}$ conduction bands.

Besides dyes and metal nanoparticles, semiconductor quantum dots (QDs) could also be used for sensitizing $\mathrm{TiO}_{2}$ photocatalysts, where the QDs absorb light energy and transfer electrons to the conduction band [227]. Recently, extending the visible- 
light harvesting with various QDs such as of PbS, InP, CdS, CdTe, CuInS $2, \mathrm{Bi}_{2} \mathrm{~S}_{3}$ and CdSe attracted a great attention for solar energy conversion [228-235]. A high performance quantum dot sensitized solar cell composed of $\mathrm{TiO}_{2} / \mathrm{CuInS}_{2^{-}}$ QDs/CdS/ZnS photoanode (Figure 13) was reported recently [235]. An efficient way to harvest the entire solar spectrum is by tuning the particle size of QDs [236]. For instance, CdSe quantum dots of particle sizes 2.3, 2.6, 3.0, and $3.7 \mathrm{~nm}$ correspond to visible-light absorptions of 557, 543, 520, and $505 \mathrm{~nm}$ respectively [237].

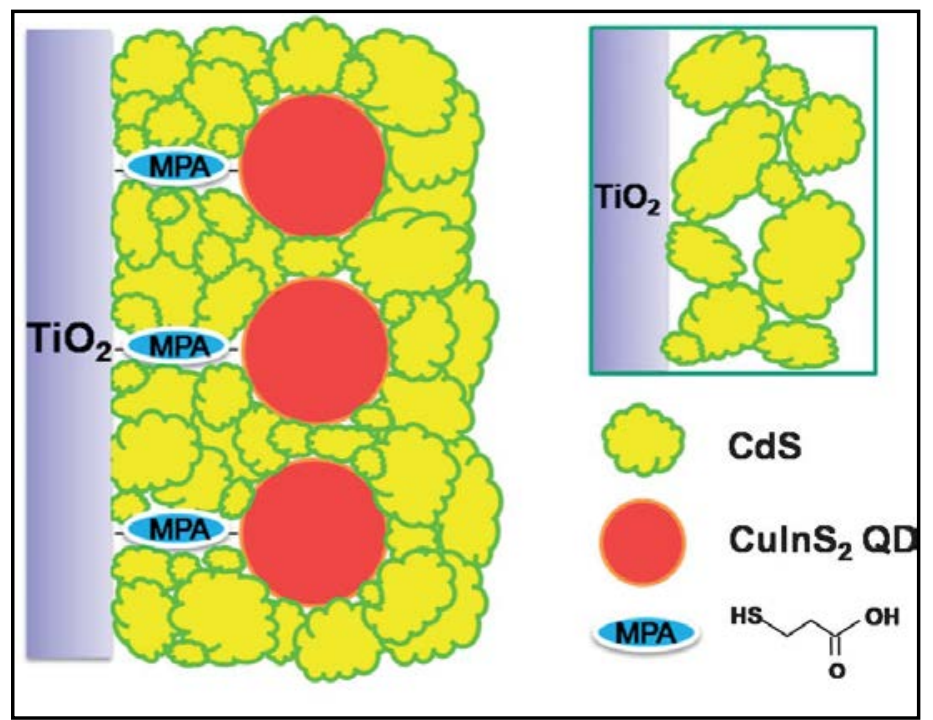

Figure 13. A conceptual schematic of the $\mathrm{CuInS}_{2}$-QDs/CdS heterostructure on the $\mathrm{TiO}_{2}$ surface. Reproduced with permission from ref. [235] Copyright 2012 The Royal Society of Chemistry

Additionally, Shockley-Queisser limit of energy conversion efficiency can be overcome by the unique electronic structure of QDs [238]. Moreover, integration of various QDs with different sizes allows energy absorption over a wide range. QDs are excellent sensitizers in solar cells due to their ability to harvest hot electrons and generate multiple carriers [239, 240]. They were also used in combination with dyesensitization and nitrogen doping to enhance the visible-light photocatalytic activity of $\mathrm{TiO}_{2}$ photocatalysts [241, 242]. 
An important chalcogenide compound $\mathrm{Ag}_{2} \mathrm{~S}$ (band gap=1.0 eV) has been investigated as for the visible-light sensitization of $\mathrm{TiO}_{2}$ nanoparticles for photocatalytic and photovoltaic applications [243, 244]. In addition to semiconductor nanoparticles, carbon quantum dots (CQDs) with excellent broadband light absorption, strong photoluminescence, chemical stability, and nontoxity has been coupled with $\mathrm{TiO}_{2}$ nanoparticles to improve the visible-light photocatalytic activities [245, 246]. Recently, carrier recombination in QDs sensitized $\mathrm{TiO}_{2}$ has been reduced by forming a ZnO layer between them [247]. From the computational point of view, the band level arrangement at the heterojunctions between $\mathrm{TiO}_{2}$ and QDs is a challenging task, even for state-of-the-art methodologies. It has been proposed to use the slab models based on the calculated value of electrostatic energy at the interface as reference for the band-edge positions [248]. This approach was shown to be successful in the case of the $\mathrm{ZnO} / \mathrm{TiO}_{2}$ interface if a proper exact exchange contribution is introduced in the hybrid functional used for performing the calculations.

\subsection{Nonstoichiometric $\mathrm{TiO}_{2}$}

Imperfections within the crystal structure significantly affect the phase stability, electronic structure and photocatalytic activity of $\mathrm{TiO}_{2}$ photocatalysts $[8,115]$. $\mathrm{TiO}_{2}$ samples containing oxygen vacancies were found to exhibit enhanced visible-light absorption, and photocatalytic activities. In the case of $\mathrm{TiO}_{2}$ containing oxygen vacancies, a partially occupied impurity energy level $\sim 2.0-2.5 \mathrm{eV}$ above the valence band was experimentally observed [249-252]. The additional energy level has also been attributed to the existence of partially occupied $\mathrm{Ti}^{3+}$ states, which create energy inter band gap energy levels just below the conduction band [253]. The theoretical modelling of $\mathrm{Ti}^{3+}$ centers in reduced $\mathrm{TiO}_{2}$ is a very delicate issue since they have a strong polaronic character (i.e. the electron trapping causes a lattice reorganization around the $\mathrm{Ti}^{3+}$ center). The proper position of $\mathrm{Ti}^{3+}$ associated states in the band gap of 
$\mathrm{TiO}_{2}$ is not an easy task and must be addresses with electron self-interaction corrected methods (DFT+U or hybrid functionals), since LDA and GGA approaches, which underestimate the band gap value and overestimate the excess electron delocalization, provide the incorrect picture of fully delocalized $\mathrm{Ti}^{3+}$ states in resonance with the bottom of the conduction band [254-257]. Heat treatment of $\mathrm{TiO}_{2}$ under oxygen deficient atmosphere and anionic doping were reported as the key synthesis methods for $\mathrm{TiO}_{2}$ containing oxygen vacancies.

Oxygen vacancy formation is more pronounced in the case of $\mathrm{N}$ doped $\mathrm{TiO}_{2}$ $[142,258,259]$. Formation of oxygen vacancies and $\mathrm{Ti}^{3+}$ ions were experimentally supported by EPR studies and DFT calculations [260]. Formation oxygen vacancies and $\mathrm{Ti}^{3+}$ in titanium dioxide calcined under hydrogen atmosphere were reported by previous researchers $[115,261,262]$. Recently, visible-light absorption of $\mathrm{TiO}_{2}$ has been improved through hydrogenation of $\mathrm{TiO}_{2}$ [263]. This is a very efficient method in which the mid-gap states above the valence band maximum (Figure 14) due to the hydrogenated, engineered disorders cause band gap narrowing [263]. Though $\mathrm{TiO}_{2}$ containing oxygen vacancies can absorb visible-light, their quantum efficiencies were low due to increased electron-hole recombination [8, 11, 17]. Identical to oxygen vacancies, oxygen excess defects can also result in new states in the band gap. Etacheri et al. recently synthesized oxygen rich $\mathrm{TiO}_{2}$ through a peroxo- $\mathrm{TiO}_{2}$ route, which demonstrated excellent visible-light photocatalytic activity [8]. In this case, in-situ formation of oxygen creates interstitial oxygen excess defects, which was confirmed from FTIR and XPS studies. These oxygen excess defects bind with lattice oxygen atoms and result in the formation of a substitutional $\mathrm{O}_{2}$ molecule, causing a decrease in lattice parameters. 


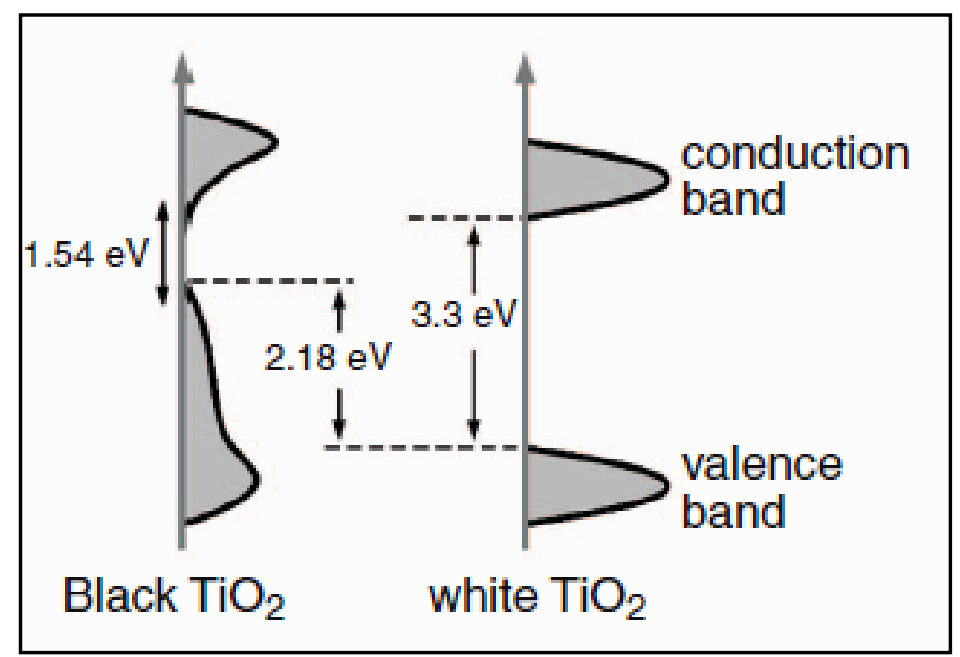

Figure 14. Electronic structure of black hydrogenated $\mathrm{TiO}_{2}$. Reproduced with permission from ref. [263] Copyright 2011 American Association for the Advancement of Science

Oxygen excess defects also cause band-gap narrowing by valence band shifting (Figure 15), which was confirmed using valence band XPS and photoluminescence (PL) studies. Oxygen rich $\mathrm{TiO}_{2}$ samples exhibited reduced PL-intensities compared to phase pure anatase $\mathrm{TiO}_{2}$ due to reduced electron-hole recombination. Oxygen excess defects also act as electron scavengers that increase the lifetime of photo-generated holes and decrease luminescence. Compared to pure anatase $\mathrm{TiO}_{2}$ and Evonik Degussa P-25, oxygen rich $\mathrm{TiO}_{2}$ exhibited six-fold and two-fold higher visible-light photocatalytic activities respectively. Only a few studies of interstitial oxygen species are available. These show that an additional neutral oxygen atom prefers to bind to a lattice oxygen atom forming an $\mathrm{O}-\mathrm{O}$ bond, instead of being stabilized as a charged species in the middle of an interstice [264, 265]. Interestingly, oxygen interstitials are predicted to be good electron traps by GGA+U calculations. The extra electron occupies a $\sigma^{*}$ state, which leads to a consistent elongation of the $\mathrm{O}-\mathrm{O}$ bond from 1.484 to

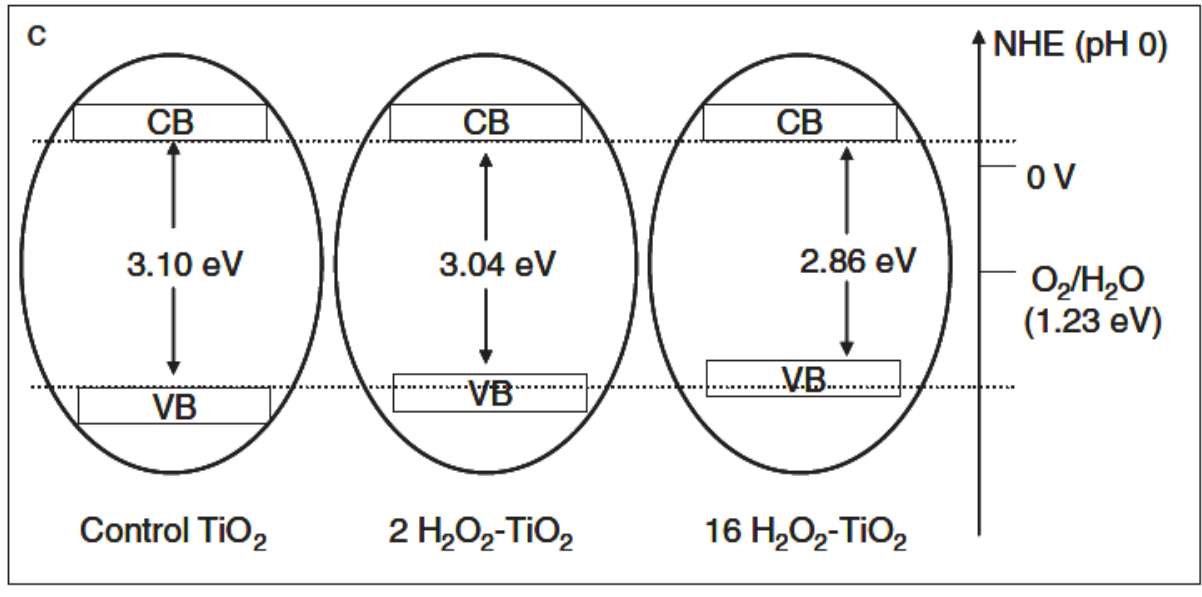

$1.970 \AA \AA$. 
Journal of Photochemistry and Photobiology C: Photochemistry Reviews, Volume 25, December 2015, Pages 1-29: doi:10.1016/j.jphotochemrev.2015.08.003

Figure 15. Electronic structure of oxygen rich $\mathrm{TiO}_{2}$. Reproduced with permission from ref. [8] Copyright 2011 Wiley VCH

\subsection{Non-metal doping}

4.6.1. Nitrogen doping 
Anion doping to enhance the visible-light photocatalytic activity in a semiconductor is a relatively a new method compared to other techniques. Improved visible-light absorption was observed for a variety of anions (N, F, C, S, etc.) doped $\mathrm{TiO}_{2}[142$, 266-269]. Non-metal dopants were found to be more efficient compared to most of the metal ions due to the less formation of recombination centers. Asahi et al. synthesized a series of anion-doped $\mathrm{TiO}_{2}$ and also determined the substitutional doping contents of these ions [142]. In contrast to other anion doped $\mathrm{TiO}_{2}$, the nitrogen-doped compositions has been found to be more effective and extensively investigated [207, 270]. $\mathrm{N}$ doped $\mathrm{TiO}_{2}$ can be synthesized through various physical and chemical methods

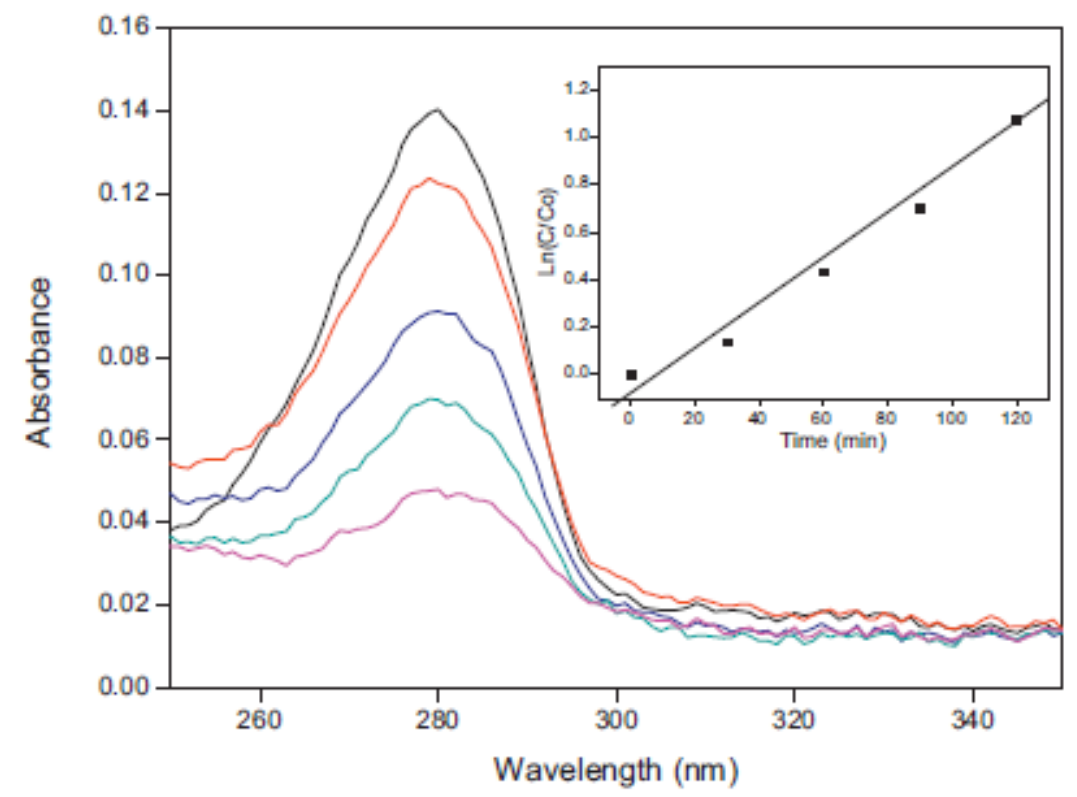

[258, 271-275].

Fabrication of

$\mathrm{N}$ doped $\mathrm{TiO}_{2}$

thin film

involved

sputtering under

$\mathrm{N}_{2} / \mathrm{Ar} \quad$ gas

atmosphere and

annealing in an

$\mathrm{N}_{2}$ atmosphere [142, 276, 277]. Sol-gel synthesis of $\mathrm{N}$-doped $\mathrm{TiO}_{2}$ use 1,3diaminopropane, and urea as precursor modifier to incorporate nitrogen [278],[10, 279]. N-doped $\mathrm{TiO}_{2}$ sample calcined at $500{ }^{\circ} \mathrm{C}$ was found to be highly effective in the degradation of 4-chlorophenol under solar irradiation (Figure 16). No degradation was recorded for the undoped $\mathrm{TiO}_{2}$ prepared under similar experimental conditions [278]. 
Figure 16. Solar photocatalysis of 4-chlorophenol using $\mathrm{N}$ doped $\mathrm{TiO}_{2}$ Reproduced with permission from ref. [278] Copyright 2012 Elsevier Science.

In another study, $\mathrm{N}$-doped $\mathrm{TiO}_{2}$ powders prepared by treating $\mathrm{TiO}_{2}$ powder with $\mathrm{NH}_{3}$ followed by calcinations was reported to be highly active for the decomposition of methylene blue under visible-light irradiation [280]. A mechanochemical method using crystalline $\mathrm{TiO}_{2}$ and hexamethylenetetramine (HMT) was also reported [281]. Hydrothermal and microwave assisted hydrothermal methods were also very effective for the synthesis of mesoporous $\mathrm{TiO}_{2}$ containing nitrogen [282, 283].

Electronic structure and type of dopant species of $\mathrm{N}$-doped $\mathrm{TiO}_{2}$ highly depends on the synthetic method. Several researchers proposed that lattice nitrogen causes the visible-light absorption, while other studies attributed NOx and NHx adsorbed on the surface to band gap narrowing [142, 284]. Thus, a controversy still remains regarding the dopants nature and electronic structure of anion doped $\mathrm{TiO}_{2}$. Asahi et al. illustrated the electronic structure and visible-light absorption of $\mathrm{N}$-doped $\mathrm{TiO}_{2}$ based on $\mathrm{Ti}-\mathrm{N}$ bonding [142]. They performed density state calculations and concluded that N-atoms substitute $\mathrm{O}$-atoms of anatase $\mathrm{TiO}_{2}$, and a consequent mixing of $\mathrm{O} 2 \mathrm{p}$ and $\mathrm{N} 2 \mathrm{p}$ state results in the band gap narrowing. This finding was also supported by the observations of Irie et al. [285]. However, a negative contribution of Ti-N bonding towards to band gap narrowing was identified by Diwald et al. [286]. However, further detailed 
investigations of electronic structure modification mechanism by of $\mathrm{N}-\mathrm{TiO}_{2}$ have subsequently been conducted by a number of researchers [258, 285, 287-290].

Di Valentin et al. performed a DFT study of $\mathrm{N}$-doped $\mathrm{TiO}_{2}$ with the hybrid functional B3LYP [260]'[269]. Their results showed that substitutional N-doping introduces localized impurity states just above the valence band level, and negligible mixing occurs between $\mathrm{N} 2 p$ and $\mathrm{O} 2 p$ states. In the same study it was also shown that $\mathrm{N}$ could enter the $\mathrm{TiO}_{2}$ lattice also in an interstitial position (NO species).

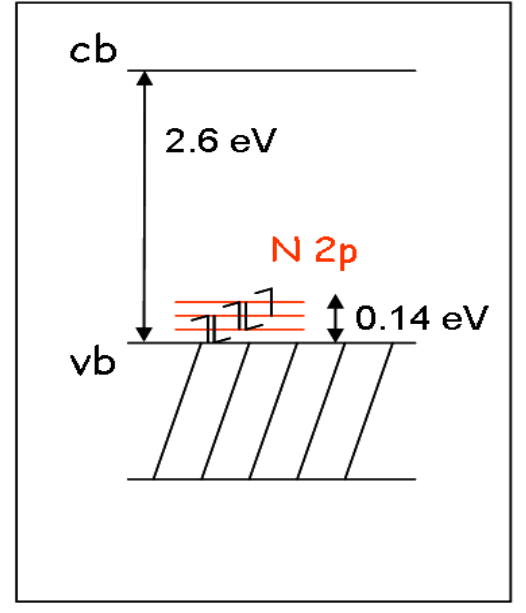

A

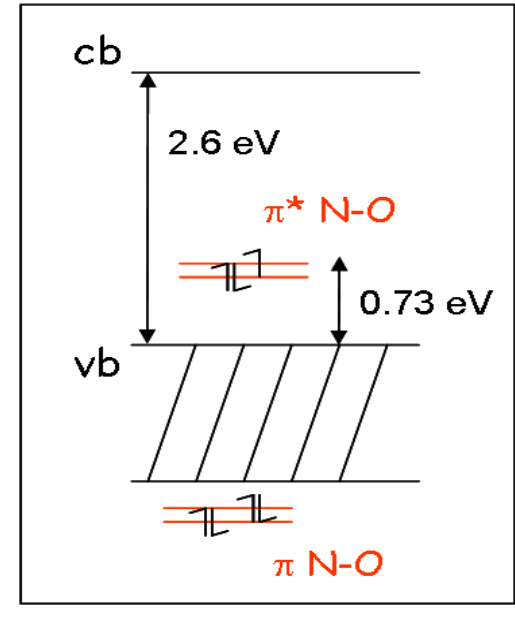

B

Figure 17. Electronic band structure of (A) substitutional and (B) interstitial N-doped anatase $\mathrm{TiO}_{2}$. Reproduced with permission from ref. [260] Copyright 2005 American Chemical Society

It is also evident that both conduction and valence band edges are unaffected by the dopants, and visible-absorption is resulted by localized energy levels generated by NO bond [285]. Two bonding energy-levels are positioned below the valence band level, and antibonding orbitals lie $0.73 \mathrm{eV}$ above the valence band. It is also proposed that antibonding NO orbitals act as stepping stone between conduction band and valence band of $\mathrm{TiO}_{2}$ (Figure 17), [237] and facilitate visible-light absorption [291-293]. Sugihara and co-workers have indicated that nitrogen doping could stabilize oxygen 
vacancies, which induce visible-light absorption [258]. This has been fully corroborated by DFT calculations in combination with EPR experiments on N-doped polycrystalline powder samples, showing that the stabilization results from electron transfer between high energy $\mathrm{Ti}^{3+}$ states to the low lying $\mathrm{N}$ induce impurity states (Figure 18) [294].

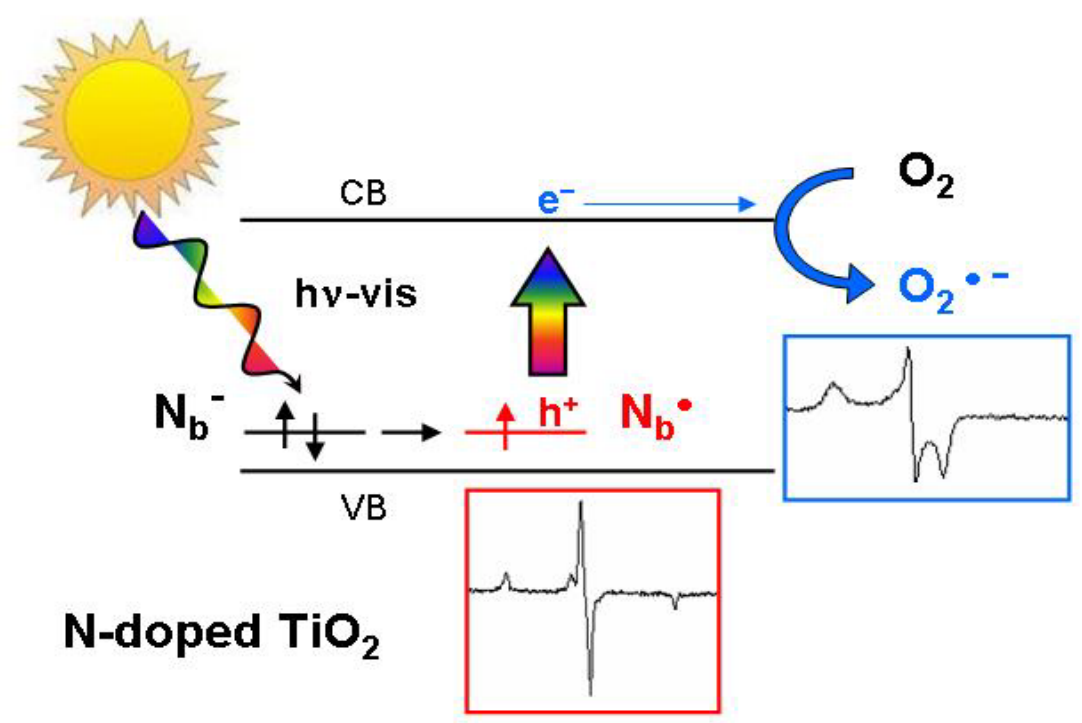

Figure 18. Schematic representation showing electron transfer between high energy $\mathrm{Ti}^{3+}$ states to the low lying $\mathrm{N}$ induce impurity states. Reproduced with permission from ref. [294] Copyright 2006 American Chemical Society

$\mathrm{TiO}_{2}$ surface nitrogen doping was also investigated by DFT calculations. Both the rutile (110) and anatase (101) surfaces were considered [295, 296]. Analogous substitutional and interstitial species were identified as in the bulk of $\mathrm{TiO}_{2}$. The electronic interplay with oxygen vacancies is found to be synergistic; confirming that surface N-doping is expected to cause an enhanced defect concentration. Pillai and coworkers [278] observed an unexpected blue shift in the UV/Vis absorbance of $\mathrm{N}-\mathrm{TiO}_{2}$ samples heat treated at $\geq 600 \circ \mathrm{C}$. XRD analysis showed that these $\mathrm{N}$ doped $\mathrm{TiO}_{2}$, processed significant amounts of rutile phase. Di Valentin and co-workers [297] had previously explained using theoretical calculations that a blue shift was observed with 
$\mathrm{N}$-doped (rutile) because not only the $\mathrm{TiO}_{2}$ valence band lowered (by $0.4 \mathrm{eV}$ ) but the newly introduced N $2 p$ states were also lower in energy than the valence band of pure rutile phase $(0.05 \mathrm{eV})$. This resulted in an overall blue shift due to an effective band gap widening (Figure 19).

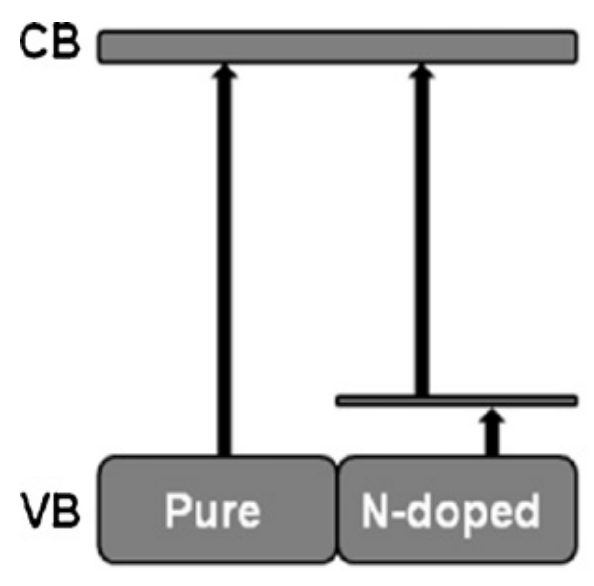

Anatase

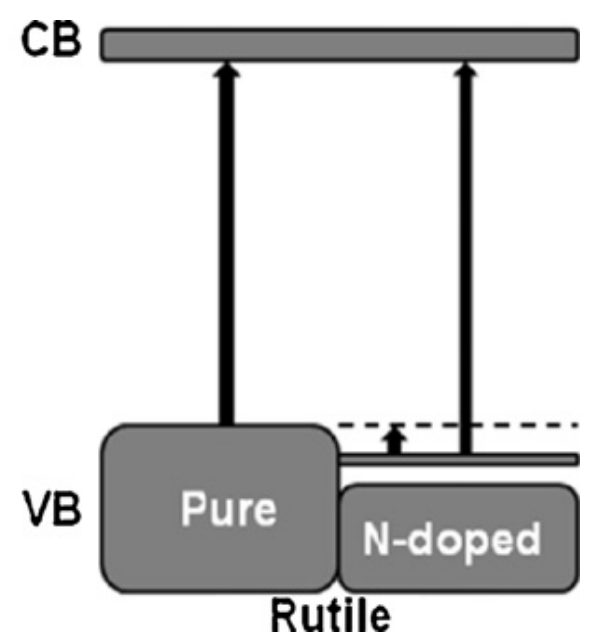

Figure 19. Schematic diagram showing the energy states of pure and N-doped anatase and rutile $\mathrm{TiO}_{2}$. Reproduced with permission from ref. [278] Copyright 2012 Elsevier Science

\subsubsection{Other non-metal doping}

Kisch and co-workers for the first time reported daylight-induced photocatalysis using carbon-modified $\mathrm{TiO}_{2}$ [298]. Many physical and chemical investigations were reported for the synthesis of carbon doped nanoparticles and thin films [19, 299-302]. This narrow band gap $\mathrm{TiO}_{2}$ showed significantly improved photocatalytic activities up on visible-light irradiation compared to pure anatase $\mathrm{TiO}_{2}$ and the standard photocatalyst Evonik Degussa P-25. Control of porosity, morphology, and synthesizing hierarchical structures further improved the visible-light photocatalytic activities of C-doped $\mathrm{TiO}_{2}$ [303-305]. Mechanism of visible-light absorption in C-doped $\mathrm{TiO}_{2}$ was explained by the formation of $\mathrm{Ti}^{3+}$ and oxygen vacancies due to carbon doping [142, 298, 306, 307] Previous researchers performed DFT calculations, and concluded that substitution of 
$\mathrm{O}^{2-}$ by C-atoms (Ti-C bond formation) resulted in the mixing of $\mathrm{O} 2 \mathrm{p}$ states with $\mathrm{C} 2 \mathrm{p}$ states, and band gap narrowing [306, 308]. However, DFT based calculations of Cdoped rutile and anatase $\mathrm{TiO}_{2}$ clearly indicate that $\mathrm{C}$ impurities can be both substitutional and interstitial, depending on the preparation conditions (i.e. oxygen partial pressure). Eventually, both types of species may even coexist since there is a synergistic effect associated to the electron transfer from the oxidized interstitial species to the reduced substitutional one [309].

Another interesting class of visible-light active photocatalyst consist of sulfurdoped $\mathrm{TiO}_{2}$. Sulfur was detected as hexavalent $\left(\mathrm{S}^{6+}\right)$, tetravalent $\left(\mathrm{S}^{4+}\right)$, or sulfide $\left(\mathrm{S}^{2-}\right)$, depending on the synthetic method of S-doped $\mathrm{TiO}_{2}[100,105,310]$. Umebayashi et al. thermally oxidized $\mathrm{TiS}_{2}$ to synthesize anionic S-doped $\mathrm{TiO}_{2}$, and Ohno et al. fabricated cationic S-doped $\mathrm{TiO}_{2}$ powder through chemical modification of titanium tetraisopropoxide using thiourea [266, 310]. These S-doped materials were found to have notably improved photocatalytic decomposition of 2-propanol and methylene blue under visible-light irradiation. Absorption of visible-light by these photocatalyst are explained by the mixing of $\mathrm{O} 2 \mathrm{p}$ and $\mathrm{S} 3 \mathrm{p}$ states $[266,310]$. On the other hand, recent studies explained the band gap narrowing by the formation of S 3p impurity states above the valance band [311, 312]. Formation of S 3p level $0.38 \mathrm{eV}$ above the valence band was identified in the case of cationic S-doped $\mathrm{TiO}_{2}$ [312]. Though Sdoped $\mathrm{TiO}_{2}$ is a promising visible-light active photocatalyst, incorporation of $\mathrm{S}$ in the $\mathrm{TiO}_{2}$ crystal structure is difficult due to its large ionic radius [313].

It was demonstrated that F-doping is useful for improving the visible-light photocatalytic activity of $\mathrm{TiO}_{2}$ [314-316]. F-doping was also effective for stabilizing the most reactive (001) facets of anatase $\mathrm{TiO}_{2}$ [317]. The photocatalytic activity of such F-doped $\mathrm{TiO}_{2}$ with dominant exposed (001) facets were remarkably higher than 
other F-doped $\mathrm{TiO}_{2}$ nanoparticles [318]. F-doped thin films also showed improved visible-light photocatalytic activities towards the photodegradation of X-3B dye [319]. Iodine doping was also successful for significantly reducing the band gap of anatase $\mathrm{TiO}_{2}$ photocatalysts [320-323]. Yu et al. explained that F-doping cause the reduction of $\mathrm{Ti}^{4+}$ to $\mathrm{Ti}^{3+}$, which resulted in the band-gap narrowing [324]. Li et al. confirmed the formation of additional energy levels below the conduction band of F-doped $\mathrm{TiO}_{2}$ due to oxygen vacancy formation [314].

Iodine is another potential dopant that can induce visible-light absorption by altering the electronic structure of $\mathrm{TiO}_{2}$ photocatalyst. Cheng et al. synthesized mesoporous bicrystalline network of mesoporous $\mathrm{TiO}_{2}$ with improved photodegradation of methylene blue under visible-light irradiation [321]. Synthesis, characterization, and electronic structure of multivalent iodine $\left(\mathrm{I}^{7+} / \mathrm{I}^{-}\right)$doped $\mathrm{TiO}_{2}$ was reported by $\mathrm{Fu}$ et al. [323] It was suggested that the recombination of photogenerated electron-hole pairs is inhibited due to the electron trapping action of the I sites [320]. A maximum absorption edge of $550 \mathrm{~nm}$ was experimentally determined for the lattice Idoped $\mathrm{TiO}_{2}$. Whereas, an extended absorption up to $800 \mathrm{~nm}$ was observed for the surface iodine doped $\mathrm{TiO}_{2}$ [325]. Photocatalytic activities of narrow band gap I-doped bronze phase $\mathrm{TiO}_{2}$ was nanosheets were also investigated recently [326]. Iodine doped $\mathrm{TiO}_{2}$ was highly effective for the degradation of dyes, 4-chlorophenol and $\mathrm{CO}_{2}$ reduction under visible-light irradiation [320, 325, 327]. In the case of I-doped $\mathrm{TiO}_{2}$, electronic excitation from the I-O-Ti states positioned just above the valence band to the I-O-I levels below the conduction band [325].

Moussab Harb has recently reported the optoelectronic properties of Se-doped $\mathrm{TiO}_{2}$ using DFT and perturbation theory approach DFPT. A range of selenium doping at various substitutional sites for oxygen or titanium, interstitial sites or at mixed substitutional and 
interstitial sites were investigated. Various structures such as $\mathrm{Ti}_{(1-2 \mathrm{x})} \mathrm{O}_{2} \mathrm{Se}_{2 \mathrm{x}}\left(\mathrm{Se}^{4+}\right.$ species), $\mathrm{TiO}_{(2-\mathrm{x})} \mathrm{Se}_{\mathrm{x}}\left(\mathrm{Se}^{2-}\right.$ species$)$, and $\mathrm{TiO}_{(2-\mathrm{x})} \mathrm{Se}_{2 \mathrm{x}}\left(\mathrm{Se}_{2}{ }^{2-}\right.$ species$)$ with visible-light optical absorption spectra were identified (Figure 20) [328]. Theoretical predictions were found to be in good agreement with the experimental results. The study of Grey et al. that boron doping of $\mathrm{TiO}_{2}$ lead to partial reduction of $\mathrm{Ti}^{4+}$ to $\mathrm{Ti}^{3+}$, which could improve the photocatalytic activity [329]. Compared to other non-metals, boron doping was not investigated in detail. Recently Chen et al. reported band gap widening for B-doped $\mathrm{TiO}_{2}$, whereas Zhao et al. showed a band gap narrowing

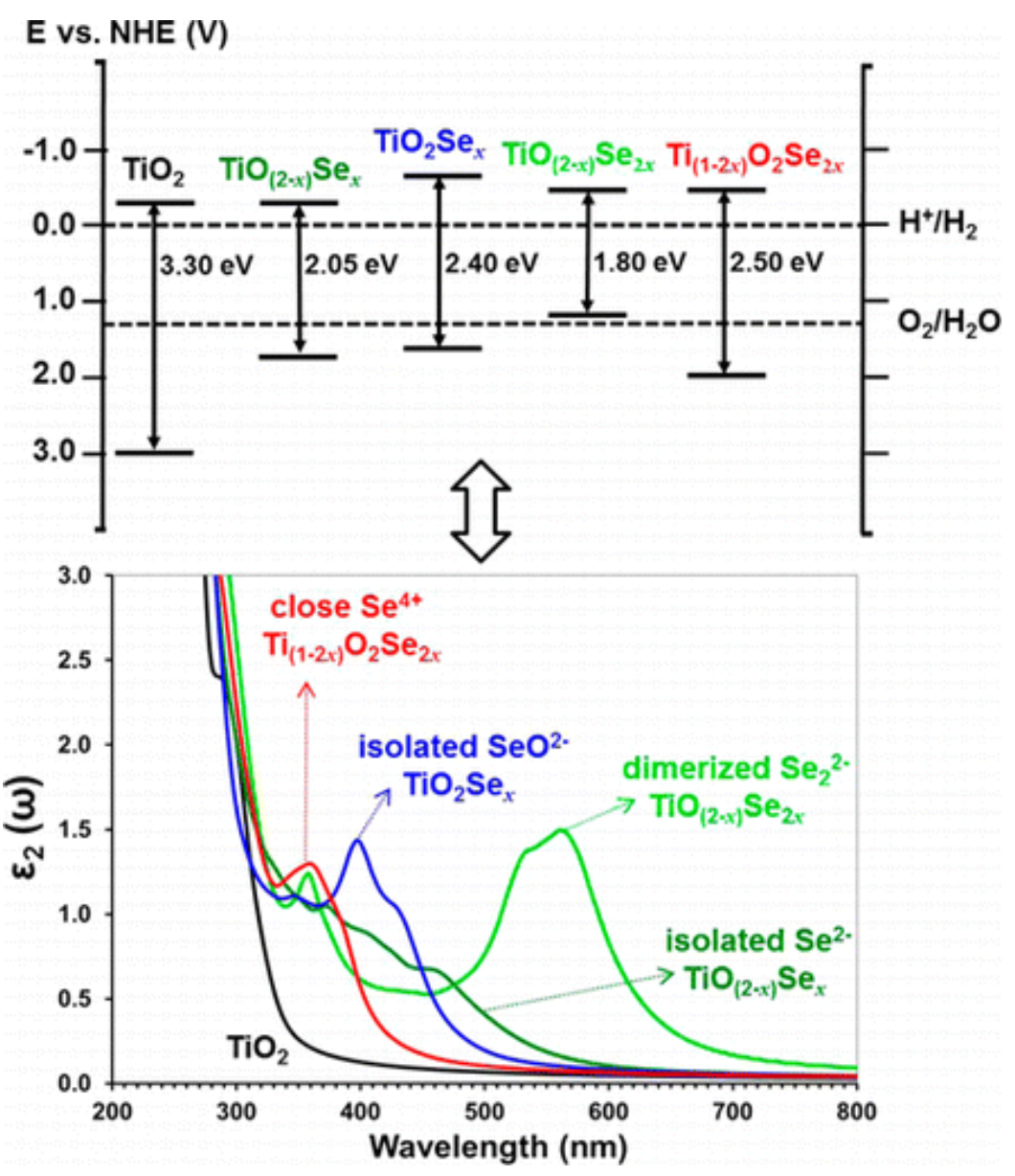

[330, 331]. 
Figure 20. Effect of selenium doping in the visible light activation of anatase TiO2. Reproduced with permission from ref. [328] Copyright 2013 American Chemical Society

It was later demonstrated that proper doping of an optimum B-doping results in significantly higher visible-light absorption and visible-light photocatalytic activities [332]. These B-doped $\mathrm{TiO}_{2}$ were successfully utilized for the decomposition of methyl orange, methyl tertiary butyl ether, orange II, 4-cholorophenol and nicotinamide adenine dinucleotide (NADH) under visible-light irradiation [330, 332-334]. Based on LDA calculations, the band gap narrowing of boron doped $\mathrm{TiO}_{2}$ was illustrated by the formation of isolated $\mathrm{B} 2 \mathrm{p}$ impurity levels in the band gap [291]. More refined hybrid density functional results indicate that $\mathrm{B}$ enters the $\mathrm{TiO}_{2}$ lattice in the interstitial sites, forming oxidized borate species and, consequently, reduced $\mathrm{Ti}^{3+}$ centers [335].

Several attempts have been reported for the spectroscopic band gap investigation of the anion doped $\mathrm{TiO}_{2}$. For instance, Etacheri et al. [17, 19] performed valence band (VB) XPS to illustrate the consequence of $\mathrm{S}, \mathrm{N}$ and $\mathrm{C}$ doping on the electronic structure of $\mathrm{TiO}_{2}$, (Figure 21). They identified similar valence band maximum $(1.95 \mathrm{eV})$ for both pure and anion doped $\mathrm{TiO}_{2}$, which was also identical to the previously reported valence band levels of pure anatase $\mathrm{TiO}_{2}$ [8, 336, 337]. Additionally, equal width $(9.5 \mathrm{eV})$ of the valence band explained identical mobilities of the photogenerated holes.

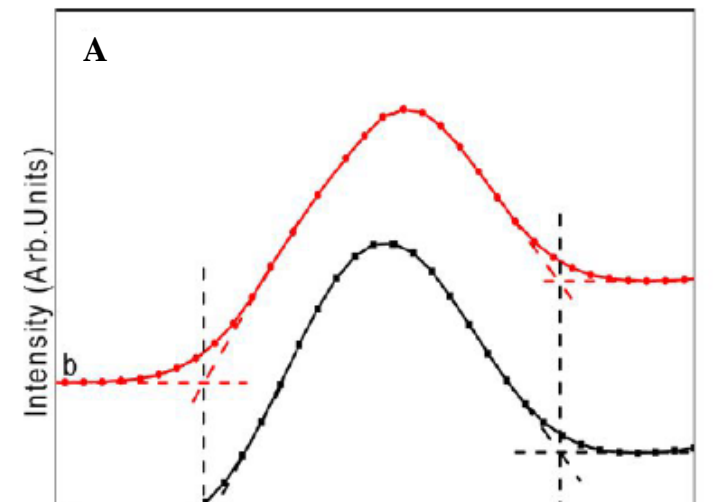

B

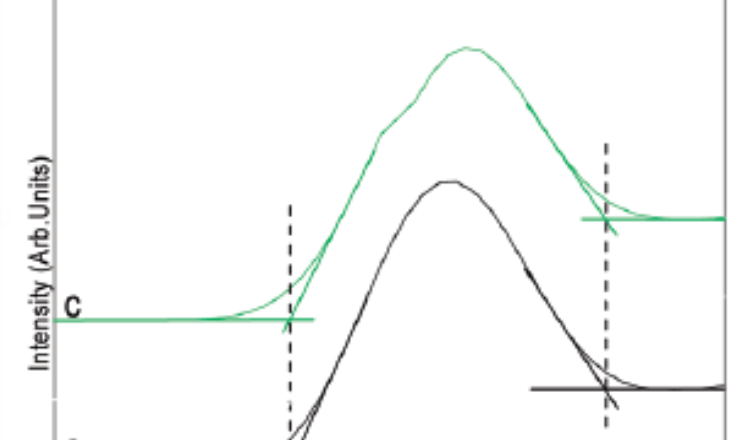


Figure 21. Valence band XPS study of (A) C-doped anatase-brookite heterojunctions (a) Pure $\mathrm{TiO}_{2}$, (b) C-doped $\mathrm{TiO}_{2}$. Reproduced with permission from ref. [19] Copyright 2013 American Chemical Society. and (B) S, N- codoped anatase-rutile heterojunctions (a) Pure $\mathrm{TiO}_{2}$ (b) S, N- codoped $\mathrm{TiO}_{2}$. Reproduced with permission from ref. [17] Copyright 2012 American Chemical Society

These spectroscopic results clearly ruled out the band gap narrowing due to the mixing of $\mathrm{O} 2 \mathrm{p}$ bands with $\mathrm{C} 2 \mathrm{p}, \mathrm{N}$ 2p and S 3p states. Electronic structure of the anion doped $\mathrm{TiO}_{2}$ highly depends on the electronegativity of dopant atoms. Only poor mixing of $\mathrm{C}$ 2p, S 3p and $\mathrm{N} 2 \mathrm{p}$ bands with $\mathrm{O} 2 \mathrm{p}$ bands can be expected due to the low electronegativity of $\mathrm{C}, \mathrm{S}$ and $\mathrm{N}$ atoms (2.55, 2.58 and 3.04 respectively) compared to oxygen (3.44) [291, 292]. Consequently, visible-light absorption of $\mathrm{TiO}_{2}$ doped with anions such as $\mathrm{C}, \mathrm{S}$, and $\mathrm{N}$ doped $\mathrm{TiO}_{2}$ can be illustrated by the electronic excitation from isolated C 2p, S 3p, N 2p, and $\Pi^{*} \mathrm{~N}-\mathrm{O}$ states in the band gap. Their findings demonstrated the fact that anion-doping does not actually causing band gap narrowing, and the visible-light absorption resulted from the isolated impurity levels in the band gap (Figure 22). 


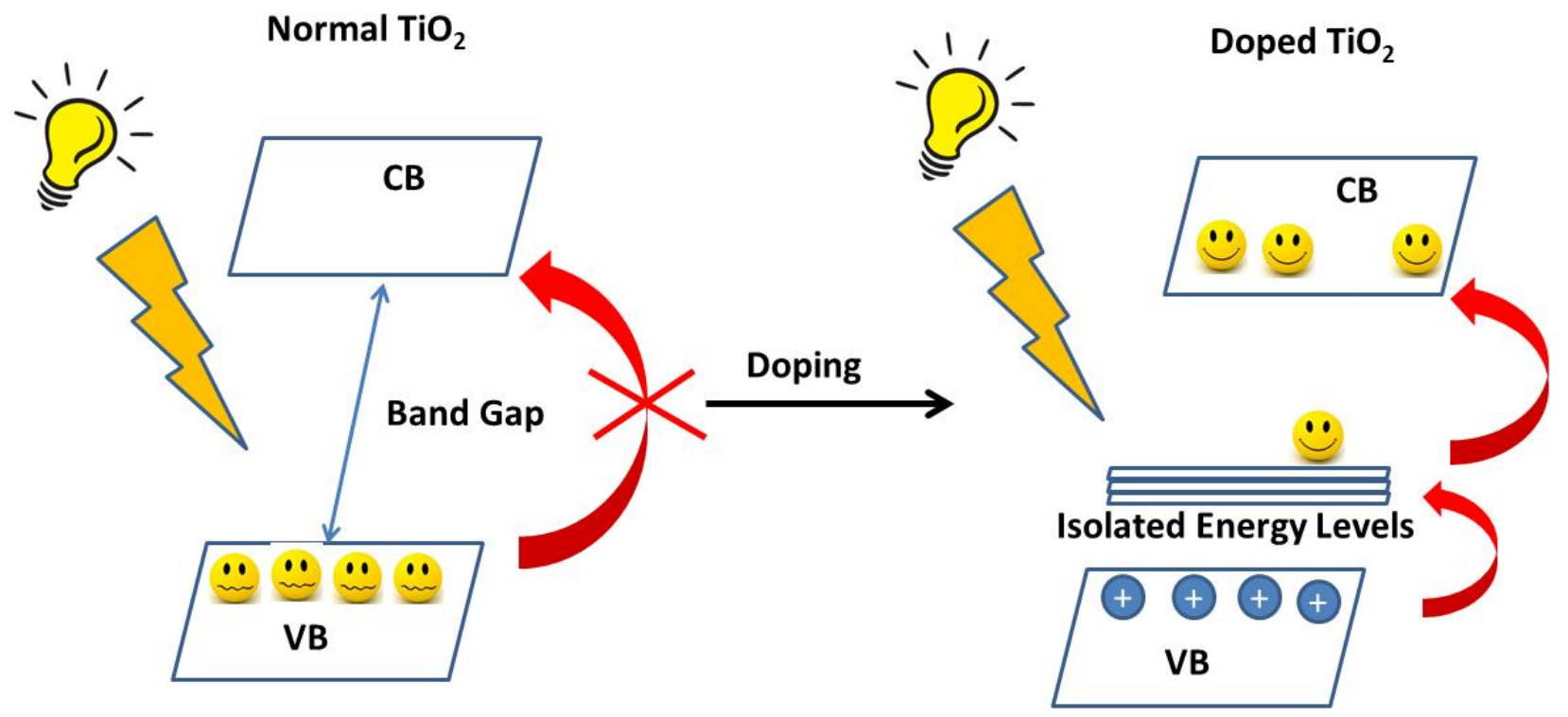

Figure 22. Schematic mechanism of band gap narrowing in anion doped $\mathrm{TiO}_{2}$.

The computational community has also made an effort to investigate and compare various non-metal dopants [309, 338-343]. Recently, a systematic comparative hybrid DFT study was reported where N, C, B, F dopants are treated at an equal footing (Figure 23) [344]. Clear trends emerged from this study. In particular, B and C are found to be preferentially oxidized by the $\mathrm{TiO}_{2}$ lattice forming borate or carbonate species and reducing $\mathrm{Ti}^{4+}$ lattice sites to $\mathrm{Ti}^{3+}$ species. Nitrogen is not inclined to oxidation; even in the interstitial NO form. ${ }^{252}$ Fluorine prefers the substitutional (to $\mathrm{O}$ ) doping mode, which also causes the reduction of lattice $\mathrm{Ti}^{4+}$ ions, given the larger atomic number $(\mathrm{F}>\mathrm{O})$. All these non-metal dopants are prone to interact with intrinsic defects such as oxygen vacancies and Ti interstitials through long-range internal charge transfer process. 


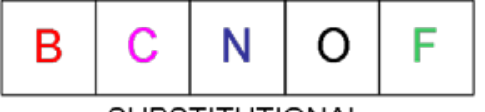

Journal of Photochemistry and PUBSTITUTOONAL Photobiology C: Photochemistry Reviews, Volume 25,
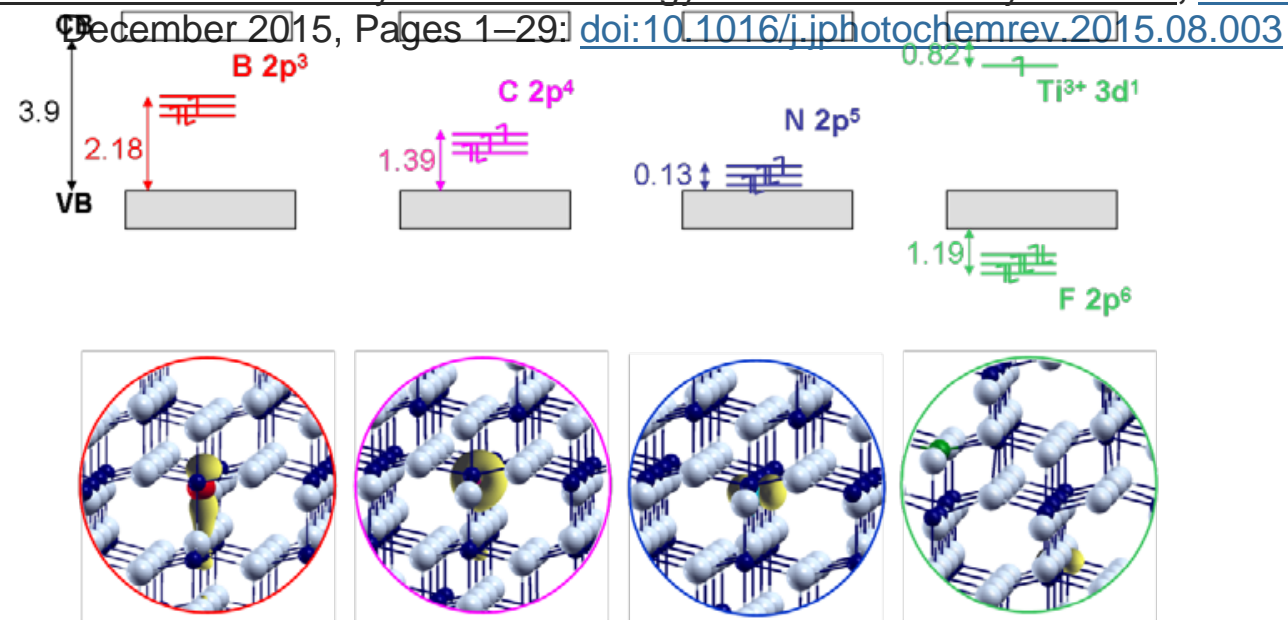

Figure 23 schematic representations of $\mathrm{B}, \mathrm{C}, \mathrm{N}$ and $\mathrm{F}$ doping in $\mathrm{TiO}_{2}$. Reproduced with permission from ref. [344] Copyright 2013 Elsevier Science

\subsubsection{Non-metal codoping}

Another efficient strategy for increasing the visible-light utilization of non-metal doped $\mathrm{TiO}_{2}$ was the incorporation of multiple dopants (codoping). For example, (S, N)-codoped anatase $\mathrm{TiO}_{2}$ exhibited enhanced visible-light photocatalytic performance compared to both S and Ndoped $\mathrm{TiO}_{2}$ [94, 345, 346]. XPS is identified as an effective tool to identify $\mathrm{N}$ and $\mathrm{S}$ incorporation in $\mathrm{TiO}_{2}$ photocatalysts $[10,11,17,19,113,347]$. Pillai and co-workers explained that the peak at $402 \mathrm{eV}$ is due to the presence of both $\mathrm{NO}$ and chemisorbed nitrogen (Figure 24). Sulfur presents in the $\mathrm{TiO}_{2}$ show a peak around $169 \mathrm{eV}$, which was assigned to $\mathrm{S}^{6+}$ cation [347]. 

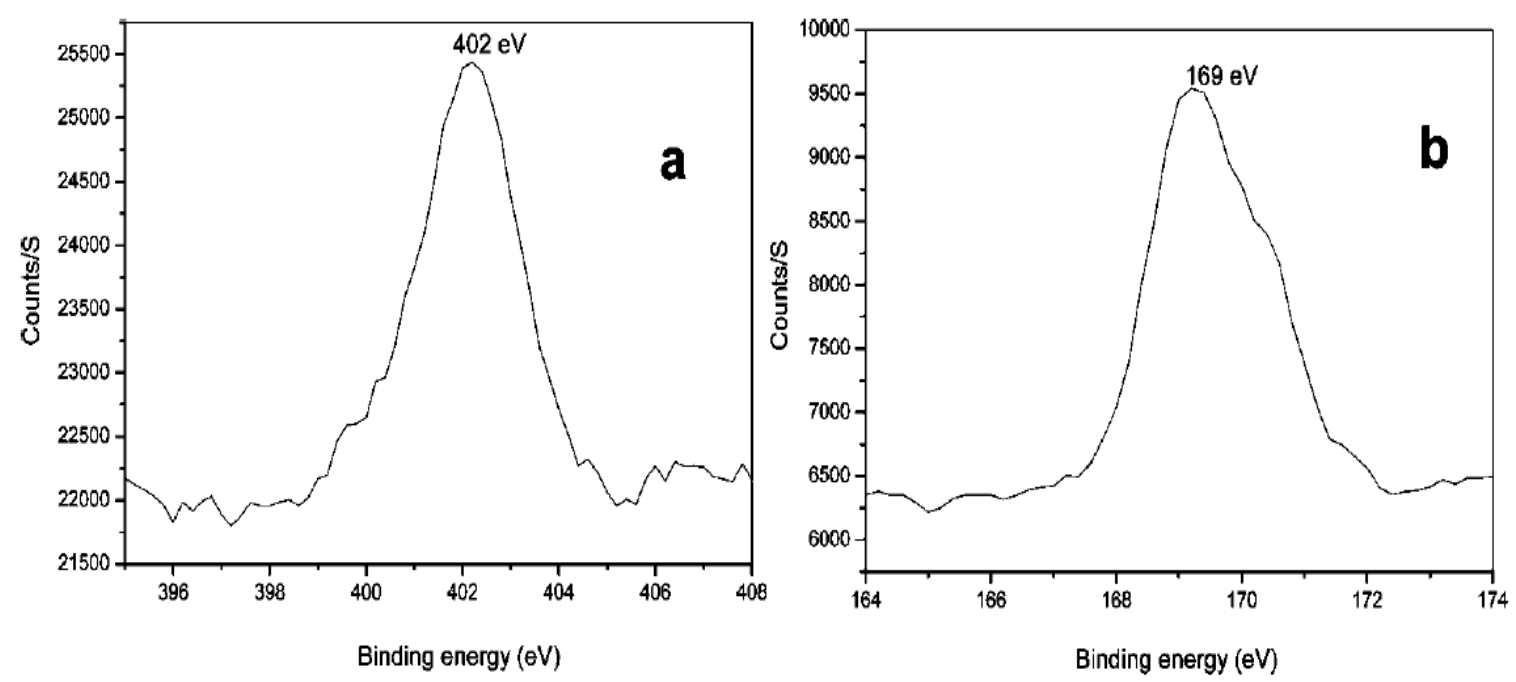

Figure 24. XPS spectra of (a) nitrogen and (b) sulfur in $\mathrm{TiO}_{2}$ Photocatalysis. Reproduced with permission from ref. [347] Copyright 2009 American Chemical Society.

Modification of $\mathrm{TiO}_{2}$ precursor by ammonium sulphate and thiourea was found to be the most promising methods for the for the cationic $\mathrm{S}$ and anionic $\mathrm{N}$-codoping of $\mathrm{TiO}_{2}$ nanoparticles [17, 347]. Additionally, Xiang et al. recently reported synthesis and improved activity of S, N- codoped (001) facet exposed anatase nanosheets [348]. Superior photocatalytic performance was endorsed to effective band gap narrowing by (S, N)-codoping and exposure of highly reactive (001) facets. Hydrothermal synthesis of $\mathrm{B}, \mathrm{N}$-codoped $\mathrm{TiO}_{2}$ was reported to be highly effective for extending the visiblelight absorption and improving visible-light photocatalytic activity. Xu et al. developed an organic-free sol-gel method for the fabrication of (C, N)-codoped $\mathrm{TiO}_{2}$ films, which showed high visible-light photocatalytic activities toward the photodegradation of stearic acid [349]. (C, N)-codoped $\mathrm{TiO}_{2}$ with special morphologies such as nanotubes and nanorods have been also reported previously. These visible-light active photocatalysts were superior to Evonik Degussa P-25 for the photodegradation of Rhodamine-B [350]. Macroporous $\mathrm{TiO}_{2}$ microspheres codoped with $\mathrm{C}$ and $\mathrm{F}$ were highly efficient for the visible-light photocatalytic degradation of styrene [351]. 
Notably improved photocatalytic performance of mesoporous hierarchical $\mathrm{TiO}_{2}$ containing $\mathrm{C}$ and $\mathrm{S}$ dopants was also reported recently [352]. First principle electronic structure calculation and XPS studies of (B, N), (B, I), (B, F) and (C, N)-codoped $\mathrm{TiO}_{2}$ identified a synergetic effect between individual anions are accountable for the improved visible-light absorption [353, 354]. Visible-light absorption up to $700 \mathrm{~nm}$ was observed in the case of $(\mathrm{C}, \mathrm{N})$-codoped $\mathrm{TiO}_{2}$. Highly visible-light active $\mathrm{B}, \mathrm{N}$ codoped red anatase $\mathrm{TiO}_{2}$ microspheres with a band gap of $1.94 \mathrm{eV}$ on the surface and $3.22 \mathrm{eV}$ in the core has been reported recently [355]. The synthesis method involved pre-doping of $\mathrm{TiO}_{2}$ with boron to weaken the Ti-O bonding, and thereby improving the solubility of the second dopant nitrogen. In this case, visible-light absorption has been extended up to $700 \mathrm{~nm}$ (Figure 25), and colour changed from white to red, which is completely different from the yellow colour and small visible-light absorption of $\mathrm{N}$ doped $\mathrm{TiO}_{2}$. Substitutional nitrogen doping in this case was also demonstrated using Raman spectroscopy.

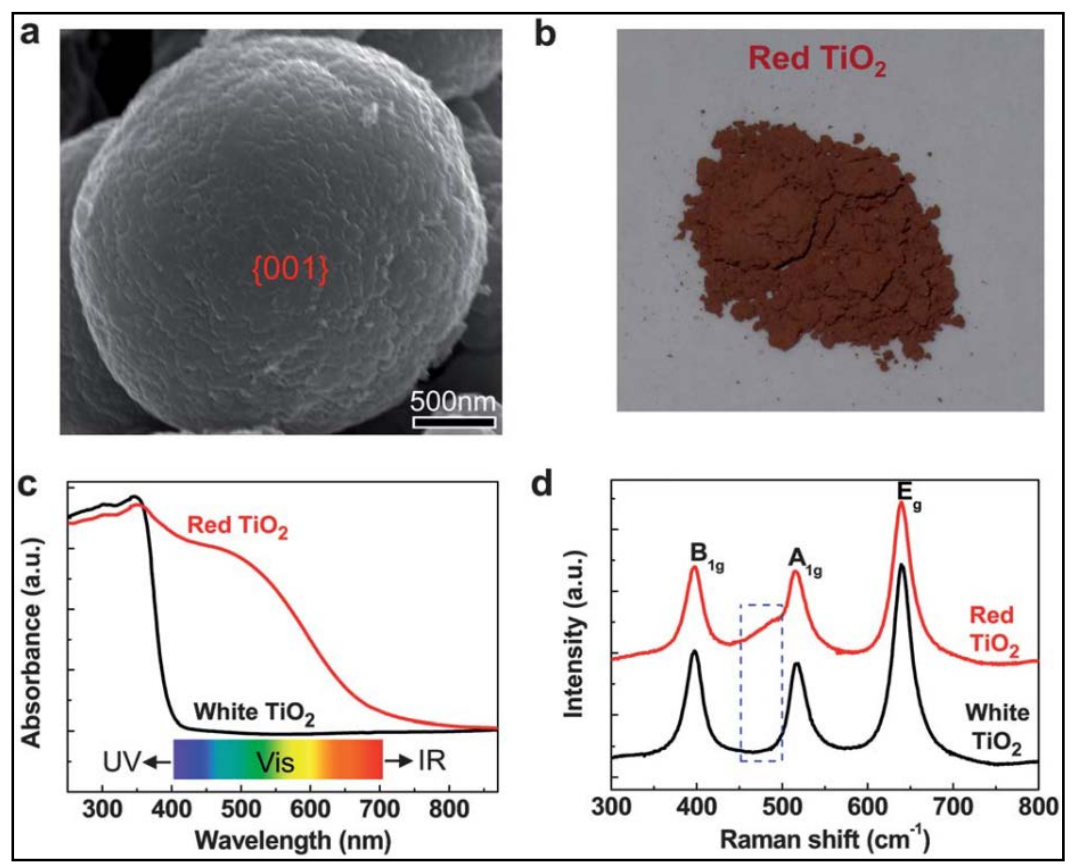

Figure 25. (a) SEM image of a red $\mathrm{TiO}_{2}$ microspheres; (b) optical photograph of the prepared red $\mathrm{TiO}_{2}$ sample; (c) and (d) UV-visible absorption and Raman spectra of the white and red $\mathrm{TiO}_{2}$. Reproduced with permission from ref. [355] Copyright 2012 The Royal Society of Chemistry 
The principles at the basis of the synergistic effect of non-metal codoping for visible-light photocatalysis were unravelled again by means of DFT calculations [356360]. The most efficient pairs, such as N-F codopants, essentially present and electron donor (F) and an electron acceptor (N) which interact through internal long-range charge transfers, in analogy with what observed for non-metal impurities with oxygen vacancies. A donor species is an excellent substituent of the oxygen vacancy; therefore it has the beneficial effect of largely reducing the sample defectivity, commonly associated for example with $\mathrm{N}$-doping. Thus, the role of one dopant (e.g. N) is to induce the visible-light absorption properties, whereas the role of the second dopant (e.g. F) is to compensate the overall electron counting, which is an efficient way to avoid the undesired formation of lattice defects. The photocatalytic activity can largely benefit from these effects since the electron/hole recombination rate is found to be directly proportional with the presence of lattice defects. Hamilton et al. [361] employed photo electrochemical measurements to examine the mechanism of visible light photocatalysis. The N,F doped $\mathrm{TiO}_{2}$ did not provide any significant photocurrent response in presence of visible light at fixed potential under monochromatic irradiation, as compared to band gap irradiation (Figure 26). Addition of KI and hydroquinone as 'hole acceptors' showed slight increases in the photocurrent. $\mathrm{KO}_{2}$ (superoxide source) produced enhancement of photocurrent under visible light. This improvement in the photocurrent is explained as the oxidation of superoxide radical to singlet oxygen by the mid-gap level formed by $\mathrm{N}$ doping.

The F-doping induces the creation of shallow $\mathrm{Ti}^{3+}$ donor levels slightly below the conduction band. Oxygen vacancies transfer electrons to re-populate $\mathrm{N}$ states. The conduction band electrons can then move to the oxygen vacancies. Therefore a cycle 
of excited electrons occurred starting at the $\mathrm{N}$ mid-gap state, to conduction band and then to $\mathrm{Ti}^{3+}$ or oxygen vacancies with subsequent re-population of the empty nitrogen states (Figure 27). The occurrence of visible light activity in this example is explained as mainly due to the reduction reaction involving conduction band electrons with molecular oxygen.

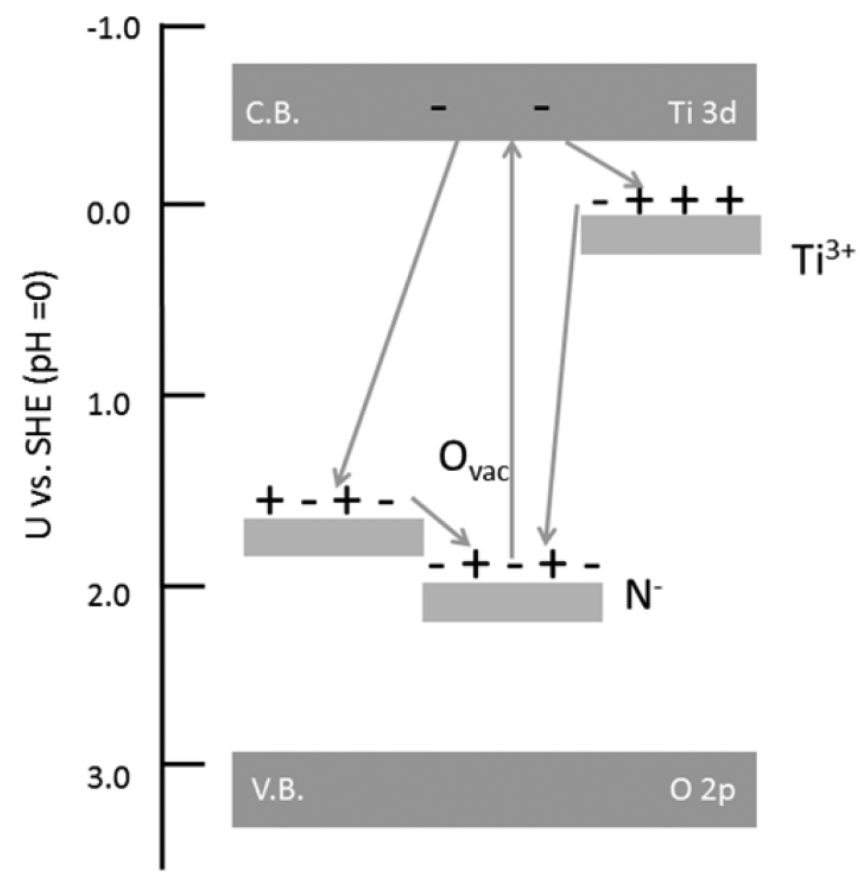

Figure 26. Mechanism of electron transfer from either $\mathrm{Ti}^{3+}$ or oxygen vacancies in N-F doped $\mathrm{TiO}_{2}$ explained using photo-electrochemical studies. Reproduced with permission from ref.

[361] Copyright 2014 American Chemical Society

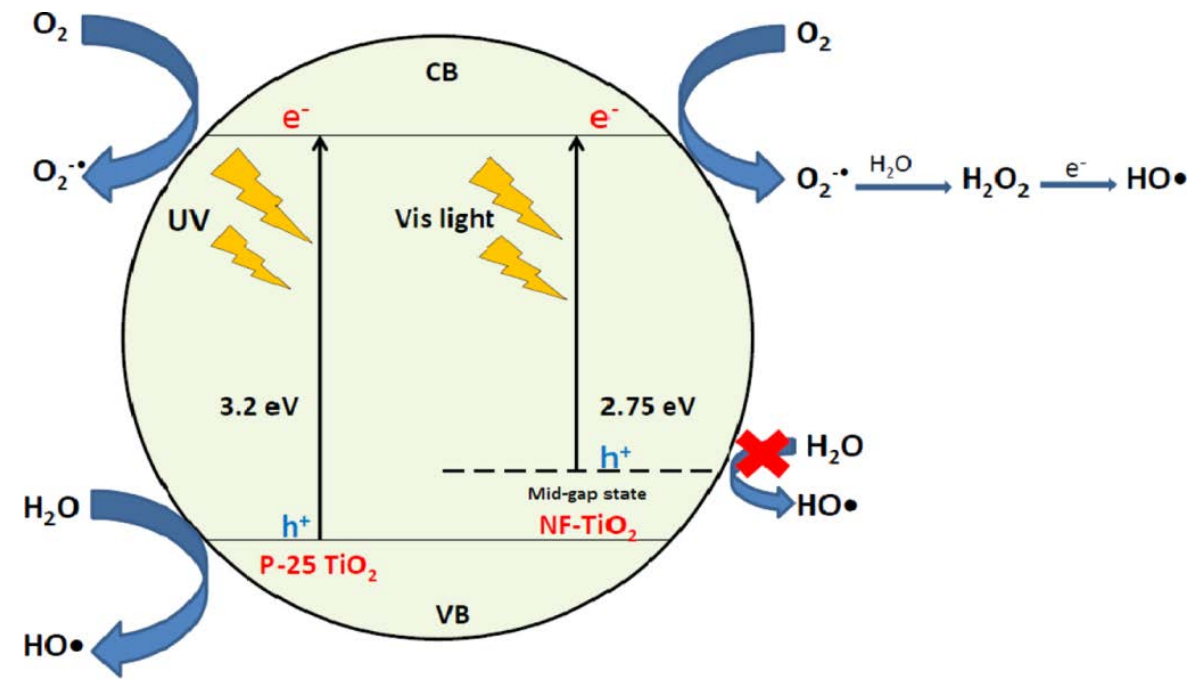


Figure 27. Role of various reactive oxidation species during the photocatalysis process of N-F doped $\mathrm{TiO}_{2}$. Reproduced with permission from ref. [362] Copyright 2014 Elsevier Science

Zhao et al. [362] conducted $\mathrm{TiO}_{2}$ photocatalysis of 6-hydroxymethyl uracil (a model Cyanobacteria toxin or cynotoxin) using various non-metal doped $\mathrm{TiO}_{2}$ materials. It was found that $\mathrm{N}-\mathrm{F}-\mathrm{TiO}_{2}$ was the most active photocatalyst, while $\mathrm{P}-\mathrm{F}-\mathrm{TiO}_{2}$ showed marginal activity and $\mathrm{S}-\mathrm{TiO}_{2}$ was fully inactive. In order to understand the mechanism of action, they also have conducted the photocatalysis in presence of a number of scavengers for $\mathrm{O}_{2}{ }^{-},{ }^{1} \mathrm{O}_{2}$, $\mathrm{HO} \cdot$ and $\mathrm{h}_{\mathrm{vb}}{ }^{+}$. These investigation showed that $\mathrm{O}_{2}{ }^{-}$, is the leading ROS (reactive oxidation species) employed for the photocatalytic destruction of 6-hydroxymethyl uracil (Figure 21).

\subsubsection{Metal non-metal codoping}

Co-alloying of anion doped $\mathrm{TiO}_{2}$ with metal ions is another effective method for improving the visible-light photocatalytic activity of $\mathrm{TiO}_{2}$ [363-366]. The benefits of co-alloying have been validated in numerous compositions including $\mathrm{N} / \mathrm{Fe}^{3+}, \mathrm{N} / \mathrm{V}^{5+}$, $\mathrm{N} / \mathrm{Sn}^{2+}, \mathrm{N} / \mathrm{Ta}^{2+}, \mathrm{N} / \mathrm{Ni}^{3+}, \mathrm{N} / \mathrm{Cr}^{3+}, \mathrm{N} / \mathrm{W}^{5+}, \mathrm{N} / \mathrm{Ce}^{3+}, \mathrm{N} / \mathrm{La}^{3+}, \mathrm{N} / \mathrm{Sm}^{3+}$ and $\mathrm{C} / \mathrm{V}^{5+}$ [367-377]. Performances of these co-doped $\mathrm{TiO}_{2}$ were significantly higher than those containing single dopants. For Instance, visible-light photocatalytic activity of Nb-coalloyed Ndoped anatase $\mathrm{TiO}_{2}$ was 7-fold higher in contrast to the undoped phase [363]. (Ga, N) codoped anatase $\mathrm{TiO}_{2}$ was reported to be highly visible-light active for the water decomposition to hydrogen [378]. Increased oxygen vacancy formation and the band gap realignment leading by the synergetic effect of $\mathrm{Ga}$ and $\mathrm{N}$-ions were responsible for the enhancement of photocatalytic activity. For increasing the visible-light photocatalytic activities, $\mathrm{Li}$ et al. successfully co-alloyed Mo with C-doped $\mathrm{TiO}_{2}$ through a hydrothermal method [379]. This resulted in the formation of narrow band 
gap $\mathrm{TiO}_{2}$ with lattice $\mathrm{Mo}^{6+}$ (Ti-site substitution) and surface adsorbed carbon impurities. In this case, synergetic effect of the individual ions resulted in the enhanced photocatalytic activity. In addition to the visible-light absorption, Mo and C dopants also improved the photogenerated electron-hole separation. A one step solution combustion method was developed by Thind et al. for the synthesis of mesoporous (N, W) codoped $\mathrm{TiO}_{2}$, which exhibited superior decomposition of Rhodamine-B under visible and UV-light irradiation [380].

Several studies on the metal/non-metal codoping of $\mathrm{TiO}_{2}$ are present in the literature [381-384]. The underlying mechanisms for the enhanced photocatalytic activity of the codoped systems are analogous to those described for non-metal codoping. The presence of one dopant is found to favour the introduction of the second in the $\mathrm{TiO}_{2}$ lattice. Besides enhancing the visible-light absorption, due to the different chemical nature, the two codopants are found to facilitate the photogenerated electronhole separation, with beneficial consequences on the measured photocurrent and observed photocatalytic activity.

\subsubsection{Non-metal doped heterojunctions}

Increased recombination of photogenerated electron-hole pairs due to inter band gap impurity energy levels is the main drawback of anion doped $\mathrm{TiO}_{2}$. Theoretical studies of these narrow band gap $\mathrm{TiO}_{2}$ using DFT calculations proved that anion doping cause a substantial lowering of energy required for oxygen vacancy formation. Photoelectrochemical studies of $\mathrm{N}$ doped anatase $\mathrm{TiO}_{2}$ demonstrated the existence of supplementary energy levels located $1.3 \mathrm{eV}$ below the conduction band level [385]. These additional energy levels act as recombination sites for the photogenerated electron-hole pairs. Increased dopant concentration also promotes carrier recombination through band gap narrowing. Thus visible-light photocatalytic activity 
of anion doped $\mathrm{TiO}_{2}$ is limited due to the increased rate of electron-hole recombination. Consequently, coupling of anion doped $\mathrm{TiO}_{2}$ with electron-hole separating agents (metal nanoparticles, quantum dots, semiconductor nanoparticles etc.) are necessary to attain high photocatalytic activity. Improved photocatalytic performance of biphasic $\mathrm{TiO}_{2}$, for example Evonik Degussa P-25 (70 \% anatase +30 \% rutile) under UV-light irradiation has been reported earlier. Efficient electron transfer from anatase to rutile was found to be responsible for the enhanced activities of these mixed phase photocatalysts $[67,386]$. Similar approaches have also been implemented for improving the performance of several anion doped $\mathrm{TiO}_{2}$ polymorphs. A microwave hydrothermal method for the synthesis of high surface area N-doped $\mathrm{TiO}_{2}$ containing anatase and rutile nanoparticles has been reported by Zhang et al.[387] These biphasic narrow band gap $\mathrm{TiO}_{2}$ outperformed the standard commercial photocatalyst Evonik Degussa P-25 towards the decomposition of $\mathrm{NO}_{\mathrm{x}}$ gas.

In addition, Etacheri et al. recently reported novel synthetic methods and superior visible-light induced photocatalytic performances of N-doped/S, N-codoped anatase-rutile heterojunctions and C-doped anatase-brookite heterojunctions [11, 17, 19]. These visible-light active $\mathrm{TiO}_{2}$ nanoheterojunctions exhibited notably higher photocatalytic activities compared to pure anatase phase, single-phase anion doped $\mathrm{TiO}_{2}$, and the commercial biphasic standard photocatalyst Evonik Degussa P-25 [11, 17]. Improved separation of electrons and holes at the anatase/rutile and anatase/brookite interface due to anatase to rutile and brookite to anatase electron transfer was demonstrated as the key reason for their very high photocatalytic activities (Figure 28). Moreover, various anion doped anatase $\mathrm{TiO}_{2}$ coupled with $\mathrm{Ag}$ and $\mathrm{Au}$ nanoparticles also exhibited superior visible-light photocatalytic activities compared to their single-phase counterparts [388-391]. These studies demonstrate the necessity of 
combining anion-doped $\mathrm{TiO}_{2}$ with electron-hole separating agents for attaining the best visible-light photocatalytic activity. As mentioned in Section 4.4, the band alignment of different materials or of different phases of the same material, as in this case (rutile vs. anatase $\mathrm{TiO}_{2}$ ), is a critical aspect and a challenging task, even for contemporary methodologies. Recently, a combined experimental and theoretical study has demonstrated that anatase possesses a higher electron affinity or work function with respect to rutile, resulting in a staggered band alignment of about $0.4 \mathrm{eV}$. The two polymorphs were modelled with QM/MM finite clusters for which the absolute values of ionization potentials and electron affinities can be obtained by computing charge states [392].

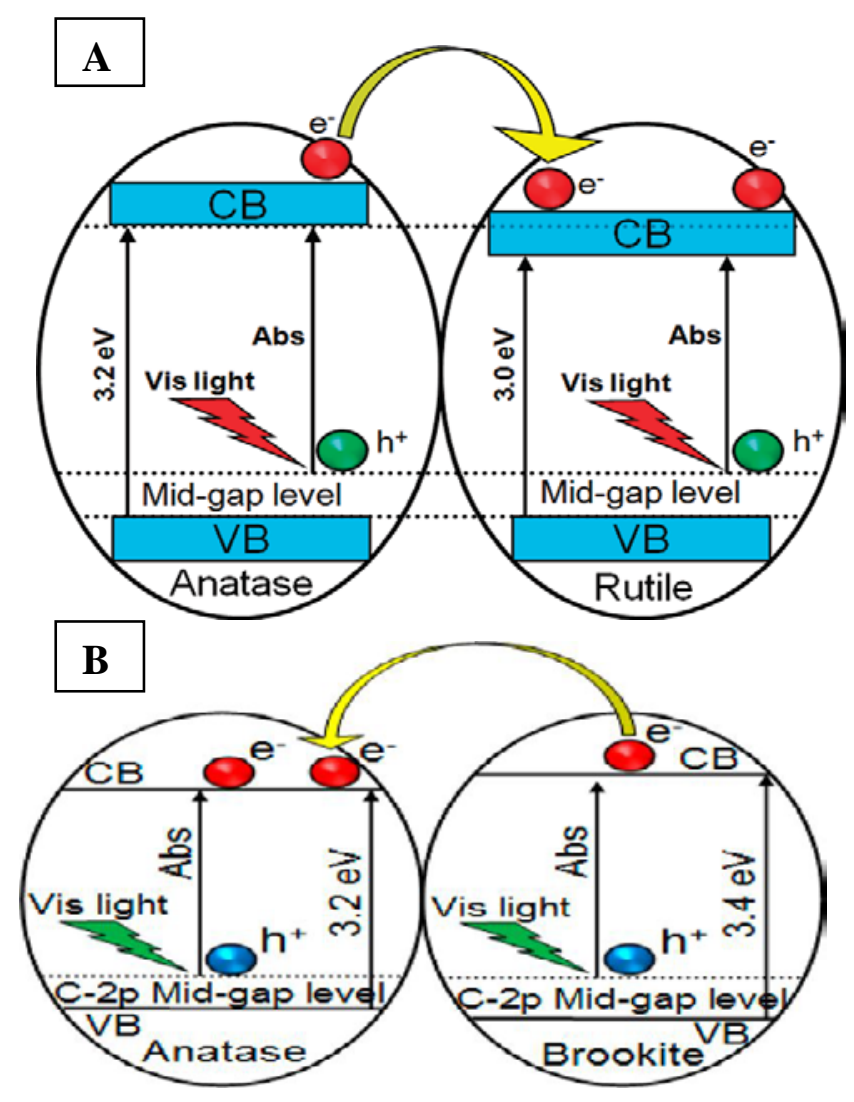

Figure 28. Electron transfer mechanism in (A) S, N- codoped anatase-rutile heterojunctions Reproduced with permission from ref. [17] Copyright 2012 American Chemical Society. (B) C-doped anatase-brookite heterojunctions. Reproduced with permission from ref. [19] Copyright 2013 American Chemical Society 


\section{Graphene, carbon nanotube, $g-\mathrm{C}_{3} \mathrm{~N}_{4}$ and perovskite modified $\mathrm{TiO}_{2}$}

Recently, coupling between $\mathrm{TiO}_{2}$ and graphene have attracted much attention for considerable improvement in the photocatalytic performance [393-397]. Strong absorption of visible-light, unique 2-D morphology, and high electronic conductivity of graphene were found to be responsible for the photocatalytic activity enhancement. Graphene is an excellent electronic conductor that scavenge photo-excited electrons on $\mathrm{TiO}_{2}$ surface $[398,399]$. In addition, large surface area and 2-D planar structure of graphene enable the anchoring of impurities and $\mathrm{TiO}_{2}$ (Figure 29) for increasing the photocatalytic activity. A number of methods have been presented for the synthesis of graphene- $\mathrm{TiO}_{2}$ composites with improved visible-light photocatalytic performance. Most of these synthetic methods involve photocatalytic, chemical and hydrothermal reduction of a suspension or thin films of graphene oxide (GO) and $\mathrm{TiO}_{2}$ [393, 398, 400-407]. These $\mathrm{TiO}_{2}$-RGO hybrids exhibited excellent photocatalytic activities towards the degradation of methylene blue, benzene, E. coli bacteria, and water oxidation. In the case of photocatalytic water splitting, RGO also act as an excellent co-catalyst due to its high surface area and superior electron mobility. 


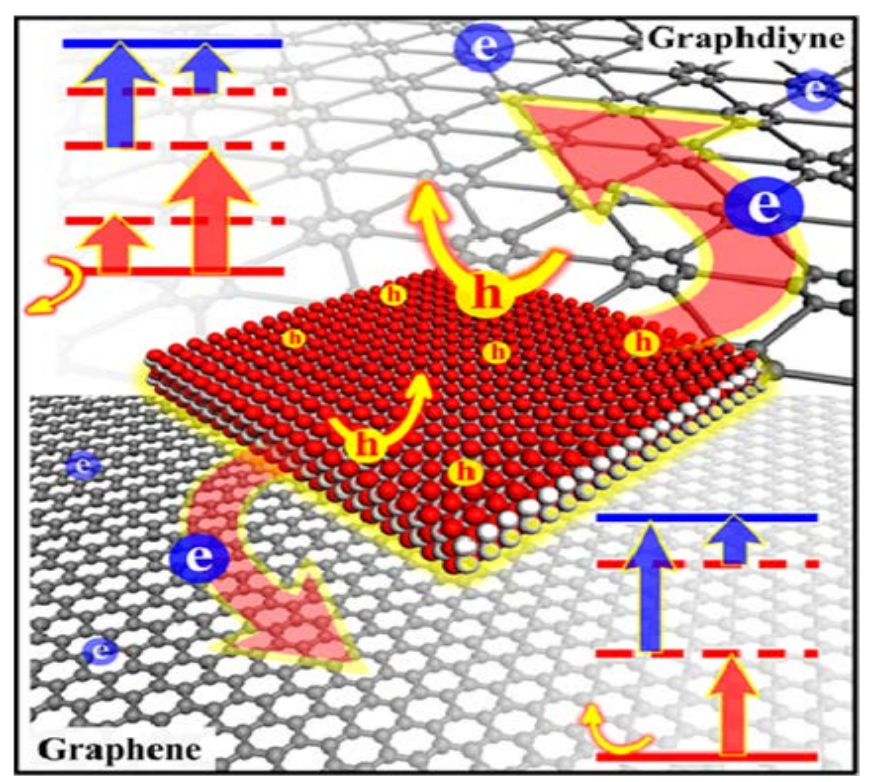

Figure 29. Photoinduced electron transfer mechanism in graphene and graphdiyne modified $\mathrm{TiO}_{2}$. Reproduced with permission from ref. [405] Copyright 2013 American Chemical Society

Recently, Kamat et al. verified the electron scavenging activity in a $\mathrm{TiO}_{2}$-graphene hybrid photocatalyst [408]. Composites consists of $\mathrm{TiO}_{2}$ nanorods and (001) face exposed nanoparticles/nanosheets on large graphene sheets were reported to exhibit enhanced photocatalytic $\mathrm{H}_{2}$-production activity [409-411]. Graphene- $\mathrm{TiO}_{2}$ composite coupled with Ag nanoparticles, which combine the plasmon sensitization and excellent electrical properties of graphene has been reported as an excellent photocatalyst under visible-light irradiation [395].

In another recent investigation to understand the photocatalytic mechanism of visible light active $\mathrm{ZnO}$-graphene composites, Kavitha et al used reagents such as a radical scavenger t$\mathrm{BuOH}$ and a hole scavenger EDTA-2Na [412]. The addition of radical scavenger t-BuOH did not provide any significant changes in the photo-degradation properties, while the incorporation of EDTA-2Na significantly reduced the photo-degradation properties. This study has proved that the photo-generated holes are the major ROS responsible for the photo- 
degradation properties. Fluorescent quenching occurred in the zinc oxide-graphene composites showed photo-induced electron transfer (Figure 30),. These charge transfer processes could significantly improve the photocatalytic activity by reducing the recombination of electron-hole pairs. It has been concluded that the appropriate absorption range, effective electron-hole charge separation and high surface area make the $\mathrm{ZnO}-$ graphene hybrids a better photocatalyst under UV and visible light [412].

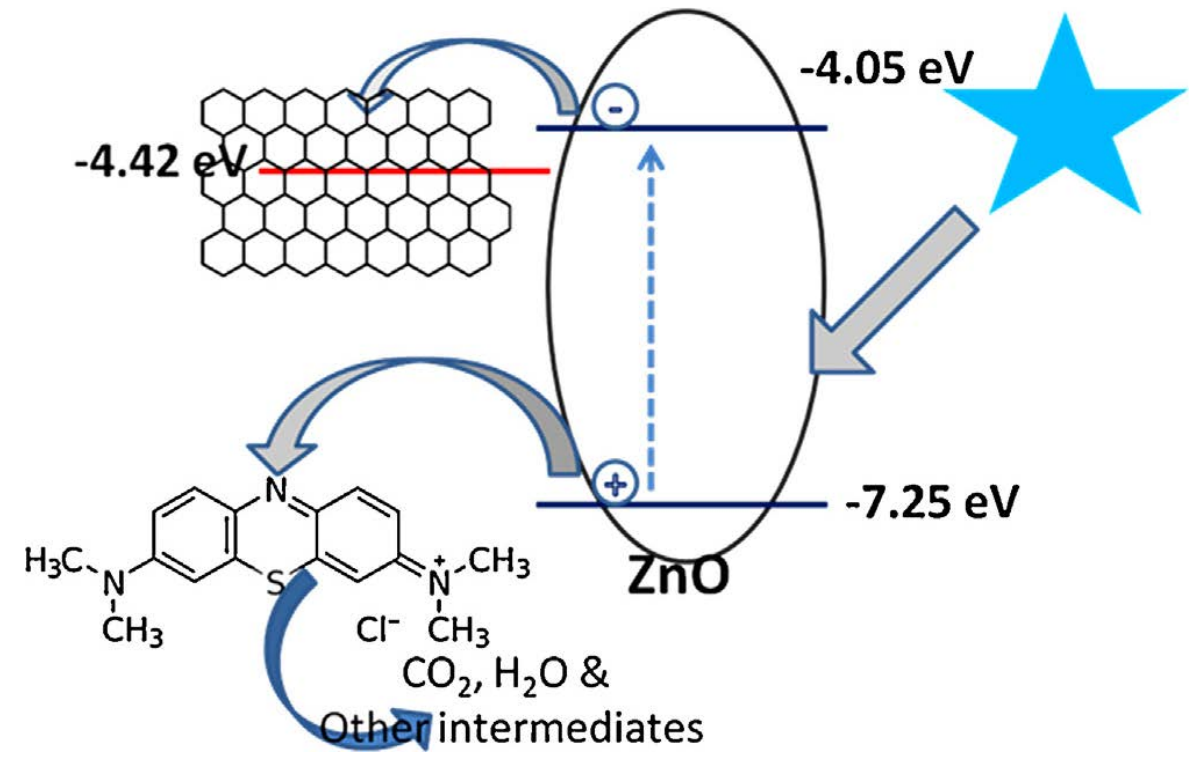

Figure 30. Mechanism of photocatalytic degradation using ZnO-Graphene hybrid. Reproduced with permission from ref. [412] Copyright 2015 Elsevier Science

In this photocatalyst, Ag nanoparticles enhance the visible-light absorption, and graphene effectively separate photogenerated electron-hole pairs, which significantly improve the photocatalytic performance. Highly visible-light active hybrid semiconductor heterostructure of $\mathrm{TiO}_{2} / \mathrm{Bi}_{2} \mathrm{O}_{3} /$ graphene has been also reported previously [413]. Formation of Ti-C chemical bonds in $\mathrm{TiO}_{2}$ /graphene composites were identified to be enhancing the efficiency of photo-induced interfacial electron transfer [414]. Photocatalytic performances of these chemically bonded composites are exceptional compared to pure $\mathrm{TiO}_{2}$ and the physically mixed samples with no chemical 
bonds. Multi-walled carbon nanotube (MWCNT) is a promising alternative to graphene for the visible-light activation of $\mathrm{TiO}_{2}$ and for electron scavenging [415].

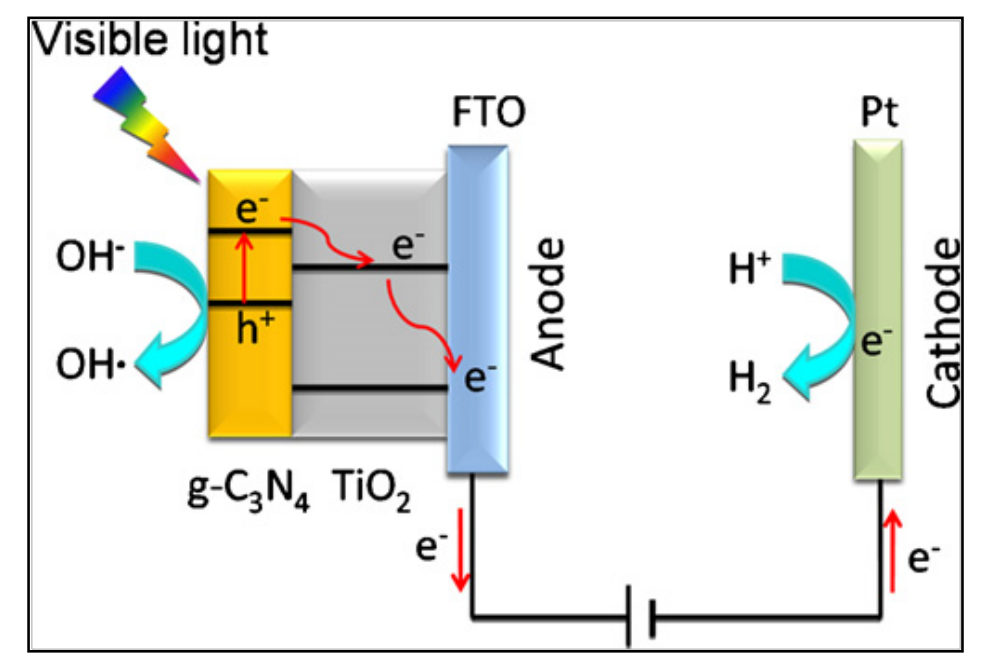

Figure 31. Mechanism of charge separation and transfer between $g-\mathrm{C}_{3} \mathrm{~N}_{4}$ and $\mathrm{TiO}_{2}$ nanorod arrays under visible-light irradiation. Reproduced with permission from ref. [416] Copyright 2012 Elsevier Science

As a result of the narrow band gap $(2.75 \mathrm{eV})$ graphitic carbon nitride $\left(g-\mathrm{C}_{3} \mathrm{~N}_{4}\right)$ has attracted a considerable interest in the field of visible-light induced photocatalysis [417-421]. Due to strong covalent bonds between nitrogen and carbon atoms, $g-\mathrm{C}_{3} \mathrm{~N}_{4}$ is considered as the most stable carbon nitride under acidic and basic conditions [416]. It was noted that nitrogen doping using urea precursor result in the formation of some carbon nitride polymers on the $\mathrm{TiO}_{2}$ surface [422, 423]. Subsequently, Wang et al. reported the powerful visible-light water splitting activity of g- $\mathrm{C}_{3} \mathrm{~N}_{4}$ with a conjugative polymeric structure [424].Visible-light photocatalytic activity of $\mathrm{TiO}_{2}$ was extensively improved after modification with $g-\mathrm{C}_{3} \mathrm{~N}_{4}[416,420,425,426]$. Yan et al. found that coupling of $\mathrm{TiO}_{2}$ with $g-\mathrm{C}_{3} \mathrm{~N}_{4}$ remarkably improved the visible-light water splitting performance by transferring photoexcited electrons from $g-\mathrm{C}_{3} \mathrm{~N}_{4}$ to $\mathrm{TiO}_{2}$ [427]. In the case of $\mathrm{TiO}_{2}-g-\mathrm{C}_{3} \mathrm{~N}_{4}$ hybrids, interfacial electron transfer is facilitated by the higher conduction band level of $\mathrm{g}-\mathrm{C}_{3} \mathrm{~N}_{4}$ [424]. It is proposed that in addition to sensitization, 
$g-\mathrm{C}_{3} \mathrm{~N}_{4}$ is also capable of separating photogenerated charge carriers (Figure 31),[416] which is analogous to other carbonaceous materials such as carbon nanotubes,[428] and graphene [429-431].

Organo-lead halide perovskites possessing narrow band gap, improved stability in dry air, high carrier mobility, and great absorption coefficient were recently reported as efficient visible-light harvesters in heterojunction solar cells [432-437]. Use of $\mathrm{CH}_{3} \mathrm{NH}_{3} \mathrm{PbI}_{3}$ as sensitizer in photo-electrochemical cells with liquid electrolyte has been reported previously [438-440]. However, dissolution of the sensitizer resulted in rapid performance decay, which was later solved by using a solid-state electrolyte [441]. A power conversion efficiency (PCE) of $8.5 \%$ has been demonstrated recently for a solid-state solar cell containing $\mathrm{CsSnI}_{3}$ perovskite hole conductor and N719 as sensitizer [442]. Extremely high room temperature hole mobility $\left(\mu \mathrm{h}=5585 \mathrm{~cm}^{2} \mathrm{~V}^{-1} \mathrm{~S}^{-}\right.$ ${ }^{1}$ ) and narrow band gap (1.3 eV) of $\mathrm{CsSnI}_{3}$ makes it an ideal sensitizer. Further increase in the power conversion efficiency $(\eta)$ and photocurrent density $\left(\mathrm{J}_{\mathrm{SC}}\right)$ was achieved by $\mathrm{F}$ and $\mathrm{SnF}_{2}$ doping of $\mathrm{CsSnI}_{3}$ [442]. A heterojunction solar cell composed of $\mathrm{CH}_{3} \mathrm{NH}_{3} \mathrm{PbI}_{3}$ perovskite (which act as absorber and hole-conductor) and (001) facet exposed $\mathrm{TiO}_{2}$ nanosheets was also reported recently (Figure 32) [443]. A remarkably high photovoltaic performance was observed for this heterojunction cell compared to the previous reports.

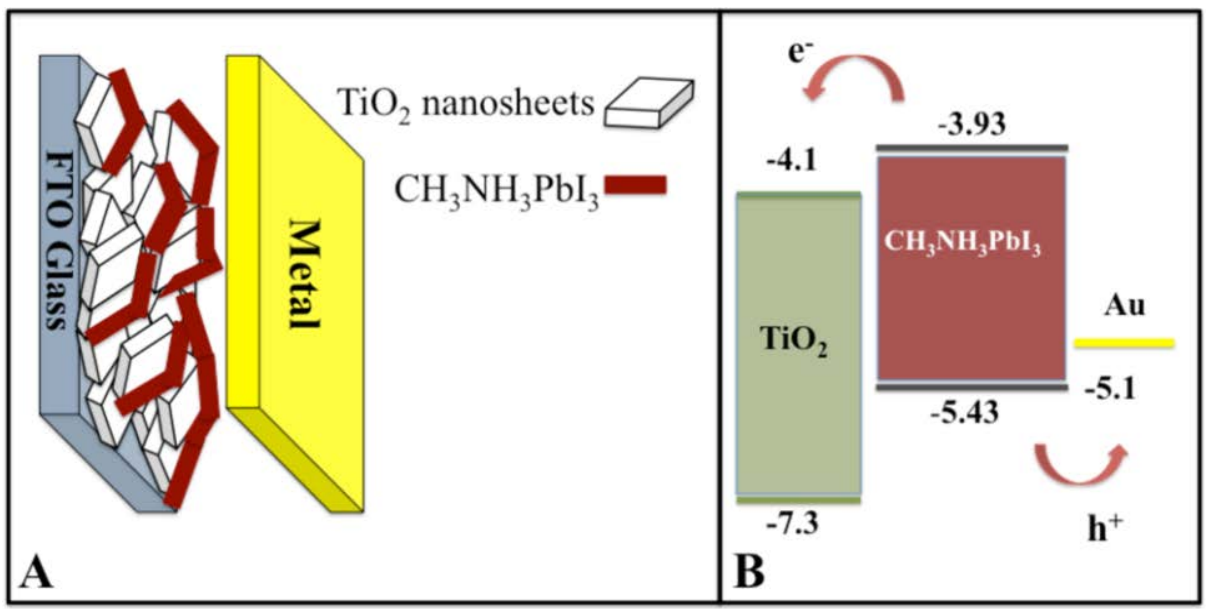


Figure 32. (A) Device structure and (B) Energy level diagram of the $\mathrm{CH}_{3} \mathrm{NH}_{3} \mathrm{PbI}_{3} / \mathrm{TiO}_{2}$ heterojunction solar cell. Reproduced with permission from ref. [443] Copyright 2012 American Chemical Society
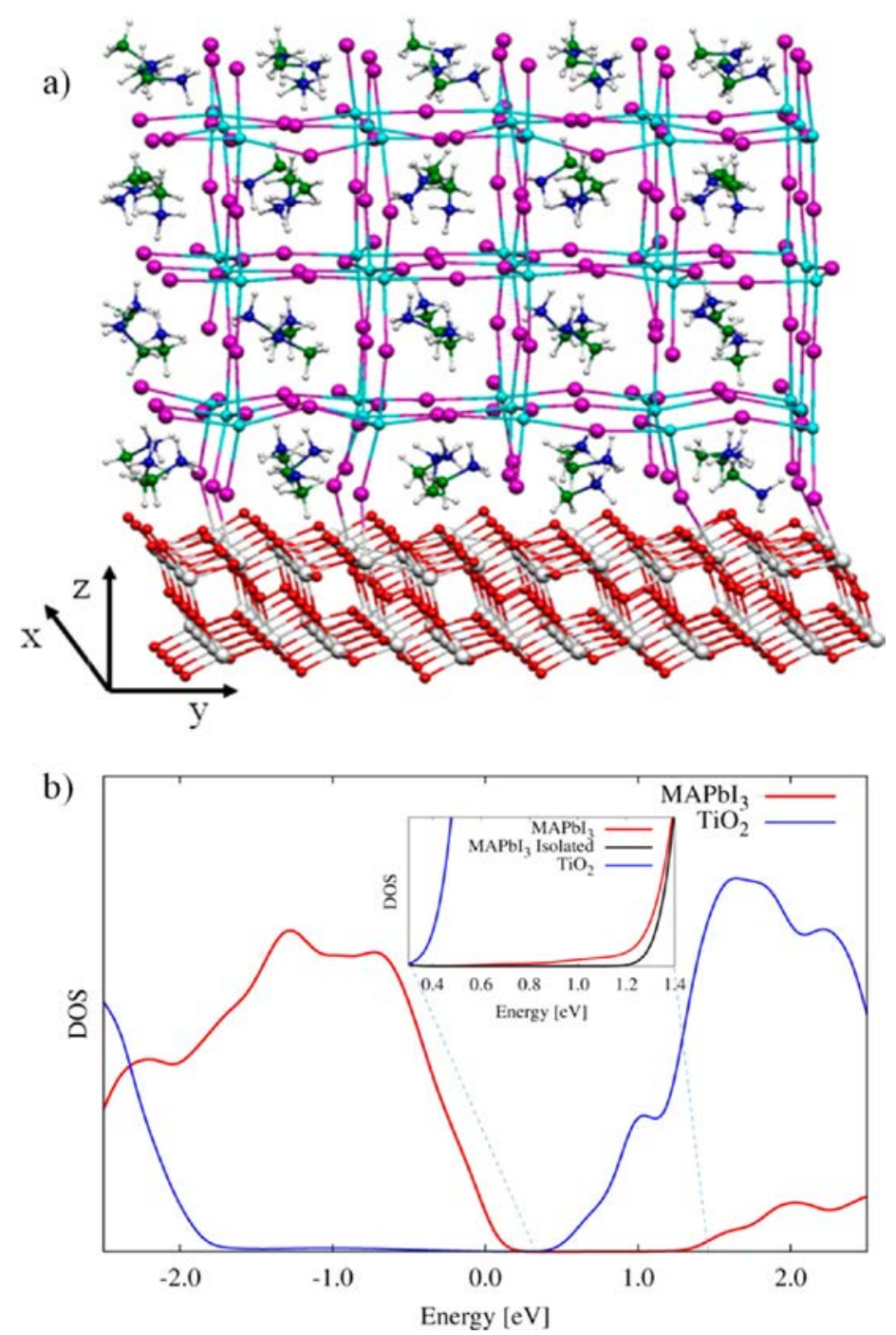

Figure 33. (a) Optimized structure of the simulated $\mathrm{TiO}_{2} / \mathrm{MAPbI}_{3}$ interface along with reference axes. (b) Calculated DOS including spin-orbit coupling for the $\mathrm{TiO}_{2} / \mathrm{MAPbI}_{3}$ interface, decomposed into the contributions of $\mathrm{MAPbI}_{3}$ (red) and $\mathrm{TiO}_{2}$ (blue).

The inset shows the bottom of the interacting perovskite DOS, compared with the noninteracting DOS at the same geometry. Reproduced with permission from ref. [444]

Copyright 2014 American Chemical Society

A number of computational studies, based on standard DFT but also on the more sophisticated GW approach (see Section 3), mostly by F. De Angelis et al., have investigated perovskitebased solar cells (Figure 33), with particular attention to the oxide/perovskite interface [444- 
452]. These works have been able to reveal fundamental aspects of the device's operational mechanism.

\section{Recent developments in visible light active $\mathrm{TiO}_{2}$}

Noteworthy advances have been recently made on the application of $\mathrm{TiO}_{2}$ photocatalysts for visible-light induced water splitting, degradation of environmental pollutants, water/air purification and antibacterial applications. While visible-light activation of $\mathrm{TiO}_{2}$ are developed through one of the modification or band-gap engineering discussed above, charge separation is another key factor need to be addressed for the efficient use of $\mathrm{TiO}_{2}$ for these applications [453]. Recent developments in the area of visible-light induced water splitting involve the use of a variety of cocatalysts and electron-hole separating agents. Since the Fermi level of noble metal are lower than that of $\mathrm{TiO}_{2}$ photocatalyst, photogenerated electrons are entrapped by the metal nanoparticles anchored on the semiconductor surface. Platinum has been widely used as the cocatalysts over many other metal oxides and up until now the highest $\mathrm{H}_{2}$ generation performance are from Pt-loaded photocatalysts [454-457]. Recently, Iwase et al. reported excellent $\mathrm{H}_{2}$ production using Au-modified $\mathrm{TiO}_{2}$ [458]. This mainly resulted due to creation of active sites for water splitting and reduced charge recombination. Another major advantage of these $\mathrm{Au}$ cocatalysts is the negligible back reaction (recombination of $\mathrm{H}_{2}$ and $\mathrm{O}_{2}$ to form $\mathrm{H}_{2} \mathrm{O}$ ) compared to Pt cocatalysts. Wu et al. investigated the photocatalytic performance of $\mathrm{Rh}$ loaded $\mathrm{TiO}_{2}$, and found enhanced rate of $\mathrm{H}_{2}$ production [459]. They explained this unusual enhancement by the Schottky barrier formed at the $\mathrm{TiO}_{2}$ Rh interface that acts as an efficient electron trap, preventing electron-hole recombination.

Type of electronic interactions between metals and semiconductors are used for explaining the effect of various noble metal cocatalysts [460]. It was suggested that smaller Schottky barrier height at the metal/semiconductor interface is beneficial for improved electron flow and photocatalytic activity for water splitting [461]. When Au/Pd bimetallic 
cocatalysts are loaded on the $\mathrm{TiO}_{2}$ surface, significant $\mathrm{H}_{2}$ production efficiency from aqueous ethanol solutions was observed due to selective donation of electrons to the protons [462]. Synergistic effect in the visible-light photocatalytic activity of $\mathrm{TiO}_{2}$ was observed by Borgarello et al. when both $\mathrm{RuO}_{2}$ and Pt nanoparticles are deposited on the surface [140]. They proposed that Schottky barrier is formed by $\mathrm{RuO}_{2}$, while Pt provides ohmic contact acting as electron trap, while holes are trapped by $\mathrm{RuO}_{2}$. Moreover, Teramura et al. reported that uniform dispersion of $\mathrm{RuO}_{2}$ nanoparticles on $\mathrm{TiO}_{2}$ is essential for obtaining improved $\mathrm{H}_{2}$ and $\mathrm{O}_{2}$ evolution [463]. Tada et al. developed a three component $\mathrm{CdS}-\mathrm{Au}-\mathrm{TiO}_{2}$ photocatalyst, which exhibited water splitting photocatalytic activity exceeding most of the single and two component systems [464]. Further investigation of this composition was carried out by Park et al., and found that direct contact between $\mathrm{CdS}$ and $\mathrm{TiO}_{2}$ are required for vectorial electron transfer and highest photocatalytic activity [465]. Similar performance increase was also observed in the case of MWCNT- $\mathrm{TiO}_{2}$ and $\mathrm{Bi}_{2} \mathrm{~S}_{3}-\mathrm{TiO}_{2}$ systems [466, 467]. 
Recently, branched $\mathrm{TiO}_{2}$ nanorod arrays modified with plasmonic Au nanoparticles are demonstrated as highly efficient for photoelectrochemical water splitting under visiblelight illumination [468]. The obtained photocurrent and efficiency was the highest value ever

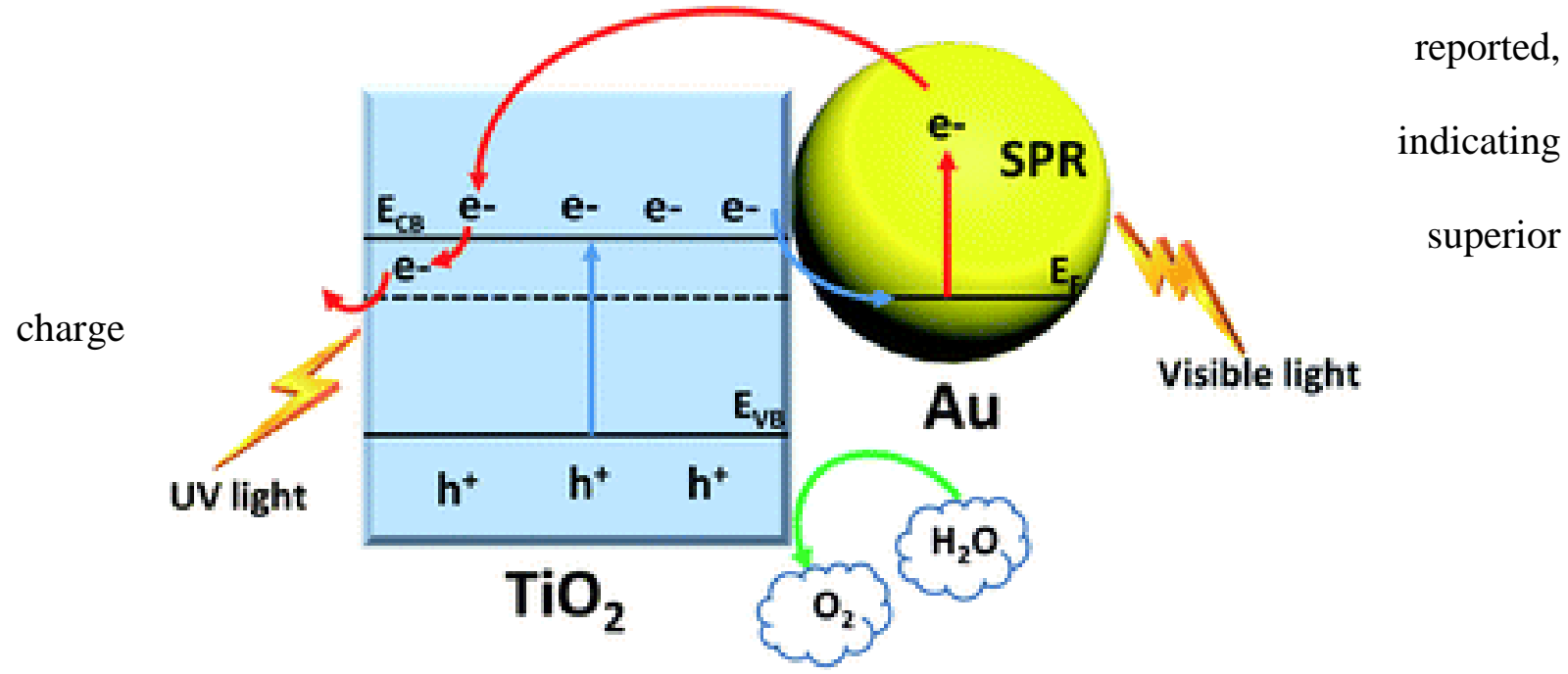
separation and transportation efficiencies. The high water splitting performance was attributed to the plasmonic effect of Au nanoparticles, which increases visible-light absorption and improve charge separation/ carrier mobility (Figure 34). Similar approach was also employed in the case of Au-nanoparticle modified $\mathrm{TiO}_{2}$ aerogel [469]. The magnitudes of photocatalytic activity improvement in this case prove that a three-phase boundary is beneficial for excited surface plasmon to charge-carrier conversion (Figure 35). 
Figure 34. Mechanism of visible-light driven photoelectrochemical water splitting on $\mathrm{Au}$ nanoparticles modified dendritic $\mathrm{TiO}_{2}$ nanorod arrays. Reproduced with permission from ref. [468] Copyright 2013 Royal Society of Chemistry

Biphasic $\mathrm{TiO}_{2}-\mathrm{Fe}_{2} \mathrm{O}_{3}$ photocatalysts are also modified with plasmonic metal nanoparticles to induce visible-light activated photocatalytic water splitting [470]. In this case, a photocurrent 20 times higher than pure $\mathrm{Fe}_{2} \mathrm{O}_{3}$ was observed using an optimized ratio of plasmonic $\mathrm{TiO}_{2}$ $\mathrm{Fe}_{2} \mathrm{O}_{3} / \mathrm{Ag}$ composition. Absorption of incident photons and charge carrier separation was enhanced due to broadband absorption and strong electric field of the composite. Improved photoelectrochemical water splitting was also reported using Fe-doped $\mathrm{TiO}_{2}$ nanorod arrays [471]. This work demonstrated Fe-doping as the most effective method to improve the photocatalytic activity of $\mathrm{TiO}_{2}$. Efficiency measurements reveal that Fe-doping improve UV/Vis absorption by creating additional energy levels near conduction band and increase the carrier density, leading to effective carrier separation. S-doped $\mathrm{TiO}_{2}$ nanotube arrays are recently reported as a highly active photocatalyst for photoelectrochemical water splitting [472]. Three component CdS- $\mathrm{TiO}_{2} /$ metallosilicates were also reported as effective for visiblelight induced photocatalytic water splitting [473].

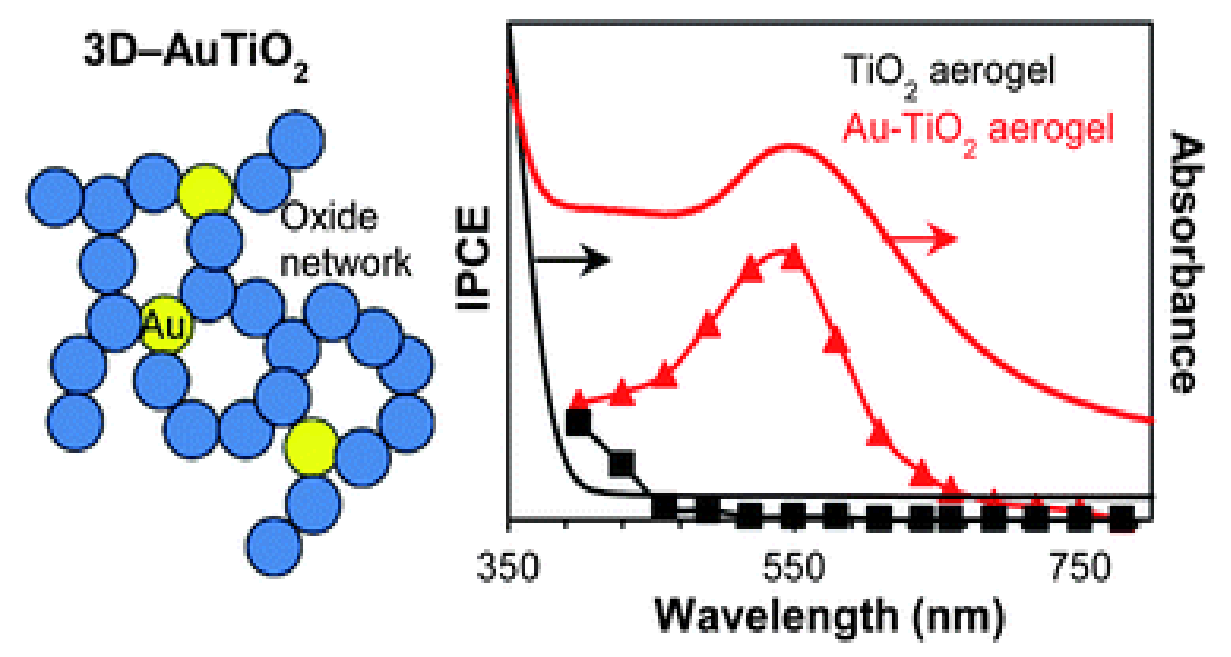

Figure 35. Plasmonic enhancement of the visible light water splitting with $\mathrm{Au}-\mathrm{TiO}_{2}$ composite aerogel. Reproduced with permission from ref. [469] Copyright 2013 Royal Society of Chemistry 
$\mathrm{TiO}_{2}$ photocatalysts are recently proved as very effective towards visible-light induced decomposition of a number of organic and inorganic pollutants [474-482]. Recent developments in this area include the synthesis of novel $\mathrm{TiO}_{2}$ compositions containing anions, cations, metal oxides and carbonaceous materials. Cavalcante et al. synthesized B-doped $\mathrm{TiO}_{2}$ through a boric acid modified sol-gel method, and tested for the sunlight driven degradation of metoprolol [474]. They found a significant increase in the photocatalytic activity (48 to $70 \%$ by doping $5 \%$ ) due to B-doping. $5 \%$ was identified as the optimum B-loading, which resulted in high surface area and mesoporous structure. Boron was introduced into the crystal structure as $\mathrm{B}-\mathrm{O}-\mathrm{Ti}$, which causes $\mathrm{Ti}^{3+}$ formation due to charge compensation. Photocatalysis play an important role in water purification. Zhang et al. reported humic acid removal from water through photocatalytic decomposition using hybrid $\mathrm{Fe}_{2} \mathrm{O}_{3} / \mathrm{TiO}_{2}$ nanowires [475]. These membranes also exhibited antifouling property up on sunlight irradiation. $\mathrm{Fe}_{2} \mathrm{O}_{3}$ played an important role in the biphasic catalyst by improving humic acid adsorption, increasing electron-hole separation by interfacial charge transfer, and by absorbing visible light. Under UV-light irradiation, electron-hole pairs are generated on both $\mathrm{TiO}_{2}$ and $\mathrm{Fe}_{2} \mathrm{O}_{3}$ (Figure 36a). Water oxidation by holes produces $\mathrm{OH}$ radicals, which in turn decompose humic acid molecules. Under visible-light irradiation, $\mathrm{Fe}_{2} \mathrm{O}_{3}$ absorbs visible light and transfer conduction band electrons formed to the electron trapping sites of anatase $\mathrm{TiO}_{2}$ (Figure 36b).

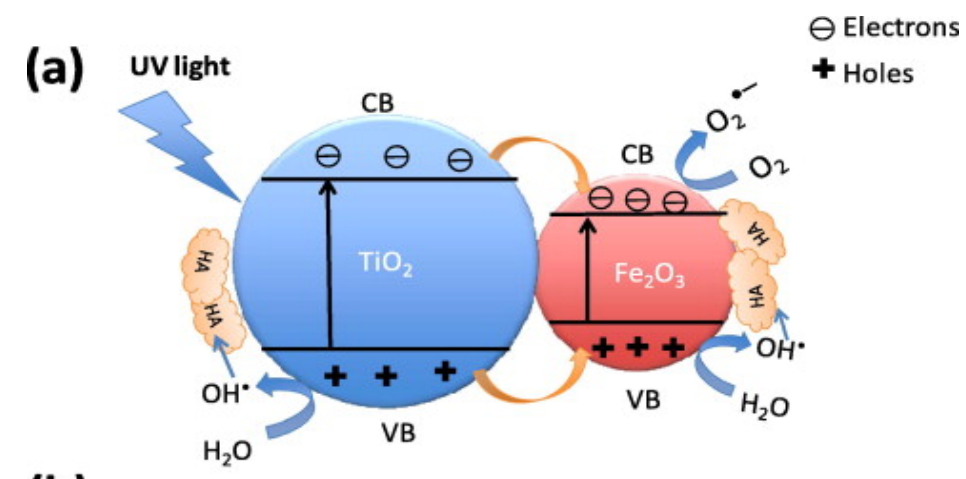

(b)

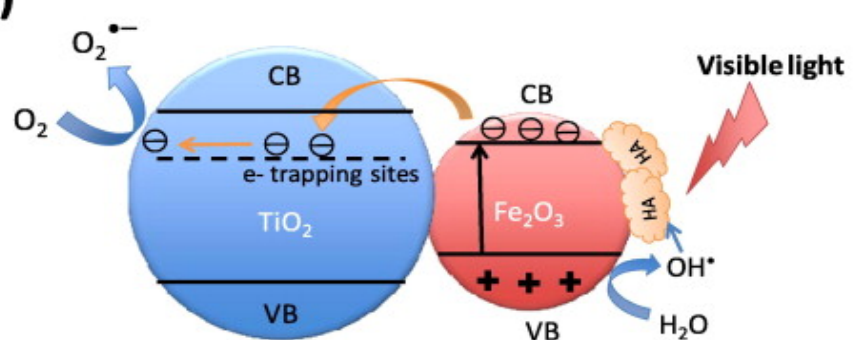


Figure 36. Proposed mechanism for the photocatalytic degradation of humic acid on $\mathrm{Fe}_{2} \mathrm{O}_{3} / \mathrm{TiO}_{2}$ hybrid nanowires under UV and visible light irradiation. Reproduced with permission from ref. [475]. Copyright 2015 Elsevier Science

Nanocomposite formation between $\mathrm{TiO}_{2}$ and clay is a recently reported method for the photocatalytic removal of phenol and methylene blue from water [476]. In this method, photoresponse of the final composite was shifted from UV to the visible light range. Their kinetic study proved that $\mathrm{TiO}_{2}$-clay nanocomposites are efficient for phenol and methylene blue removal from water under UV and visible light.

An efficient sonophotocatalytic degradation of reactive blue 19 (RB 19) using sulfurdoped $\mathrm{TiO}_{2}$ nanoparticles was reported recently [477]. In this method, coupling of ultrasound and photocatalysis improved dye degradation through synergistic effect, which increased the amount of reactive radicals $\mathrm{OH}^{\bullet}$ and $\mathrm{H}_{2} \mathrm{O}_{2}$. It is also proposed that ultrasound increases the mass transport between the solution phase and catalyst surface, and de-agglomeration of particles increase the surface area of the catalyst. Jiang et al. recently reported a novel ternary photocatalyst composed of $\mathrm{TiO}_{2}-\mathrm{In}_{2} \mathrm{O}_{3}$ nanocrystals decorated with g- $\mathrm{C}_{3} \mathrm{~N}_{4}$ for dye degradation and $\mathrm{H}_{2}$ evolution [481]. These ternary composites exhibited the highest RhB degradation rate, which is 6.6 times higher than that of $g-\mathrm{C}_{3} \mathrm{~N}_{4} \cdot \mathrm{H}_{2}$-generation rate was 48 times of the pure $g-\mathrm{C}_{3} \mathrm{~N}_{4}$. They attributed the enhanced photocatalytic activity to efficient interfacial transfer of photogenerated electrons and holes among $\mathrm{TiO}_{2}, \mathrm{In}_{2} \mathrm{O}_{3}$ and $g-\mathrm{C}_{3} \mathrm{~N}_{4}$ (Figure 37).

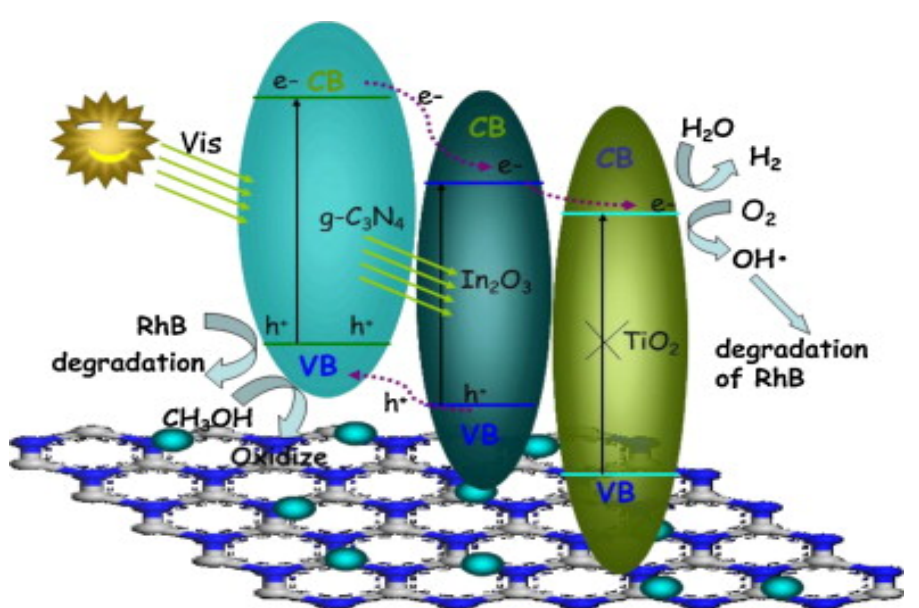


Figure 37. Possible photocatalytic mechanism of the $\mathrm{TiO}_{2}-\mathrm{In}_{2} \mathrm{O}_{3}-\mathrm{g}-\mathrm{C}_{3} \mathrm{~N}_{4}$ ternary hubrid composite. Reproduced with permission from ref. [481]. Copyright 2015 Elsevier Science

Other recent developments in the area of visible-light induced environmental cleaning involve the use of $\mathrm{GO}-\mathrm{TiO}_{2}$ composites for Microcystin-LA removal [479], N-doped $\mathrm{TiO}_{2}$ on glass spheres for Eriochrome Black-T decomposition [480], and $\mathrm{CdO} / \mathrm{TiO}_{2}$ coupled semiconductor for Reactive Orange degradation [478]. Superior decomposition of air pollutants by visiblelight active $\mathrm{TiO}_{2}$ photocatalysts have been lately reported by several researchers [483-487]. Bacterial killing under visible-light irradiation is one of the most versatile applications of $\mathrm{TiO}_{2}$ photocatalysis. Various strategies are recently developed for the visible-light activation of $\mathrm{TiO}_{2}$ for visible-light induced bacterial killing. Lin et al. reported the synthesis of Se/Te$\mathrm{TiO}_{2}$ nanorods with dominant (001) facets with high visible-light photocatalytic activity [488]. In this case, highly active (001) facets exhibited significantly higher antibacterial activity than Degussa P25 when activated under visible-light. A sol-gel method is recently demonstrated for the synthesis of $\mathrm{Ni}^{2+}$ doped $\mathrm{TiO}_{2}$ with superior antibacterial activity towards Staphylococcus aureus, Escherichia coli, Bacillus subtilis, and Salmonella abony under visible-light irradiation [489, 490]. Surprisingly, antibacterial performances of this $\mathrm{Ni}^{2+}$-doped $\mathrm{TiO}_{2}$ are superior to $\mathrm{N}$-doped $\mathrm{TiO}_{2}$ under similar experimental conditions. 


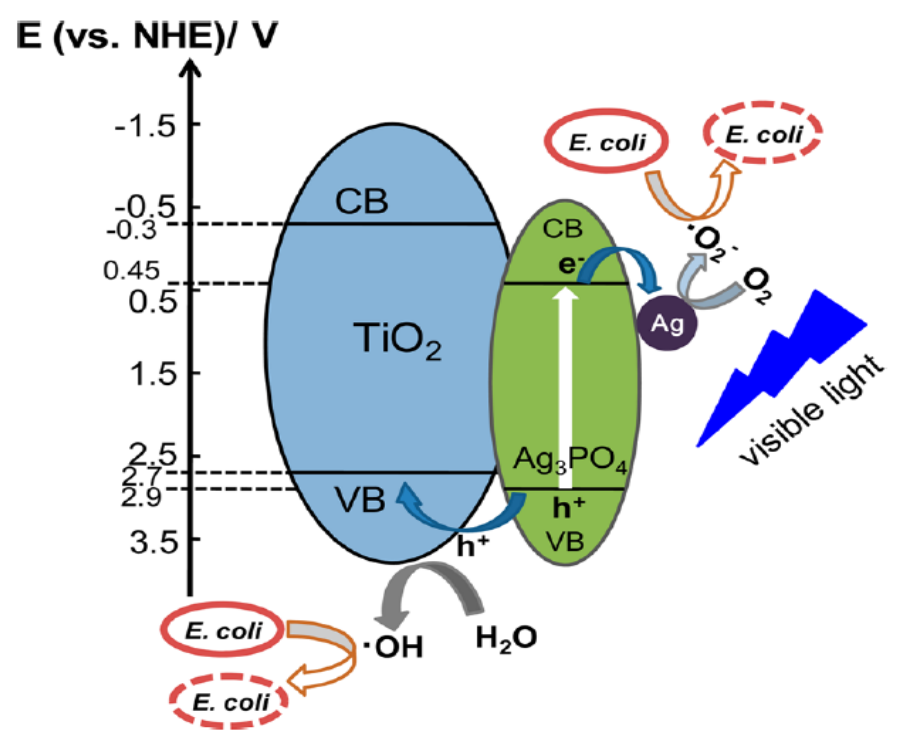

Figure 38. Visible-light induced antibacterial activity $\mathrm{Ag}_{3} \mathrm{PO}_{4} / \mathrm{TiO}_{2} / \mathrm{Fe}_{3} \mathrm{O}_{4}$ heterostructure toward E. Coli. Reproduced with permission from ref. [491]. Copyright 2014 American Chemical Society

Heterojunctions with carbonaceous materials, metal nanoparticles, metal oxides and phosphates are reported as effective for improving the visible-light induced antibacterial activity of $\mathrm{TiO}_{2}$ [491-496]. Akhavan et al. incorporated CNTs with $\mathrm{TiO}_{2}$ thin films for the visible light photoinactivation of Escherichia coli bacteria [492]. Post annealing of this film resulted in the formation of $\mathrm{Ti}-\mathrm{C}$ and $\mathrm{Ti}-\mathrm{O}-\mathrm{C}$ bonds. Bacterial inactivation in the dark was also observed for films containing higher CNT loading. Improved visible-light was assigned to the charge transfer between $\mathrm{CNTs}$ and $\mathrm{TiO}_{2}$ through the carbonaceous bonds formed. $\mathrm{Xu}$ et al. recently reported the synthesis of magnetically separable $\mathrm{Ag}_{3} \mathrm{PO}_{4} / \mathrm{TiO}_{2} / \mathrm{Fe}_{3} \mathrm{O}_{4}$ heterostructure for photoinactivation of bacteria [491]. This three component photocatalyst exhibited excellent photocatalytic activity, and photogenerated oxidants $\left(\cdot \mathrm{OH}\right.$ and $\left.\bullet \mathrm{O}_{2}{ }^{-}\right)$ formed caused a strong considerable morphological changes in the cells and bactericidal effects toward Escherichia coli. Visible-light activation was caused by narrow band gap $\mathrm{Ag}_{3} \mathrm{PO}_{4}$, and effective transfer of photogenerated holes to the valence band of $\mathrm{TiO}_{2}$ (Figure 38). Moreover, Etacheri et al. reported outstanding antibacterial performance of C-doped 
$\mathrm{TiO}_{2}$ heterojunctions composed of nanosized anatase and brookite nanoparticles. A microwave synthetic method was used for the rapid synthesis of these nanoheterojunctions, and 90\% bacterial killing occurred within $3 \mathrm{~h}$ visible-light irradiation. High visible-light induced photocatalytic activity was attributed to the efficient transfer of photogenerated electrons from the conduction band of brookite to that of anatase (Figure 39), which facilitate the formation of reactive oxygen species and bacterial killing.

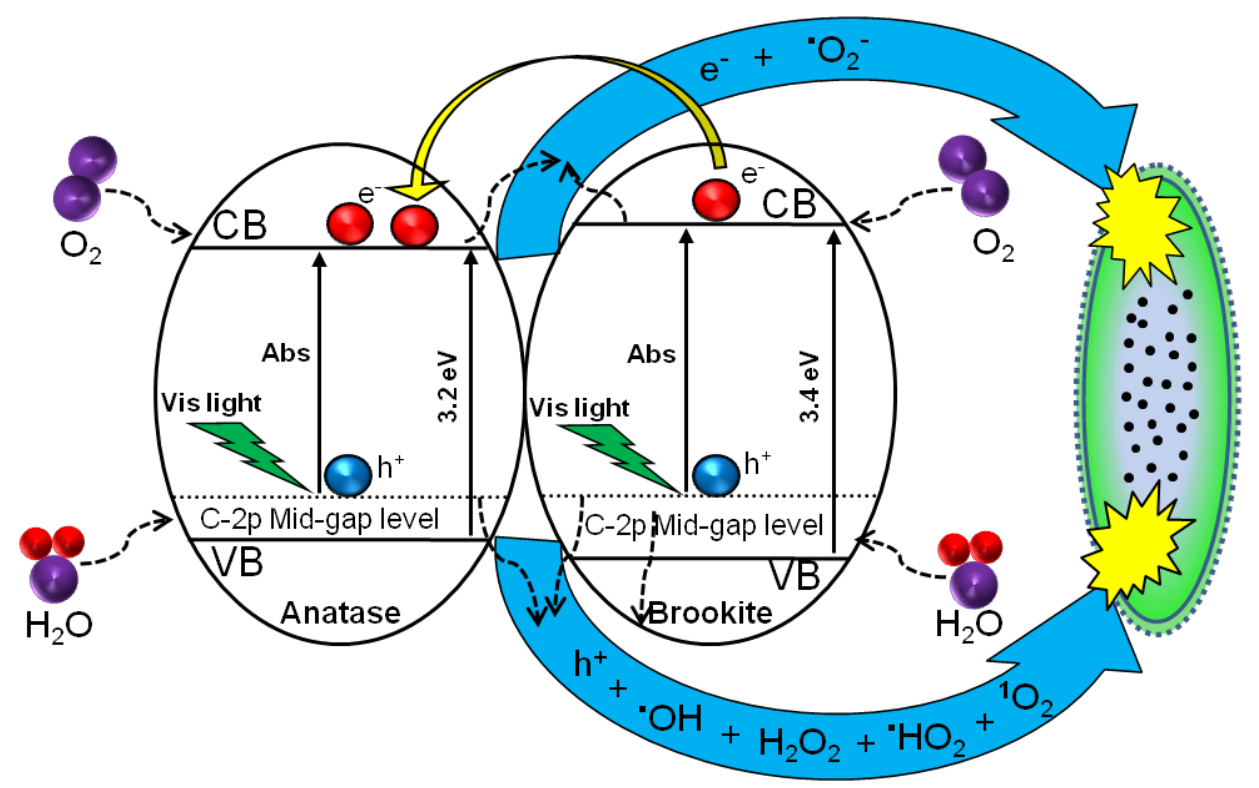

Figure 39. Mechanism of visible-light induced photocatalytic bacterial killing using carbon doped anatase-brookite heterojunctions. Reproduced with permission from ref. [497].

Copyright 2013 American Chemical Society

\section{Strategies to select dopants and future recommendations for an improved electron-}

\section{hole separation}

In the last decades great attention has been paid to the synthesis of transition-metal ion doped $\mathrm{TiO}_{2}$ possessing high photocatalytic activities to satisfy the requirements for practical applications. However, until now many questions are still open considering 
both the mechanism by which metal doping improves the photocatalytic activity as well as the determination of the optimal doping ratio. It is assumed that at low doping concentration the doping ions traps electron-hole pairs thus reducing the recombination rate, while at a higher doping ratio the formation of recombination centers occurs [40]. Consequently, for every transition metal doped $\mathrm{TiO}_{2}$ there is an optimal dopant concentration. Bloh et al. developed a theoretical model, which describes the dependency of the photonic efficiency on the doping ratio and which can thus be applied for the determination of optimal transition metal-ion ratio [498]. The idea behind this model is that the direct cationic neighbourhood of two dopant metal cations can be considered as recombination center, while more distant dopants can be ignored, since they induce a lower recombination probability. With increasing doping ratio, both the probability for the formation of the clusters and the amount of the doping atoms increases. The cluster ratio $r_{c}$, i.e., the product of the doping ratio and the cluster probability, depends quadratically on the doping ratio $r_{d}$ and can be describe by the following equation:

$$
\mathrm{r}_{\mathrm{c}}=\mathrm{nr}_{\mathrm{d}}^{2}
$$

Where, $n$ corresponds to the number of the neighbouring cations $\left(n=12\right.$ for $\mathrm{TiO}_{2}$ or $\mathrm{ZnO}$ (wurzite)). It is assumed that the photonic efficiency increases linearly with the doping ratio due to the formation of the charge carrier trapping centers, while it concurrently decreases quadratically with the doping ratio due to the formation of recombination centers. The relation between doping ratio and photonic efficiency is shown in Figure 40. Moreover, the experimentally determined data correlate very well with developed theoretical model. However, both the position and the height of the maximum can vary depending on the nature of dopants, ionic radius, number of the cationic neighbours, and the separation among the cations. 


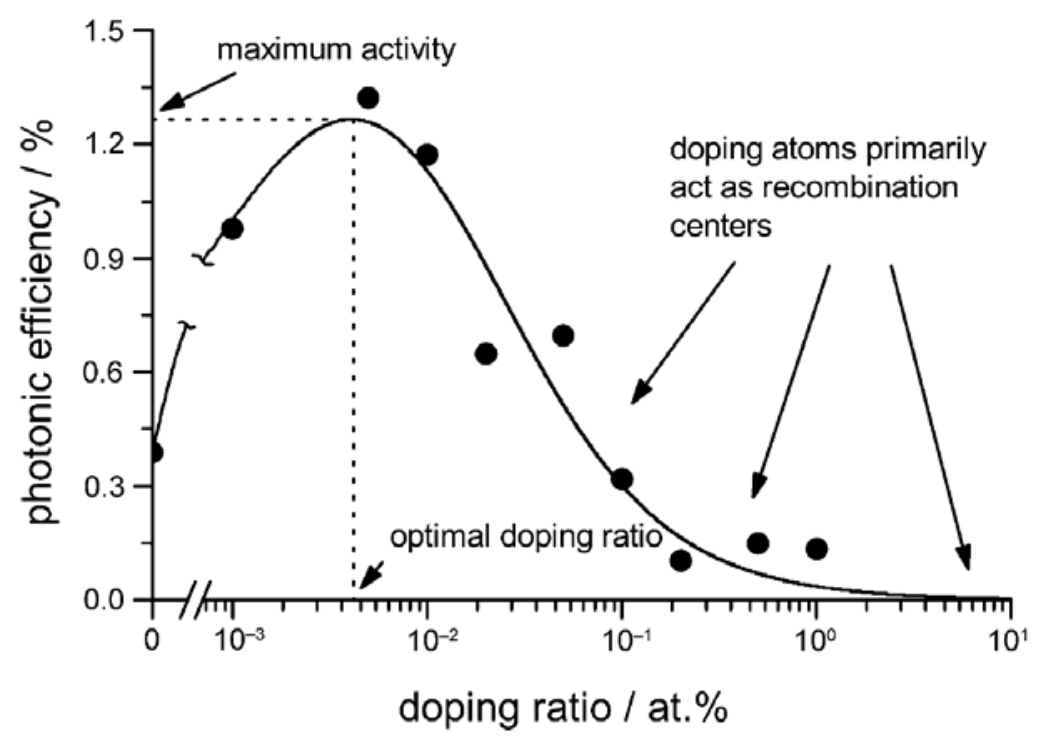

Figure 40. The photocatalytic activity as a function of the doping ratio. Reproduced with permission from ref. [498] Copyright 2013 Wiley VCH

The drawback of the above-described model is that it does not consider the dependency between particle size, morphology, and optimum dopant ratio. Zhang et al. suggested a theory indicating a correlation between the optimal $\mathrm{Fe}^{3+}$-doping ratio and the particle size of $\mathrm{TiO}_{2}$, though, they have not developed a model to describe this phenomenon [499]. In a similar study, Bloh et al. presented another model that explaining the relationship between dopant content, particle size and photocatalytic activity [500]. This model assumed small dopant concentration, formation of recombination centers, and presence of at least one dopant atom per particle to achieve a doping action. This model (Figure 41) includes the correlation between particle size and dopant content, defining regions with too many empty particles or too many cluster occurs, respectively. For larger particles, the optimal loading of dopants is rather wide, and for smaller particles it gets smaller. No optimal solution can be obtained for particles below the critical size $\left(2.8 \mathrm{~nm}\right.$ for $\mathrm{ZnO}$ and $3.2 \mathrm{~nm}$ for $\left.\mathrm{TiO}_{2}\right)$. The plotting of the experimentally determined data into the graph clearly shows a good agreement 
with the theory. There is no dependence between the material and the optimum dopant loading, which can be calculated using the following equation [500].

$$
r_{\mathrm{d}, \mathrm{opt}} \approx \frac{6 M}{N_{\mathrm{A}} \rho \pi d^{2}}\left(2.40 \mathrm{~nm}^{-1}\right)
$$

Where, $\mathrm{r}_{\mathrm{d} \text {,opt }}$ is the optimum doping ratio, $\mathrm{M}$ is the molar mass, $\mathrm{N}_{\mathrm{A}}$ is the Avogadro number, $\rho$ is density of the material and $d$ the particle diameter. This calculation is based on the assumption that individual semiconductor particles contain 2.4 dopant atoms for each nanometer of particle diameter. A good agreement of the calculated optimal doping ratio with the experimentally determined values was observed. Hence, this model allows, for the first time, to calculate the optimal doping concentration for a particular material and a given particle size.

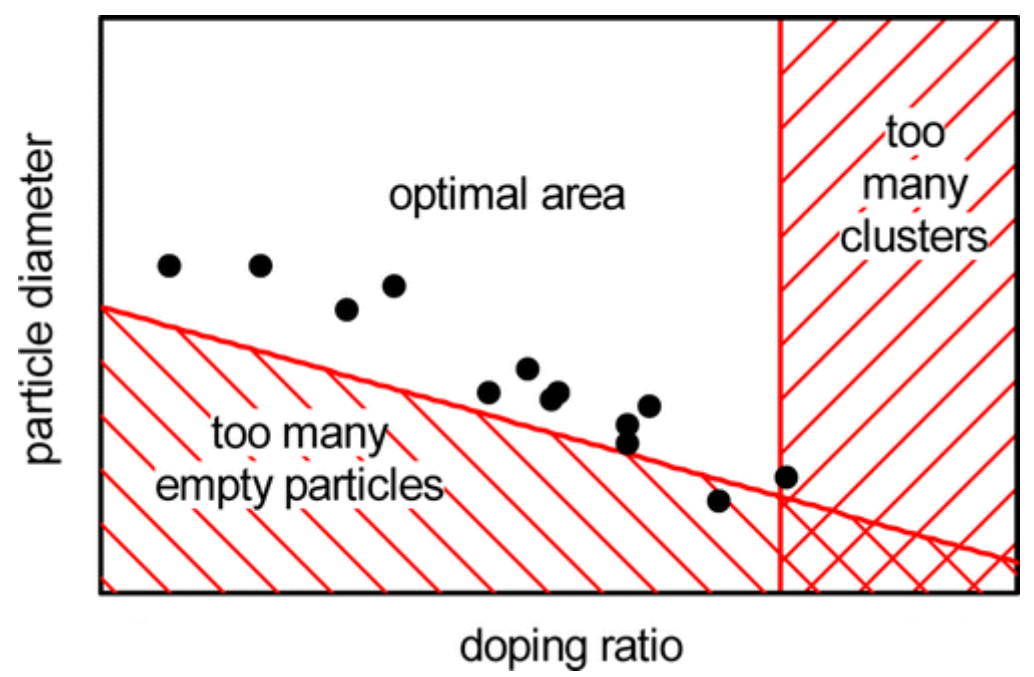

Figure 41. Optimal combinations of particle size and doping ratio. Reproduced with permission from ref. [500] Copyright 2012 American Chemical Society

As mentioned earlier, visible-light photocatalytic activity of cation doped $\mathrm{TiO}_{2}$ was limited due to the formation of electron hole recombination centers. In addition, recent studies proved that non-metal or metalloids doped $\mathrm{TiO}_{2}$ materials are much promising than metal-doped counterparts [1,2,17,501-506]. A number of recent reviews also address the use of modified $\mathrm{TiO}_{2}$ for various environmental 
applications. ${ }^{507-512}$ It is clear that the future development of visible-light active $\mathrm{TiO}_{2}$ would mainly be based on anion doping. The main shortcoming of anion doped $\mathrm{TiO}_{2}$ is the formation of oxygen vacancies that accelerate the recombination of photo-excited electron-hole pairs. The photocatalytic activity can be significantly improved by reducing the recombination rate of photoexcited electron-hole pairs. This can be pursued through different approaches. For instance, co-doping of $\mathrm{TiO}_{2}$ is efficient in reducing the formation of compensating oxygen vacancies with a positive effect on the photocatalytic performance of the material. Alternatively, one may combine anion doped $\mathrm{TiO}_{2}$ with small band gap semiconductors to improve electron-hole separation. Coupling of anion-doped anatase $\mathrm{TiO}_{2}$ with $\mathrm{WO}_{3}, \mathrm{Fe}_{2} \mathrm{O}_{3}$ and $\mathrm{V}_{2} \mathrm{O}_{5}$ (which has less negative conduction band level compared to anatase) can effectively trap photo-excited electrons and thereby reducing electron-hole recombination. Metal nanoparticles (Au, Ag, Pt, Pd etc.) can also be employed as photo-excited electron trap and thereby increasing the photocatalytic performance [63]. Due to the different conduction band energy levels of anatase, rutile and brookite phases, anion-doped multiphase $\mathrm{TiO}_{2}$ is highly recommended over single phase photocatalyst. This would enable the efficient electron transfer from the conduction band of brookite to anatase, brookite to rutile and anatase to rutile, which can lead to a momentous enhancement in the photocatalytic activity $[11,17,19]$.

Coupling of anionic doped $\mathrm{TiO}_{2}$ with sensitizers such as graphene and carbon nanotubes, is highly recommended considering the fact that these visible-light absorbing carbonaceous dopants can sensitize $\mathrm{TiO}_{2}$ and separate photogenerated electron-hole pairs. Modification of anion-doped $\mathrm{TiO}_{2}$ with quantum dots could be very useful for significantly improving the visible-light photocatalytic activity. Semiconductor and noble metal quantum dots can simultaneously sensitize $\mathrm{TiO}_{2}$ 
through LSPR and act as electron-hole separating agents. In addition, coupling of anion doped $\mathrm{TiO}_{2}$ with multiple sensitizers and electron-hole separating agents could be effective for utilizing the whole visible spectrum. Since the photocatalytic activity of $\mathrm{TiO}_{2}$ highly depends on the particle size, morphology and amount of exposed (001) crystal planes, it is highly recommended to optimize these parameters of anion doped $\mathrm{TiO}_{2}$ to attain the best results.

Investigation of the electronic structure through DFT calculations can play a fundamental role in the study of these new generation composite photocatalysts. Through these types of calculations it is possible to determine how the band structure is modified when different materials are put into contact to create oxide/oxide, metal/oxide, QD/oxide or sensitizers/oxide heterojunctions for an efficient visible-light absorption and subsequent charge separation at the interface. Theoretical modelling provides solid basis for identifying the key factors into play and for controlling the heterojunctions performance through band structure engineering. Such investigations can be used for predicting novel efficient photocatalytic systems and for improving the existing ones, in the continuous attempt to enhance the control of the structureproperties relationship of materials for photocatalytic applications.

\section{Conclusions}

Titanium dioxide has been the focus of research efforts in the area of photocatalysis due to its improved chemical stability and high redox potential over other semiconductor photocatalysts. Improving the visible-light spectral sensitivity of $\mathrm{TiO}_{2}$ is one of the key challenges faced by the community involved in the research of photocatalysts. Recent developments in the area of $\mathrm{TiO}_{2}$ photocatalysts were promising enough for the development of $\mathrm{TiO}_{2}$ active in the visible-light region of the 
electromagnetic spectrum. A number of techniques have been employed by previous researchers to overcome the main shortcoming of $\mathrm{TiO}_{2}$ photocatalyst, the poor visiblelight induced photocatalytic activity. In this review, various strategies activation of $\mathrm{TiO}_{2}$ photocatalysts under visible-light irradiation was discussed in detail. The effect of various visible-light activation techniques on the electronic structure and photocatalytic activities of $\mathrm{TiO}_{2}$ was critically investigated. Recent theoretical developments explaining the electronic structure of visible-light active $\mathrm{TiO}_{2}$ were explored. Previous studies demonstrated the fact that various non-metal doped $\mathrm{TiO}_{2}$ materials are more promising than metal doped counterparts. Each anionic dopant was found to have a distinctive consequence on the electronic structure and photocatalytic activities of $\mathrm{TiO}_{2}$. The main drawback of the non-metal-doped $\mathrm{TiO}_{2}$ is the increased carrier recombination, which makes them considerably less active under visible-light than UV-light. Since the synthesis methods, dopant concentration and phase purity crucially affect the photocatalytic activity of $\mathrm{TiO}_{2}$, further optimization of these parameters are necessary for increasing the visible-light performance of anion-doped $\mathrm{TiO}_{2}$. Another vital challenge is the fabrication of thermally stable $\mathrm{TiO}_{2}$ with predictable performance under visible and UV-light. Since the charge carrier recombination is the major drawback of current generation anion-doped $\mathrm{TiO}_{2}$, future research should be devoted for enhancing the lifetime of electron-hole pairs. The advancements made to date in the area of visible-light activated $\mathrm{TiO}_{2}$ photocatalysts are encouraging and further widens its scope of applications in environmental protection. A number of recommendations for enhancing the photocatalytic performance of the current generation visible-light active $\mathrm{TiO}_{2}$ are also presented. 
Journal of Photochemistry and Photobiology C: Photochemistry Reviews, Volume 25,

December 2015, Pages 1-29: doi:10.1016/j.jphotochemrev.2015.08.003

\section{Acknowledgements}

The authors would like to thank Enterprise Ireland for funding (CFTD/06/IT/326 and ARE/2008/0005). SP wish to acknowledge financial support under the U. S.-Ireland R\&D Partnership programme from the Science Foundation Ireland (SFI-grant number 10/US/I1822(T). One of the authors VE would also like to thank Dr. Michael Seery for providing valuable comments during his PhD. CDV thanks Gianfranco Pacchioni and Annabella Selloni for many helpful discussions and Cariplo foundation for an Advanced Materials grant 2013-0615.

\section{References}

[1] S. Banerjee, S. C. Pillai, P. Falaras, K. E. O'Shea, J. A. Byrne, D. D. Dionysiou, J. Phys. Chem. Lett., 5 (2014) 2543.

[2] M. Pelaez, N. T. Nolan, S. C. Pillai, M. K. Seery, P. Falaras, A. G. Kontos, P. S. M. Dunlop, J. W. J. Hamilton, J. A. Byrne, K. O’Shea, M. H. Entezari, D. D. Dionysiou, Appl. Catal., B, 125 (2012) 331.

[3] J. Schneider, M. Matsuoka, M. Takeuchi, J. Zhang, Y. Horiuchi, M. Anpo, D. W. Bahnemann, Chem. Rev., 114 (2014) 9919.

[4] S. Banerjee, D. D. Dionysiou, S. C. Pillai, Applied Catalysis B: Environmental, 176177 (2015) 396.

[5] A. Fujishima, K. Honda, Nature, 238 (1972) 37.

[6] A. Mills, S. K. Lee, J. Photochem. Photobiol., A, 152 (2002) 233.

[7] P. V. Kamat, J. Phys. Chem. C, 111 (2007) 2834.

[8] V. Etacheri, M. K. Seery, S. J. Hinder, S. C. Pillai, Adv. Funct. Mater., 21 (2011) 3744.

[9] D. A. Keane, K. G. McGuigan, P. F. Ibáñez, M. I. Polo-López, J. A. Byrne, P.S.M. Dunlop, K. O'Shea, D. D. Dionysiou, S. C. Pillai, RSC Catal. Sci. Technol., 4 (2014) 1211.

[10] S. C. Pillai, P. Periyat, R. George, D. E. McCormack, M. K. Seery, H. Hayden, J. Colreavy, D. Corr, S. J. Hinder, J. Phys. Chem. C, 111 (2007) 1605.

[11] V. Etacheri, M. K. Seery, S. J. Hinder, S. C. Pillai, Chem. Mater., 22 (2010) 3843.

[12] L. Vayssieres, Adv. Mater. , 15 (2003) 464.

[13] V. Etacheri, R. Roshan, V. Kumar, ACS Appl. Mater. Interfaces, 4 (2012) 2717.

[14] G. S. Li, D. Q. Zhang, J. C. Yu, Environ. Sci. Technol., 43 (2009) 7079.

[15] A. Kudo, M. Sekizawa, Chem. Commun., (2000) 1371.

[16] F. F. Kong, L. L. Huang, L. L. Luo, S. S. Chu, Y. Y. Wang, Z. Z. Zou, J. Nanosci. Nanotechnol. , 12 (2012) 1931.

[17] V. Etacheri, M. K. Seery, S. J. Hinder, S. C. Pillai, Inorg. Chem., 51 (2012) 7164.

[18] M. R. Hoffmann, S. T. Martin, W. Choi, D. W. Bahnemann, Chem. Rev., 95 (1995) 69.

[19] V. Etacheri, G. Michlits, M. K. Seery, S. J. Hinder, S. C. Pillai, ACS Appl. Mater. Interfaces, 5 (2013) 1663. 
[20] N. Wetchakun, S. Chaiwichain, B. Inceesungvorn, K. Pingmuang, S. Phanichphant, A. I. Minett, J. Chen, ACS Appl. Mater. Interfaces, 4 (2012) 3718.

[21] S. Polisetti, P. A. Deshpande, G. Madras, Ind. Eng. Chem. Res., 50 (2011) 12915.

[22] L. Li, M. Krissanasaeranee, S. W. Pattinson, M. Stefik, U. Wiesner, U. Steiner, D. Ede, Chem. Commun., 46 (2010) 7620.

[23] Y. Liu, L. Yu, Y. Hu, C. Guo, F. Zhanga, X. W. D. Lou, Nanoscale, 4 (2012) 183.

[24] D. Chu, J. Mo, Q. Peng, Y. Zhang, Y. Wei, Z. Zhuang, Y. Li, ChemCatChem, 3 (2011) 371.

[25] M. Gratzel, Heterogeneous Photochemical Electron Transfer, CRC Press: Boca Raton Florida, 1989.

[26] T. Daimon, T. Hirakawa, M. Kitazawa, J. Suetake, Y. Nosaka, Appl. Catal., A, 340 (2008) 169.

[27] Y. Nosaka, T. Daimon, A.Y. Nosaka, Y. Murakami, Phys. Chem. Chem. Phys., 6 (2004) 2917.

[28] H. Sakai, R. Baba, K. Hashimoto, A. Fujishima, J. Phys. Chem., 99 (1995) 11896.

[29] K. T. Ranjit, I. Willner, S. H.Bossmann, A. M. Braun, Environ. Sci. Technol., 35 (2001) 1544.

[30] J. R. Harbour, M. L. Hair, J. Phys. Chem., 83 (1979) 652.

[31] P. Periyat, N. Leyland, D. E. McCormack, J. Colreavy, D. Corr, S.C. Pillai, J. Mater. Chem., 20 (2010) 3650.

[32] D. W. Synnott, M. K. Seery, S. J. Hinder, G. Michlits, S.C. Pillai, Appl. Catal. B: Environ., 106-111 (2013) 130.

[33] B. O’Regan, M. Grätzel, Nature, 353 (1991) 737.

[34] B. Kraeutler, A. J. Bard, J. Am. Chem. Soc., 100 (1978) 2239.

[35] D. F. Ollis, H. Al-Ekabi, Photocatalytic Purification and Treatment of Water and Air, Elsevier, Amsterdam, 1993.

[36] R. Cai, Y. Kubota, T. Shuin, H. Sakai, K. Hashimoto, A. Fujishima, Cancer Res. , 52 (1992) 2346.

[37] J. Yuan, S. Tsujikawa, J. Electrochem. Soc., 142 (1995) 3444.

[38] H. Honda, A. Ishizaki, R. Soma, K. Hashimoto, A. Fujishima, J. Illum. Eng. Soc., 27 (1998) 42.

[39] S. L. Pugh, J. T. Guthrie, Dyes Pigm., 55 (2002) 109.

[40] W. Choi, A. Termin, M. R. Hoffmann, J. Phys. Chem., 98 (1994) 13669.

[41] H. A. Macleod, Thin Film Optical Filters, MacMillan, New York, 1986.

[42] P. T. Moseley, B. C. Tofield, Solid State Gas Sensors, Adam Hilger, Bristol, 1987.

[43] E. M. Logothetis, Ceram. Proc. Eng. Sci, 1 (1980) 281.

[44] L. D. Birkefeld, A. M. Azad, S. A. Akbar, J. Am. Ceram. Soc., 75 (1992) 2964.

[45] N. Savage, B. Chwieroth, A. Ginwalla, B. R. Patton, S.A. Akbar, P.K. Dutta, Sens. Actuators, B, 79 (2001) 17.

[46] Y. He, D. Langsdorf, L. Li, H. Over, J. Phys. Chem. C, 119 (2015) 2692.

[47] H. Tong, S. Ouyang, Y. Bi, N. Umezawa, M. Oshikiri, J. Ye, Adv. Mater., 24 (2012) 229.

[48] M. Wang, J. Iocozzia, L. Sun, C. Lin, Z. Lin, Energy Environ. Sci., 7 (2014) 2182.

[49] A. E. R. Mohamed, S. Rohani, Energy Environ. Sci., 4 (2011) 1065.

[50] H. Li, Y. Zhou, W. Tu, J. Ye, Z. Zou, Adv. Funct. Mater., 25 (2015) 998.

[51] S. Chakrabarti, B. K. Dutta, J. Hazard. Mater., 112 (2004) 269.

[52] S. N. Frank, A. J. Bard, J. Am. Chem. Soc., 99 (1977) 303.

[53] S. N. Frank, A. J. Bard, J. Phys. Chem., 81 (1977) 1484.

[54] M. A. Fox, M. T. Dulay, Chem. Rev., 93 (1993) 341. 
[55] J. Zhao, T. Wu, K. Wu, K. Oikawa, H. Hidaka, N. Serpone, Environ. Sci. Technol., 32 (1998) 2394.

[56] R. Wang, K. Hashimoto, A. Fujishima, M. Chikuni, E. Kojima, A. Kitamura, Nature, 388 (1997) 431.

[57] Y. Wang, Y. Huang, W. Ho, L. Zhang, Z. Zou, S. Lee, J. Hazard. Mater., 169 (2009) 77.

[58] C. Su, C.M. Tseng, L.F. Chen, B. H. You, B. C. Hsu, S. S. Chen, Thin Solid Films, 498 (2006) 259.

[59] R. Asahi, Y. Taga, W. Mannstadt, A. J. Freeman, Phys. Rev. B: Condens. Matter, 61 (2000) 7459.

[60] A. Amtout, R. Leonelli, Phys. Rev. B: Condens. Matter, 51 (1995) 6842.

[61] M. Koelsch, S. Cassaignon, C. T. T. Minh, J. F. Guillemoles, J. P. Jolivet, Thin Solid Films, 451 (2004) 86.

[62] N. T. Nolan, M. K. Seery, S. C. Pillai, J. Phys. Chem. C, 113 (2009) 16151.

[63] N. T. Nolan, L. F. Healy, M. K. Seery, S. J. Hinder, S. C. Pillai, J. Phys. Chem. C, 114 (2010) 13026.

[64] A. L. Linsebigler, G. Lu, Y. T. Yates, Chem. Rev., 95 (1995) 735.

[65] M. Muruganandham, M. Swaminathan, Sol. Energ. Mater. Sol. Cells., 81 (2004) 439.

[66] T. Miyagi, M. Kamei, T. Mitsuhashi, T. Ishigaki, A.Yamazaki, Chem. Phys. Lett., 390 (2004) 399.

[67] L. Kavan, M. Grtzel, S.E. Gilbert, C. Klemenz, H. J. Scheel, J. Am. Chem. Soc., 118 (1996) 6716.

[68] M. Toyoda, Y. Nanbu, Y. Nakazawa, M. Hirano, M. Inagaki, Appl. Catal. B-Environ., 49 (2004) 227.

[69] E. Beyers, P. Cool, E. F. Vansant, J. Phys. Chem. B, 109 (2005) 10081.

[70] A. Wisitsoraat, A. Tuantranont, E. Comini, G. Sberveglieri, W. Wlodarski, Thin Solid Films, 517 (2009) 2775.

[71] G. Tomandl, F. D. Gnanam, Sol-Gel Processing of Advanced Ceramics, Oxford and IBH Publishing Co. Pvt. Ltd, New Delhi, 1996.

[72] A. C. Pierre, Introduction to Sol gel Processing, Kluwer academic press, Boston, 1990.

[73] G. Mills, M. R. Hoffmann, Environ. Sci. Technol., 27 (1993) 1681.

[74] D. F. Ollis, C. Y. Hsiao, L. Budiman, C.L. Lee, J. Catal., 88 (1984) 89.

[75] C. S. Turchi, D. F. Ollis, J. Catal., 119 (1989) 480.

[76] H. Noda, K. Oikawa, H. Kamada, Bull. Chem. Soc. Jpn., 66 (1993) 455.

[77] M. Anpo, T. Shima, Y. Kubokawa, Chem. Lett., 14 (1985) 1799.

[78] R. F. Howe, M. Gratzel, J. Phys. Chem., 89 (1985) 4495.

[79] R. F. Howe, M. Gratzel, J. Phys. Chem., 91 (1987) 3906.

[80] R. F. Howe, M. Gratzel, J. Phys. Chem., 94 (1990) 2566.

[81] Y. Mao, C. Schoneich, K. D. Asmus, J. Phys. Chem., 95 (1991) 80.

[82] C. Kormann, D. W. Bahnemann, M. R. Hoffmann, Environ. Sci. Technol., 25 (1991) 494.

[83] J. Moser, S. Punchihewa, P. P. Infelta, M. Gratzel, 7 (1991) 3012.

[84] R. B. Draper, M. A. Fox, Langmuir., 6 (1990) 1396.

[85] E. R. Carraway, A. J. Hoffman, M. R. Hoffmann, Environ. Sci. Technol., 28 (1994) 786.

[86] C. J. Richard, J. Photochem. Photobiol., A, 72 (1993) 179.

[87] M. Mrowetz, E. Selli, J. Photochem Photobiol A: Chem, 180 (2006) 15.

[88] C. M. Wang, A. Heller, H. Gerischer, J. Am. Chem. Soc., 114 (1992) 5230.

[89] H. Gerischer, A. Heller, J. Phys. Chem., 95 (1991) 5261. 
[90] A. J. Hoffmann, E. R. Carraway, M. R. Hoffmann, Environ. Sci. Technol., 28 (1994) 776.

[91] K. Sunada, T. Watanabe, K. Hashimoto, J. Photochem. Photobiol. A, 156 (2003) 227.

[92] K. Sunada, Y. Kikuchi, K. Hashimoto, A. Fujishima, Environ. Sci. Technol., 32 (1998) 726.

[93] J. Podporska-Carroll, E. Panaitescu, B. Quilty, L. Wang, L. Menon, S. C. Pillai, Applied Catalysis B: Environmental, 176 (2015) 70.

[94] J. A. Rengifo-Herrera, C. Pulgarin, Sol. Energy, 84 (2010) 37.

[95] J.A. Byrne, P.A. Fernandez-Ibanez, P.S.M. Dunlop, D.M.A. Alrousan, J.W.J.

Hamilton, Int. J. Photoenergy, 2011 (2011) 1.

[96] M. B. Fisher, D. A. Keane, P. Fernández-Ibáñez, J. Colreavy, S. J. Hinder, K. G. McGuigan, S. C. Pillai, Appl. Catal. B: Environ., 130-131 (2013) 8.

[97] N. Daneshvar, A. Niaei, S. Akbari, S. Aber, N. Kazemian, Glob. Nest J., 9 (2007) 132.

[98] J. Zhang, Y. Nosaka, J. Phys. Chem. C, 118 (2014) 10824.

[99] X. Chen, S. S. Mao, Chem. Rev., 107 (2007) 2891.

[100] A. Sclafani, J. Phys. Chem., 100 (1996) 13655.

[101] J. Liqiang, Q. Yichun, W. Baiqi, L. Shudan, J. Baojiang, Y. Libin, F. Wei, F. Honggang, S. Jiazhong, Sol. Energy Mater. Sol. Cells, 90 (2006) 1773.

[102] N. Serpone, J. Photochem. Photobiol. A: Chem., 104 (1997) 1.

[103] J. Soria, J.C. Conesa, V. Augugliaro, L. Palmisano, M. Schiavello, A. Sclafani, J. Phys. Chem., 95 (1991) 274.

[104] J. C. Yu, L. Zhang, J. G. Yu, Chem. Mater., 14 (2002) 4647.

[105] Y. R. Do, K. Lee, K. Dwight, W. Wold, J. Solid State Chem., 108 (1994) 198.

[106] J. Engweiler, J. Harf, A. Baiker, J. Catal., 159 (1996) 259.

[107] K. Vinodgopal, P. V. Kamat, Environ. Sci. Technol., 29 (1995) 841.

[108] A. J. Maira, K. L. Yeung, C. Y. Lee, P. L. Yue, C. K. Chan, J. Catal., 192 (2000) 185.

[109] Z. L. Xu, J. Shang, C. M. Liu, C. Kang, H. C. Guo, Y. G. Du, Mater. Sci. Eng., B, 63 (1999) 211.

[110] Y. Li, D.S. Hwang, N. H. Lee, S. J. Kim, Chem. Phys. Lett., 404 (2005) 25.

[111] R. Georgekutty, M. K. Seery, S. C. Pillai, J. Phys. Chem. C, 112 (2008) 13563.

[112] G. Balasubramanian, D. D. Dionysiou, M. T. Suidan, I. Baudin, J. M. Laine, Appl. Catal., B, 47 (2004) 73.

[113] P. Periyat, S. C. Pillai, D. E. McCormack, J. Colreavy, S. J. Hinder, J. Phys. Chem. C, 112 (2008) 7644.

[114] J. A. Gamboa, D. M. Pasquevich, J. Am. Ceram. Soc., 75 (1992) 2934.

[115] R. D. Shannon, J. A. Pask, J. Am. Ceram. Soc., 48 (1965) 391.

[116] R. A. Eppler, J. Am. Ceram. Soc., 70 (1987) 64.

[117] H. Zhang, J. F. Banfield, J. Mater. Chem., 8 (1998) 2073.

[118] A. A. Gribb, J. F. Banfield, Am. Mineral., 82 (1997) 717.

[119] Y. Q. Wang, X. J. Yu, D. Z. Sun, J. Hazard. Mater., 144 (2007) 328.

[120] G. Mattioli, P. Alippi, F. Filippone, R. Caminiti, A. A. Bonapasta, J. Phys. Chem. C, 114 (2010) 21694.

[121] C. D. Valentin, G. Pacchioni, Acc. Chem. Res., 47 (2014) 3233.

[122] C. Freysoldt, B. Grabowski, T. Hickel, J. Neugebauer, G. Kresse, A. Janotti, C.G.V.d. Walle, Rev. Mod. Phys., 86 (2014) 253.

[123] M. Choi, F. Oba, I. Tanaka, Phys. Rev. B 78 (2008) 014115.

[124] P. Reunchan, N. Umezawa, S. Ouyang, J. Ye, Phys. Chem. Chem. Phys., 14 (2012) 1876.

[125] A. Kafizas, N. Noor, P. Carmichael, D.O. Scanlon, C.J. Carmalt, I.P. Parkin, Adv. Funct. Mater., 24 (2014) 1758. 
[126] J. B. Varley, A. Janotti, C. G. V.d. Walle, Adv. Mater., 23 (2011) 2343.

[127] B. A. Peter Deák, T. Frauenheim, Phys. Rev. B, 83 (2011) 155207.

[128] C. Gionco, M. C. Paganini, E. Giamello, R. Burgess, C. D. Valentin, G. Pacchioni, J. Phys. Chem. Lett., 4 (2014) 447.

[129] K. Lai, Y. Zhu, Y. Dai, B. Huang, J. Appl. Phys., 112 (2012) 043706.

[130] H. Wan, L. Xu, W. Q. Huang, G. F. Huang, C. N. He, J. H. Zhou, P. Peng, Appl. Phys. A, 116 (2014) 741.

[131] L. M. Tang, L. L. Wang, D. Wang, J. Z. Liu, K. Q. Chen, J. Appl. Phys. , 107 (2010) 083704.

[132] M. V. Schilfgaarde, T. Kotani, S. Faleev, Phys. Rev. Lett. , 96 (2006) 226401.

[133] W. Kang, M. S. Hybertsen, Phys. Rev. B, 82 (2010) 085203.

[134] L. Chiodo, J. M. GarcÃa-Lastra, A. Iacomino, S. Ossicini, J. Zhao, H. Petek, A. Rubio, Phys. Rev. B, 82 (2011) 045207.

[135] C. D. Valentin, A. Selloni, J.Phys.Chem.Lett., 2 (2011) 2223.

[136] M. Watanabe, T. Hayashi, J. Lumin., 112 (2005) 88.

[137] Y. F. Li, A. Selloni, J. Am. Chem. Soc., 135 (2013) 9195.

[138] C. D. Valentin, D. Fittipaldi, J. Phys. Chem. Lett., 4 (2013) 1901.

[139] H. H. Kristoffersen, U. Martinez, B. Hammer, Top Catal. , 57 (2014) 171.

[140] E. Borgarello, J. Kiwi, M. Gratzel, E. Pelizzetti, M. Visca, J. Am. Chem. Soc, 104 (1982) 2996.

[141] S. Sato, Chem. Phys. Lett., 123 (1986) 126.

[142] R. Asahi, T. Morikawa, T. Ohwaki, K. Aoki, Y. Taga, Science, 293 (2001) 269.

[143] C. Dette, M. A. Pérez-Osorio, C. S. Kley, P. Punke, C. E. Patrick, P. Jacobson, F. Giustino, S. J. Jung, K. Kern, Nano Lett, 14 (2014) 6533.

[144] W. Li, Phys. Status Solidi RRL 9(2015) 10.

[145] K. Gurunathan, P. Maruthamuthu, V. Sastri, Int. J. Hydrogen Energy, 22 (1997) 57.

[146] K. Dhanalakshmi, S. Latha, S. Anandan, P. Maruthamuthu, Int. J. Hydrogen Energy, 26 (2001) 669.

[147] A. Jana, J. Photochem. Photobiol., A, 132 (2000) 1.

[148] A. Polo, M. Itokazu, N. Iha, Coord. Chem. Rev., 248 (2004) 1343.

[149] R. Abe, K. Sayama, H. Arakawa, Chem. Phys. Lett., 362 (2002) 441.

[150] S. Yan, J. Hupp, J. Phys. Chem. B, 100 (1996) 6867.

[151] T. Hannappel, B. Burfeindt, W. Storck, J. Phys. Chem. B, 101 (1997) 6799.

[152] I. Martini, J. Hodak, G. Hartland, J. Phys. Chem. B, 102 (1998) 607.

[153] B. Burfeindt, T. Hannappel, W. Storck, F. Willig, J. Phys. Chem., 100 (1996) 16461.

[154] J. Rehm, G. Mclendon, Y. Nagasawa, K. Yoshihara, J. Moser, M. Gratzel, J. Phys. Chem., 100 (1996) 9577.

[155] W. J. Youngblood, S. H. A. Lee, K. Maeda, T. E. Mallouk, Acc. Chem. Res., 42 (2009) 1966.

[156] J. R. Swierka, T. E. Mallouk, Chem. Soc. Rev., 42 (2013) 2357.

[157] P. Chowdhury, J. Moreira, H. Gomaa, A. K. Ray, Ind. Eng. Chem. Res., 51 (2012) 4523.

[158] G. Qin, Z. Sun, Q. Wu, L. Lin, M. Liang, S. Xue, J. Hazard. Mater. , 192 (2011) 599.

[159] M. R. John, A. J. Furgals, A. F. Sammells, J. Phys. Chem., 87 (1983) 801.

[160] G. R. Bamwenda, S. Tsubota, T. Nakamura, M. Haruta, J. Photochem. Photobiol., A, 89 (1995) 177.

[161] S. Sakthivel, M. V. Shankar, M. Palanichamy, B. Arabindoo, D.W. Bahnemann, V. Murugesan, Water Res., 38 (2004) 3001.

[162] V. Subramanian, E. Wolf, P. Kamat, J. Phys. Chem. B, 105 (2001) 11439.

[163] M. Jakob, H. Levanon, P. V. Kamat, Nano Lett., 3 (2003) 353. 
[164] I. H. Tseng, J.C.S. Wu, H. Y. Chou, J. Catal., 221 (2004) 432.

[165] A. Takai, P. V. Kamat, ACS Nano, 5 (2011) 7369.

[166] T. L. Phan, P. Zhang, H. D. Tran, S. C. Yu, J. Korean Phys. Soc., 57 (2010) 1270.

[167] M. Anpo, M. Takeuchi, J. Catal., 216 (2003) 505.

[168] M. K. Seery, R. George, P. Floris, S. C. Pillai, J. Photochem. Photobiol., A, 189 (2007) 258.

[169] K. M. Rahulan, S. Ganesan, P. Aruna, Adv. Nat. Sci: Nanosci. Nanotechnol. , 2 (2011) 25012.

[170] J. Taing, M. H. Cheng, J. C. Hemminger, ACS Nano, 5 (2011) 6325.

[171] K. Awazu, M. Fujimaki, C. Rockstuhl, J. Tominaga, H. Murakami, Y. Ohki, N. Yoshida, T. Watanabe, J. Am. Chem. Soc., 130 (2008) 1676.

[172] H. A. Atwater, A. Polman, Nat. Mater., 9 (2010) 205.

[173] M. Murdoch, G. I. N. Waterhouse, M. A. Nadeem, J.B. Metson, M. A. Keane, R. F. Howe, J. LIorca, H. Idriss, Nat. Chem. , 3 (2011) 489.

[174] S. D. Standridge, G. C. Schatz, J. T. Hupp, J. Am. Chem. Soc., 131 (2009) 8407.

[175] Y. Ide, M. Matsuoka, M. Ogawa, J. Am. Chem. Soc., 132 (2010) 16762.

[176] Y. Tian, T. Tatsuma, J. Am. Chem. Soc., 127 (2005) 7632.

[177] Y. Tian, T. Tatsuma, Chem. Commun. , 16 (2004) 1810.

[178] A. Furube, L. Du, K. Hara, R. Katoh, M. Tachiya, J. Am. Chem. Soc. , 129 (2007) 14852.

[179] Y. Nishijima, K. Ueno, Y. Yokota, K. Murakoshi, H. Misawa, J. Phys. Chem. Lett., 1 (2010) 2031.

[180] M. D. Brown, T. Suteewong, R.S.S. Kumar, V. D’Innocenzo, A. Petrozza, M.M. Lee, U. Wiesner, H. J. Snaith, Nano Lett., 11 (2011) 438.

[181] A. M. Glass, P. F. Lioa, J. G. Bergman, D. H. Olson, Opt. Lett., 5 (1980) 368.

[182] B. Rand, P. Peumans, S. Forrest, J. Appl. Phys., 96 (2004) 7519.

[183] S. K. Cushing, J. Li, F. Meng, T. R. Senty, S. Suri, M. Zhi, M. Li, A. D. Bristow, N. Wu, J. Am. Chem. Soc., 134 (2012) 15033.

[184] Z. Bian, T. Tachikawa, W. Kim, W. Choi, T. Majima, J. Phys. Chem. C, 116 (2012) 25444.

[185] X. Shi, K. Ueno, N. Takabayashi, H. Misawa, J. Phys. Chem. C, 117 (2013) 2494.

[186] C. Wen, K. Ishikawa, M. Kishima, K. Yamada, Sol. Energy Mater. Sol. Cells, 61 (2000) 339.

[187] J. Okumu, C. Dahmen, A. N. Sprafke, M. Luysberg, v.P. G, M. Wuttig, J. Appl. Phys., 97 (2005) 94305.

[188] G. Sandmann, H. Dietz, W. Plieth, J. Electroanal. Chem., 491 (2000) 78.

[189] L. Miao, Y. Ina, S. Tanemura, T. Jiang, M. Taneura, K. Kaneko, S. Toh, Y. Mori, Surf. Sci., 601 (2007) 2792.

[190] C. He, Y. Xiong, J. Chen, C. Zha, X. Zhu, J. Photochem. Photobiol., A, 157 (2003) 71.

[191] H. Hidaka, H. Honjo, S. Horikoshi, N. Serpone, Sens. Actuators, B, 123 (2007) 822.

[192] M. Ye, J. Gong, Y. Lai, C. Lin, Z. Lin, J. Am. Chem. Soc., 134 (2012) 15720.

[193] C. Hu, T. Peng, X. Hu, Y. Nie, X. Zhou, J. Qu, H. He, J. Am. Chem. Soc., 132 (2010) 857.

[194] P. Christopher, D. B. Ingram, S. Linic, J. Phys. Chem. C, 114 (2010) 9173.

[195] L. Wang, C. Clavero, Z. Huba, K. J. Carroll, E. E. Carpenter, D. Gu, R. A. Lukaszew, Nano Lett., 11 (2011) 1237.

[196] W. Choi, A. Termin, M. Hoffmann, J. Phys. Chem., 84 (1994) 13669.

[197] M. Litter, Appl. Catal., B, 23 (1999) 89.

[198] D. Dvoranova, V. Brezova, M. Mazur, M. Malati, Appl. Catal., B, 37 (2002) 91.

[199] A. Xu, Y. Gao, H. Liu, J. Catal., 207 (2002) 151. 
[200] A.D. Paola, G. Marci, L. Palmisano, M. Schiavello, K. Uosaki, S. Ikeda, J Phys Chem B, 106 (2002) 637.

[201] X. Wu, Z. Ma, Y. Qin, X. Qi, Z. Liang, Chin. J. Chem. Phys., 20 (2004) 138.

[202] K. Wilke, H. D. Breuer, J Photochem Photobiol A: Chem, 121 (1999) 49.

[203] M. Ni, M. K. H. Leung, D. Y. C. Leung, K. Sumathy, Renewable Sustainable Energy Rev., 11 (2007) 401.

[204] H. Irie, S. Miura, K. Kamiya, K. Hashimoto, Chem. Phys. Lett., 457 (2008) 202.

[205] H. Yu, H. Irie, Y. Shimodaira, Y. Hosogi, Y. Kuroda, M. Miyauchi, K. Hashimoto, J. Phys. Chem. C, 114 (2010) 16481.

[206] T. Morikawa, T. Ohwaki, K. I. Suzuki, S. Moribe, S. Tero-Kubota, Appl. Catal. B, 83 (2008) 56.

[207] R. Asahi, T. Morikawa, H. Irie, T. Ohwaki, Chem. Rev., 114 (2014) 9824.

[208] S. Peng, Y. Li, F. Jiang, G. Lu, S. Li, Chem. Phys. Lett., 398 (2004) 235.

[209] N. L. Wu, M. S. Lee, Int. J. Hydrogen Energy, 29 (2004) 1601.

[210] M. Takeuchi, H. Yamashita, M. Matsuoka, M. Anpo, T. Hirao, N. Itoh, Catal. Lett., 67 (2000) 135.

[211] H. Yamashita, M. Harada, J. Misaka, Takeuchi, M.I. K, M. Anpo, J. Photochem. Photobiol., A, 148 (2002) 257.

[212] Y. Yalçın, Murat Kılıç, Z. Çınar, Appl. Catal. B, 99 (2010) 469.

[213] A. Mattsson, M. Leideborg, K. Larsson, G. Westin, L. Österlund, J. Phys. Chem. B, 110 (2006) 1210.

[214] B. J. Morgan, D. O. Scanlona, G. W. Watson, J. Mater. Chem., 19 (2009) 5175.

[215] J. Yu, Q. Xiang, M. Zhou, Appl. Catal. B, 90 (2009) 595.

[216] C. D. Valentin, G. Pacchioni, H. Onishi, A. Kudo, Chem. Phys. Lett. , 469 (2009) 166.

[217] G. Shao, J. Phys. Chem. C, 113 (2009) 6800.

[218] X. Li, X. Chen, H. Niu, X. Han, T. Zhang, J. Liu, H. Lin, F. Qu, J Colloid Interface Sci, 452 (2015) 89.

[219] I. Tamiolakis, I. N. Lykakis, G. S. Armatas, Cat. Today, 250 (2015) 180.

[220] R. A. Doong, C.H. Chen, R. A. Maithreepala, S. M. Chang, Water Res., 35 (2001) 2873.

[221] M. G. Kang, H.E. Han, K. J. Kim, J. Photochem. Photobiol., A, 125 (1999) 119.

[222] W. W. So, K. J. Kim, S.J. Moon, Int. J. Hydrogen Energy, 29 (2004) 229.

[223] G. C. De, A. M. Roy, S.S. Bhattacharya, Int. J. Hydrogen Energy, 21 (1996) 19.

[224] A. Koca, M. Sahin, Int. J. Hydrogen Energy, 27 (2002) 363.

[225] V. Keller, F. Garin, Catal. Commun., 4 (2003) 377.

[226] D. Li, H. Haneda, N. Ohashi, S. Hishita, Y. Yoshikawa, Catal. Today, 93 (2004) 895.

[227] Y. L. Lee, Y. S. Lo, Adv. Funct. Mater. , 19 (2009) 604.

[228] A. Braga, S. Gimenez, I. Concina, A. Vomiero, I. Mora-Sero, J. Phys. Chem. Lett., 2 (2011) 454.

[229] H. J. Lee, P. Chen, S. J. Moon, F. Sauvage, K. Sivula, T. Bessho, D. R. Gamelin, P. Comte, S. M. Zakeeruddin, S. I. Seok, M. Gratzel, M. K. Nazeeruddin, Langmuir, 25 (2009) 7602.

[230] P. Sudhagar, J. H. Jung, S. Park, Y. G. Lee, R. Sathyamoorthy, Y. S. Kang, H. Ahn, Electrochem. Commun., 11 (2009) 2220.

[231] V. Gonzalez-Pedro, X. Q. Xu, I. Mora-Sero, J. Bisquert, ACS Nano, 4 (2010) 5783.

[232] R. Vogel, P. Hoyer, H. Weller, J. Phys. Chem. B, 98 (1994) 3183.

[233] A. Zaban, O. I. Micic, B. A. Gregg, A. J. Nozik, Langmuir, 14 (1998) 3153.

[234] L. M. Peter, K. G. U. Wijayantha, D. J. Riley, J. P. J. Waggett, Phys. Chem. B, 107 (2003) 8378.

[235] T. L. Li, Y. L. Lee, H. Teng, Energy Environ. Sci., 5 (2012) 5315. 
[236] A. M. Smith, S. M. Nie, Acc. Chem. Res., 43 (2010) 190.

[237] A. Kongkanand, K. Tvrdy, K. Takechi, M. Kuno, P. V. Kamat, J. Am. Chem. Soc, 130 (2008) 4007.

[238] W. A. Tisdale, K. J. Williams, B. A. Timp, D. J. Norris, E. S. Aydil, X. Y. Zhu, Science, 328 (2010) 1543.

[239] V. I. Klimov, J. Phys. Chem. B, 110 (2006) 16827.

[240] J. B. Sambur, T. Novet, B. A. Parkinson, Science, 330 (2010) 66.

[241] J. Fang, J. Wu, X. Lu, Y. Shen, Z. Lu, Chem. Phys. Lett., 270 (1997) 145.

[242] T. Lo'pez-Luke, A. Wolcott, L. P. Xu, S. Chen, Z. Wen, J. Li, E. D. l. Rosa, J. Z. Zhang, J. Phys. Chem. C, 112 (2008) 1282.

[243] H. M. Pathan, P. V. Salunkhe, B. R. Sankapal, C. D. Lokhande, Mater. Chem. Phys., 72 (2001) 105.

[244] Y. Xie, S. H. Heo, Y. N. Kim, S. H. Yoo, S. O. Cho, Nanotechnology, 21 (2010) 15703.

[245] H. T. Li, X.D. He, Z. H. Kang, H. Huang, Y. Liu, J. L. Liu, S. Y. Lian, C. C.A. Tsang, X. B. Yang, S. T. Lee, Angew. Chem., Int. Ed., 49 (2010) 4430.

[246] H. C. Zhang, H. Huang, H. Ming, H.T. Li, L. L. Zhang, Y. Liu, Z. H. Kang, J. Mater. Chem., 22 (2012) 10501.

[247] W. Lee, S. H. Kang, J. Y. Kim, G. B. Kolekar, Y. E. Sung, S. H. Han, Nanotechnology, 20 (2009) 335706.

[248] J. C. Conesa, J. Phys. Chem. C, 116 (2012) 18884.

[249] A. A. Lisachenko, V. N. Kuznetsov, M. N. Zacharov, R. V. Michailov, Kinet. Catal. , 45 (2004) 189.

[250] I. Nakamura, N. Negishi, S. Kutsuna, T. Ihara, S. Sugihara, K. Takeuchi, J. Mol. Catal. A-Chem., 161 (2000) 205.

[251] D. Zhang, M. Yang, S. Dong, RSC Adv., 5 (2015) 35661.

[252] X. Xin, T. Xu, J. Yin, L. Wang, C. Wang, Appl. Catal. B, 176-177 (2015) 354.

[253] A. G. Thomas, W. R. Flavel, R. Stockbauer, S. Patel, M. Gratzel, R. Hengerer, Phys. Rev. B, 67 (2003) 035110.

[254] C. D. Valentin, G. Pacchioni, A. Selloni, Phys. Rev. Lett. , 97 (2006) 166803.

[255] B. J. Morgan, G. W. Watson, Surf. Sci., 601 (2007) 5034.

[256] C. J. Calzado, N. C. Hernández, J. F. Sanz, Phys. Rev. B, 77 (2008) 045118.

[257] G. Mattioli, F. Filippone, P. Alippi, A. A. Bonapasta, Phys. Rev. B, 78 (2008) 241201.

[258] T. Ihara, M. Miyoshi, Y. Iriyama, O. Matsumoto, S. Sugihara, Appl. Catal., B: Environ., 42 (2003) 403.

[259] J. L. Gole, J. D. Stout, C. Burda, Y. Lou, X. Chen, J. Phys. Chem. B, 108 (2004) 1230.

[260] C. D. Valentin, G. Pacchioni, A. Selloni, S. Livraghi, E. Giamello, J. Phys. Chem. B, 109 (2005) 11414.

[261] H. Liu, H.T. Ma, X.Z. Li, W.Z. Li, M. Wu, X.H. Bao, Chemosphere, 50 (2003).

[262] H. Y. Yin, X. L. Wang, L. Wang, Q. L. N, H.T. Zhao, J. Alloys Compd., 640 (2015) 68.

[263] X. Chen, L. Liu, P.Y. Yu, S.S. Mao, Science, 331 (2011) 746.

[264] S. Na-Phattalung, M.F. Smith, K. Kim, M. H. Du, S. H. Wei, S. B. Zhang, S. Limpijumnong, Phys. Rev. B: Condens. Matter, 73 (2006) 125205.

[265] H. Kamisaka, K. Yamashita, J. Phys. Chem. C, 115 (2011) 8265.

[266] T. Umebayashi, T. Yamaki, H. Itoh, K. Asai, Appl. Phys. Lett., 81 (2002) 454.

[267] S. U.M. Khan, M.A. S. Jr, W. BI, Science., 297 (2002) 2243.

[268] A. Hattori, M. Yamamoto, H. Tada, S. Ito, Chem. Lett., 216 (1998) 707.

[269] G. Torres, T. Lindgren, J. Lu, C. Granqvist, S. Lindquist, J. Phys. Chem. B, 108 (2004) 5995. 
[270] H. Li, Y. Hao, H. Lu, L. Liang, Y. Wang, J. Qiu, X. Shi, Y. Wang, J. Yao, Appl. Surf. Sci., 344 (2015) 112.

[271] Y. Cong, J. Zhang, F. Chen, M. Anpo, J. Phys. Chem. C, 111 (2007) 6976.

[272] S. Shakthivel, H. Kisch, Chem. Phys. Chem., 13 (2003) 2996.

[273] T. Lindgren, J. M. Mwabora, E. Avenano, J. Jonsson, A. Hoel, C. G. Granqvist, S. E. Lindquist, J. Phys. Chem. B, 107 (2003) 5709.

[274] Y. Aita, M. Komatsu, S. Yin, T. Sato, J. Solid State Chem., 177 (2004) 3235.

[275] S. Livraghi, M. Pelaez, J. Biedrzycki, I. Corazzari, E. Giamello, D. D. Dionysiou, Cat. Today, 209 (2013) 54.

[276] K. Prabakar, T. Takahashi, T. Nezuka, K. Takahashi, T. Nakashima, Y. Kubota, A. Fujishima, Renewable Energy, 33 (2008) 277.

[277] Y. Liu, K. Mu, J. Zhong, K. Chen, Y. Zhang, G. Yang, L. Wang, S. H. Deng, F. Shen, X. Zhang, RSC Adv., (2015) 10.1039/C1035RA05367F.

[278] N. T. Nolan, D. W. Synnott, M. K. Seery, S. J. Hinder, A. V. Wassenhoven, S. C. Pillai, J. Hazard. Mater., 211- 212 (2012) 88.

[279] T. C. Jagadale, S. P. Takale, R. S. Sonawane, H. M. Joshi, S. I. Patil, B. B. Kale, S. B. Ogale, J. Phys. Chem. C, 112 (2008) 14595.

[280] H. Li, J. Li, Y. Huo, J. Phys. Chem. B, 110 (2006) 1559.

[281] S. Yin, H. Yamaki, M. Komatsu, Q. Zhang, J. Wang, Q. Tang, F. Saito, T. Sato, J. Mater. Chem., 13 (2003) 2996.

[282] D. Wu, M. Long, W. Cai, C. Chen, Y. Wu, J. Alloys Compd., 502 (2010) 289.

[283] F. Peng, L. Cai, H. Yu, H. Wang, J. Yang, J. Solid State Chem., 181 (2008) 130.

[284] T. Morikawa, R. Asahi, T. Ohwaki, K. Aoki, Y. Taga, Jpn. J. Appl. Phys, 40 (2001) L561.

[285] H. Irie, Y. Watanabe, K. Hashimoto, J. Phys. Chem. B, 107 (2003) 5483.

[286] O. Diwald, T.L. Thompson, E. G. Goralski, S. D. Walck, J. T. Yates, J. Phys. Chem. B, 108 (2004) 52.

[287] R. Nakamura, T. Tanaka, Y. Nakoto, J. Phys. Chem. B, 108 (2004) 10617.

[288] A. V. Emeline, V. N. Kuznetsov, V. K. Rybchuk, N. Serpone, Int. J. Photoenergy, 258 (2008) 1.

[289] F. Spadavecchia, G. Cappelletti, S. Ardizzone, M. Ceotto, L. Falciola, J. Phys. Chem. C, 115 (2011) 6381.

[290] I. N. Martyanov, S. Uma, S. Rodrigues, K. J. Klabunde, Chem. Commun., 7 (2004) 2476.

[291] X. Tian-hua, S. Chen-lu, L. Yong, H. Gao-rong, Journal of Zhejiang University Science B, 7 (2006) 299.

[292] M. D. Segall, P. J. D. Lindan, M. J. Probert, C. J. Pickard, P. J. Hasnip, S. J. Clark, M. C. Payne, J. Phys.: Condens. Matter, 14 (2002) 2717.

[293] G. Barolo, S. Livraghi, M. Chiesa, M. C. Paganini, E. Giamello, J. Phys. Chem. C, 116 (2012) 20887.

[294] S. Livraghi, M. C. Paganini, E. Giamello, A. Selloni, C. D. Valentin, G. Pacchioni, J. Am. Chem. Soc., 128 (2006) 15666.

[295] E. Finazzi, C. D. Valentin, J. Phys. Chem. C, 111 (2007) 9275.

[296] J. Graciani, L. J. Álvarez, J. A. Rodriguez, J. F. Sanz, J. Phys. Chem. C, 112 (2008) 2624.

[297] C. D. Valentin, E. Finazzi, G. Pacchioni, A. Selloni, S. Livraghi, M. C. Paganini, E. Giamello, Chem. Phys. Chem., 339 (2007) 44.

[298] S. Sakthivel, H. Kisch, Angew. Chem., Int. Ed., 42 (2003) 4908.

[299] G. Wu, T. Nishikawa, B. Ohtani, A. Chen, Chem. Mater., 19 (2007) 4530. 
[300] J. W. Park, D. W. Kim, H. S. Seon, K. S. Kim, D. W. Park, Thin Solid Films, 518 (2010) 4113.

[301] D. Chu, X. Yuan, G. Qin, M. Xu, P. Zheng, J. Lu, L. Zha, J. Nanopart. Res., 10 (2008) 357.

[302] P. Shao, J. Tian, Z. Zhao, W. Shi, S. Gao, F. Cui, Appl. Surf. Sci., 324 (2015) 35.

[303] J. H. Park, S. Kim, A. J. Bard, Nano Lett., 6 (2006) 24.

[304] Z. Wu, F. Dong, W. Zhao, H. Wang, Y. Liu, B. Guan, Nanotechnology, 20 (2009) 235701.

[305] J. W. Shi, X. Zong, X. Wu, H. J. Cui, B. Xu, L. Wang, M. L. Fu, Chem. Cat. Chem., 4 (2012) 488.

[306] S. U. M. Khan, M. Al-Shahry, W. B. Ingler, Science, 297 (2002) 2243.

[307] Y. Choi, T. Umebayashi, M. Yoshikawa, J. Mater. Sci., 39 (2004) 1837.

[308] H. Irie, Y. Watanabe, K. Hashimoto, Chem. Lett., 32 (2003) 772.

[309] C. D. Valentin, G. Pacchioni, A. Selloni, Chem. Mater., 17 (2005) 6656.

[310] T. Ohno, M. Akiyoshi, T. Umebayashi, K. Asai, T. Mitsui, M. Matsumura, Appl. Catal., A, 265 (2004) 115.

[311] Y. Cui, H. Du, L. Wen, Solid State Commun., 149 (2009) 634.

[312] F. Tian, C. Liu, W. Zhao, X. Wang, Z. Wang, J.C. Yu, J. Comput. Sci. Eng., 1 (2011) 32.

[313] F. Dong, W. Zhao, Z. Wu, Nanotechnology, 19 (2008) 365607.

[314] D. Li, H. Haneda, N. K. Labhsetwar, S. Hishita, N. Ohashi, Chem. Phys. Lett., 401 (2005) 579.

[315] W. Ho, J. C. Yu, S. Lee, Chem. Commun., 10 (2006) 1115.

[316] S. C. Padmanabhan, S. C. Pillai, J. Colreavy, S. Balakrishnan, D. E. McCormack, T. S. Perova, Y. Gun'ko, S. J. Hinder, J. M. Kelly, Chem. Mat., 19 (2007) 4474.

[317] J. Yu, J. Fan, K. Lv, Nanoscale, 2 (2010) 2144.

[318] M. V. Dozzi, E. Selli, Catalysts, 3 (2013) 455.

[319] J. Xu, Y. Ao, D. Fu, C. Yuan, Appl. Surf. Sci., 254 (2008) 3033.

[320] S. Tojo, T. Tachikawa, M. Fujitsuka, T. Majima, J. Phys. Chem. C, 112 (2008) 14948.

[321] G. Liu, Z. Chen, C. Dong, Y. Zhao, F. Li, G.Q. Lu, H. M. Cheng, J. Phys. Chem. B, 110 (2006) 20823.

[322] X. Hong, Z. Wang, W. Cai, F. Lu, J. Zhang, Y. Yang, N. Ma, Y. Liu, Chem. Mater., 17 (2005) 1548.

[323] W. Su, Y. Zhang, Z. Li, L. Wu, X. Wang, J. Li, X. Fu, Langmuir, 24 (2008) 3422.

[324] J. C. Yu, J. G. Yu, W. K. Ho, Z. T. Jiang, L. Z. Zhang, Chem. Mater., 14 (2002) 3808.

[325] G. Liu, C. Sun, X. Yan, L. Cheng, Z. Chen, X. Wang, L. Wang, S. C. Smith, G. Q. Lu, H. M. Cheng, J. Mater. Chem., 19 (2009) 2822.

[326] G. Xiang, T. Li, J. Zhuang, X. Wang, Chem. Commun., 46 (2010) 6801.

[327] Q. Zhang, Y. Li, E. A. Ackerman, M. G. Josifovska, H. Li, Applied Catalysis A: General, 400 (2011) 195.

[328] M. Harb, J. Phys. Chem. C, 117 (2013) 25229.

[329] I. E. Grey, C. Li, C. Macrae, J. Solid State Chem., 127 (1996) 240.

[330] D. Chen, D. Yang, Q. Wang, Z. Y. Jiang, Ind. Eng. Chem. Res., 45 (2006) 4110.

[331] W. Zhao, W. H. Ma, C.C. Chen, J. C. Zhao, Z. G. Shuai, J. Am. Chem. Soc., 126 (2004) 4782.

[332] S. In, A. Orlov, R. Berg, F. Garc1'a, S. P. Jimenez, M. S. Tikhov, D. S. Wright, R. M. Lambert, J. Am. Chem. Soc., 129 (2007) 13790.

[333] J. Xu, Y. Ao, M. Chen, D. Fu, J. Alloys Compd., 484 (2009) 73.

[334] V. Stengl, V. Houskova, S. Bakardjieva, N. Murafa, ACS Appl. Mater. Interfaces, 2 (2010) 575. 
[335] E. Finazzi, C.D. Valentin, G. Pacchioni, J. Phys. Chem. C, 113 (2009) 220.

[336] J. Pan, G. Liu, G. Q. Lu, H. M. Cheng, Angew. Chem., Int. Ed., 50 (2011) 2133.

[337] G. Zheng, J. Wang, X. Liu, A. Yang, H. Song, Y. Guo, H. Wei, C. Jiao, S. Yang, Q. Zhu, Z. Wang, Appl. Surf. Sci. , 256 (2010) 7327.

[338] FengHui, ChengBu, J. Phys. Chem. B, 110 (2006) 17866.

[339] K. Yang, Y. Dai, B. Huang, J. Phys. Chem. C, 111 (2007) 12086.

[340] K. Yang, Y. Dai, B. Huang, J. Phys. Chem. C, 111 (2007) 18985.

[341] K. Yang, Y. Dai, B. Huang, M. H. Whangbo, Chem. Mater., 20 (2008) 6528.

[342] J. Graciani, Y. Ortega, J. F. Sanz, Chem. Mater., 21 (2009) 1431.

[343] R. Long, Y. Dai, B. Huang, Comp. Mater. Sci, 45 (2009) 223.

[344] C. D. Valentin, G. Pacchioni, Cat. Today 206 (2013) 12.

[345] J. H. Xu, J. Li, W. L. Dai, Y. Cao, H. Li, K. Fan, Appl. Catal. B: Environ., 79 (2008) 72.

[346] J. A. R. Herrera, E. Mielczarski, J. Mielczarski, N. C. Castillo, J. Kiwi, Appl. Catal. B: Environ., 84 (2008) 448.

[347] P. Periyat, D. E. McCormack, S. J. Hinder, S. C. Pillai, J. Phys. Chem. C, 113 (2009) 3246.

[348] Q. Xiang, J. Yu, M. Jaroniec, Phys. Chem. Chem. Phys., 13 (2011) 4853.

[349] Q. C. Xu, D. V. Wellia, S. Yan, D. W. Liao, T. M. Lim, T. T. Tan, J. Hazard Mater., 188 (2011) 172.

[350] J. Wang, B. Huang, Z. Wang, X. Qin, X. Zhang, Rare Metals, 30 (2011) 161.

[351] M. Lim, Y. Zhou, B. Wood, Y. Guo, L. Wang, V. Rudolph, G. Lu, J. Phys. Chem. C, 112 (2008) 19655.

[352] P. Xu, T. Xu, J. Lu, S. Gao, N.S. Hosmane, B. Huang, Y. Daid, Y. Wang, Energy Environ. Sci., 3 (2010) 1128.

[353] R. Zhang, Q. Wang, Q. Li, J. Dai, D. Huang, Physica B: Cond. Matter, 406 (2011) 3417.

[354] M. Xing, Y. Wu, J. Zhang, F. Chen, Nanoscale, 7 (2010) 1233.

[355] G. Liu, L. C. Yin, J. Wang, P. Niu, C. Zhen, Y. Xie, H. M. Cheng, Energy Environ. Sci., 5 (2012) 9603.

[356] Y. Lin, Z. Jiang, C. Zhu, X. Hu, X. Zhang, H. Zhu, J. Fan, S. H. Lin, J. Mater. Chem. A, 1 (2013) 4516.

[357] C. D. Valentin, E. Finazzi, G. Pacchioni, A. Selloni, S. Livraghi, A. M. Czoska, M.C. Paganini, E. Giamello, Chem. Mater., 20 (2008) 3706.

[358] A.M. Czoska, S. Livraghi, M.C. Paganini, E. Giamello, C.D. Valentin, G. Pacchioni, Phys. Chem. Chem. Phys., 13 (2011) 136.

[359] P. Zhou, J. Yu, Y. Wang, Appl. Catal. B, 142 (2013) 45.

[360] V. Gombac, L.D. Rogatis, A. Gasparotto, G. Vicario, T. Montini, D. Barreca, G. Balducci, P. Fornasiero, E. Tondello, M. Graziani, Chem. Phys., 339 (2007) 111.

[361] J. W. J. Hamilton, J. A. Byrne, P. S. M. Dunlop, D. D. Dionysiou, M. Pelaez, K. O’Shea, D. Synnott, S.C. Pillai, J. Phys. Chem. C, 118 (2014) 12206.

[362] C. Zhao, M. Pelaez, D. D. Dionysiou, S. C. Pillai, J. A. Byrne, K. E. O'Shea, Catal. Today, 224 (2014) 70.

[363] T. M. Breault, B. M. Bartlett, J. Phys. Chem. C, 116 (2012) 5986.

[364] T. M. Breault, B. M. Bartlett, J. Phys. Chem. C, 117 (2013) 8611.

[365] M. Nasir, Z. Xi, M. Xing, J. Zhang, F. Chen, B. Tian, S. Bagwasi, J. Phys. Chem. C, 117 (2013) 9520.

[366] L. Sun, X. Zhao, X. Cheng, H. Sun, Y. Li, P. Li, W. Fan, Langmuir, 28 (2012) 5882.

[367] M.J. Yang, C. Hume, S. Lee, Y.H. Son, J.K. Lee, J. Phys. Chem. C, 114 (2010) 15292. 
[368] J. W. Liu, R. Han, Y. Zhao, H. T. Wang, W. J. Lu, T. F. Yu, Y. X. Zhang, J. Phys. Chem. C, 115 (2011) 4507.

[369] E. J. Wang, T. He, L. S. Zhao, Y. M. Chen, Y. A. Cao, J. Mater. Chem., 21 (2011) 144.

[370] H. B. Liu, Y. M. Wu, J. L. Zhang, ACS Appl. Mater. Interfaces, 3 (2011) 1757.

[371] J. Zhang, Y. Wu, M. Xing, S. A. K. Leghari, S. Sajjad, Energy Environ. Sci., 3 (2010) 715.

[372] Y. Cong, J. L. Zhang, F. Chen, M. Anpo, J. Phys. Chem. C, 111 (2007) 10618.

[373] M. Y. Xing, J. L. Zhang, F. Chen, J. Phys. Chem. C, 113 (2009) 12848.

[374] K. Obata, H. Irie, K. Hashimoto, Chem. Phys. Chem., 339 (2007) 124.

[375] X. Zhang, Q. Liu, Appl. Surf. Sci., 254 (2008) 4780.

[376] D. E. Gu, B. C. Yang, Y. D. Hu, Catal. Commun., 9 (2008) 1472.

[377] L. Yu, X. Yang, J. He, Y. He, D. Wang, J. Alloys Compd. , 637 (2015) 308.

[378] X. Li, Q. Liu, X. Jiang, J. Huang, Int. J. Electrochem. Sci., 7 (2012) 11519.

[379] Y. F. Li, D. Xu, J. I. Oh, W. Shen, X. Li, Y. Yu, ACS Catal., 2 (2012) 391.

[380] S. S. Thind, G. Wu, M. Tian, A. Chen, Nanotechnology, 23 (2012) 475706.

[381] M. E. Kurtoglu, T. Longenbach, K. Sohlberg, Y. Gogotsi, J. Phys. Chem. C, 115 (2011) 17392.

[382] N. Feng, Q. Wang, A. Zheng, Z. Zhang, J. Fan, S. B. Liu, J. P. Amoureux, F. Deng, J. Am. Chem. Soc., 135 (2013) 1607.

[383] Y. Su, Y. Xiao, Y. Li, Y. Du, Y. Zhang, Mater. Chem. Phys., 126 (2011) 761-768.

[384] S. Bouhadoun, C. Guillard, F. Dapozze, S. Singh, D. Amans, J. Bouclé, N. HerlinBoime, Appl. Catal. B, 174-175 (2015) 367.

[385] G. R. Torres, T. Lindgren, J. Lu, C. G. Granqvist, S. E. Lindquist, J. Phys. Chem. B 108 (2004) 5995.

[386] T. Kawahara, Y. Konishi, H. Tada, N. Tohge, J. Nishii, S. Ito, Angew. Chem., Int. Ed., 41 (2002) 2811.

[387] P. Zhang, B. Liu, S. Yin, YuhuaWang, V. Petrykin, M. Kakihana, T. Sato, Mater. Chem. Phys., 116 (2009) 269.

[388] Y. Yuan, J. Ding, J. Xu, J. Deng, J. Guo, J. Nanosci. Nanotechnol. , 10 (2010) 4868.

[389] Y. Ortega, N.C. Hernández, E. M. Proupin, J. Graciani, J. F. Sanz, Phys. Chem. Chem. Phys., 13 (2011) 11340.

[390] D. B. Hamal, J. A. Haggstrom, G. L. Marchin, M. A. Ikenberry, K. Hohn, K.J. Klabunde, Langmuir, 26 (2010) 2805.

[391] P. Wu, R. Xie, K. Imlay, J. K. Shang, Environ Sci Technol., 44 (2010) 6992.

[392] D. O. Scanlon, C. W. Dunnill, J. Buckeridge, S. A. Shevlin, A. J. Logsdail, S. M. Woodley, C. R. A. Catlow, M. J. Powell, R. G. Palgrave, I. P. Parkin, G. W. Watson, T. W. Keal, P. Sherwood, A. Walsh, A. A. Sokol, Nat. Mater., 12 (2013) 798.

[393] H. Zhang, X. Lv, Y. Li, Y. Wang, J. Li, ACS Nano, 4 (2010) 380.

[394] K. K. Manga, S. Wang, M. Jaiswal, Q. Bao, K.P. Loh, Adv. Mater., 22 (2010) 5265.

[395] Y. Wen, H. Ding, Y. Shan, Nanoscale, 3 (2011) 4411.

[396] N. Li, G. Liu, C. Zhen, F. Li, L. Zhang, H. M. Cheng, Adv. Funct. Mater., 21 (2011) 1717.

[397] Y. T. Liang, B. K. Vijayan, K. A. Gray, M. C. Hersam, Nano Lett., 11 (2011) 2865.

[398] G. Williams, B. Seger, P. V. Kamat, ACS Nano, 2 (2008) 1487.

[399] N. J. Bell, Y. H. Ng, A. Du, H. Coster, S. C. Smith, R. Amal, J. Phys. Chem. C, 115 (2011) 6004.

[400] C. Nethravathi, M. Rajamathi, Carbon, 46 (2008) 1994.

[401] T. N. Lambert, C. A. Chavez, B. H. Sanchez, P. Lu, N. S. Bell, A. Ambrosini, T. Friedman, T. J. Boyle, D. R. Wheeler, D. L. Huber, J. Phys. Chem. C, 113 (2009) 19812. 
[402] O. Akhavan, E. Ghaderi, J. Phys. Chem. C, 113 (2009) 20214.

[403] X. Y. Zhang, H. P. Li, X. L. Cui, Y. Lin, J. Mater. Chem., 20 (2010) 2801.

[404] Y. Zhang, Z. R. Tang, X. Fu, Y. J. Xu, ACS Nano, 4 (2010) 7303.

[405] N. Yang, Y. Liu, HaoWen, Z. Tang, H. Zhao, Y. Li, DanWang, ACS Nano, 7 (2013) 1504.

[406] W. Liu, J. Cai, Z. Ding, Z. Li, Appl. Catal. B, 174-175 (2015) 421.

[407] L. L. Tan, W. J. Ong, S. P. Chai, A.R. Mohamed, Nanoscale Res. Lett., 8 (2013) 465.

[408] I. V. Lightcap, T. H. Kosel, P. V. Kamat, Nano Lett., 10 (2010) 577.

[409] J. C. Liu, H. W. Bai, Y. J. Wang, Z. Y. Liu, X. W. Zhang, D. D. Sun, Adv. Funct. Mater., 20 (2010) 4175.

[410] Q. Xiang, J. Yu, M. Jaroniec, Nanoscale, 3 (2011) 3670.

[411] L. Sun, Z. L. Zhao, Y. C. Zhou, L. Liu, Nanoscale, 4 (2012) 613.

[412] M. K. Kavitha, S. C. Pillai, P. Gopinath, H. John, J. Environ. Chem. Eng, 3 (2015) 1194.

[413] J. Hou, C. Yang, Z. Wang, S. Jiao, H. Zhu, Appl. Catal., B: EnViron., 129 (2013) 333.

[414] Q. Huang, S. Tian, D. Zeng, X. Wang, W. Song, Y. Li, W. Xiao, C. Xie, ACS Catal., 3 (2013) 1477.

[415] K. Woan, G. Pyrgiotakis, W. Sigmund, Adv. Mater., 21 (2009) 2233.

[416] J. Wang, W. D. Zhang, Electrochim. Acta, 71 (2012) 10.

[417] S. C. Yan, Z.S. Li, Z. G. Zou, Langmuir, 26 (2010) 3894.

[418] L. Ge, C. Han, J. Liu, Appl. Catal. B, 108-109 (2011) 100.

[419] L. Song, S. Zhang, X. Wu, Q. Wei, Chem. Eng. J., 184 (2012) 256.

[420] H. Ji, F. Chang, X. Hu, W. Qin, J. Shen, Chem. Eng. J., 218 (2013) 183.

[421] Y. Li, J. Wang, Y. Yang, Y. Zhang, D. He, Q. An, G. Cao, J. Hazard Mater., 292 (2015) 79.

[422] D. Mitoraj, H. Kisch, Angew. Chem. Int. Ed. , 47 (2008) 9975.

[423] G. Li, N. Yang, W. Wang, W. Zhang, J. Phys. Chem. C, 113 (2009) 14829.

[424] X. Wang, K. Maeda, A. Thomas, K. Takanabe, G. Xin, J.M. Carlsson, K. Domen, M. Antonietti, Nat. Mater., 8 (2009) 76.

[425] X. Lu, Q. Wang, D. Cui, J. Mater. Sci. Technol., 26 (2010) 925.

[426] B. Chai, T. Peng, J. Mao, K. Li, L. Zan, Phys. Chem. Chem. Phys., 14 (2012) 16745.

[427] H. J. Yan, H. X. Yang, J. Alloys Compd., 509 (2011) L26.

[428] W. D. Zhang, L. C. Jiang, J. S. Ye, J. Phys. Chem. C, 113 (2009) 16247.

[429] Q. J. Xiang, J. G. Yu, M. Jaroniec, J. Phys. Chem. C, 115 (2011) 7355.

[430] W. D. Zhang, B. Xu, L. C. Jiang, J. Mater. Chem., 20 (2010) 6383.

[431] L. C. Jiang, W. D. Zhang, Electrochim. Acta, 56 (2010) 406.

[432] C. I. Covaliu, L. C. Chioaru, L. Craciun, O. Oprea, I. Jitaru, Optoelectron. Adv. Mater. , 5 (2011) 1097.

[433] C. R. Kagan, D. B. Mitzi, C. D. Dimitrakopoulos, Science 286 (1999) 945.

[434] D. B. Mitzi, C. A. Feild, Z. Schlesinger, R. B. Laibowitz, J. Solid State Chem., 114 (1995) 159.

[435] A. Kojima, M. Ikegami, K. Teshima, T. Miyasaka, Chem. Lett., 41 (2012) 397.

[436] J. Burschka, N. Pellet, S. J. Moon, R. H. Baker, P. Gao, M. K. Nazeeruddin, M. Grätzel, Nature 499 (2013) 316.

[437] M. M. Lee, J. Teuscher, T. Miyasaka, T. N. Murakami, H. J. Snaith, Science, 338 (2012) 643.

[438] A. Kojima, K. Teshima, Y. Shirai, T. Miyasaka, J. Am. Chem. Soc., 131 (2009) 6050.

[439] J. H. Im, J. Chung, S. J. Kim, N. G. Park, Nanoscale Res. Lett., 7 (2012) 353.

[440] J. H. Im, C. R. Lee, J. W. Lee, S. W. Park, N. G. Park, Nanoscale, 3 (2011) 4088. 
[441] H. S. Kim, C. R. Lee, J. H. Im, K. B. Lee, T. Moehl, A. Marchioro, S.J. Moon, R.H. Baker, J. H. Yum, J. E. Moser, M. Grätzel, N. G. Park, Nat. Sci. Rep., 2 (2012) 591.

[442] I. Chung, B. Lee, J. He, R. P. H. Chang, M. G. Kanatzidis, Nature, 485 (2012) 486.

[443] L. Etgar, P. Gao, Z. Xue, Q. Peng, A. K. Chandiran, B. Liu, M. K. Nazeeruddin, M. Grätzel, J. Am. Chem. Soc., 134 (2012) 17396.

[444] F. D. Angelis, Acc. Chem. Res., 47 (2014) 3349.

[445] P. Umari, E. Mosconi, F.D. Angelis, Sci. Rep., 4 (2014) 4467.

[446] S. Colella, E. Mosconi, P. Fedeli, A. Listorti, F. Gazza, F. Orlandi, P. Ferro, T. Besagni, A. Rizzo, G. Calestani, G. Gigli, F. D. Angelis, R. Mosca, Chem. Mater., 25 (2013) 4613.

[447] A. Amat, E. Mosconi, E. Ronca, C. Quarti, P. Umari, M. K. Nazeeruddin, M. Grätzel, F. D. Angelis, Nano Lett., 14 (2014) 3608.

[448] J. Even, L. Pedesseau, J. M. Jancu, C. Katan, J. Phys. Chem. Lett., 4 (2013) 2999.

[449] J. M. Azpiroz, E. Mosconi, J. Bisquert, F. D. Angelis, Energy Environ. Sci., 8 (2015) 2118.

[450] R. Gottesman, E. Haltzi, L. Gouda, S. Tirosh, Y. Bouhadana, A. Zaban, J. Phys. Chem. Lett., 5 (2014) 2662.

[451] V. Roiati, E. Mosconi, A. Listorti, S. Colella, G. Gigli, F.D. Angelis, Nano Lett., 14 (2014) 2168.

[452] E. Mosconi, A. Amat, M. K. Nazeeruddin, M. Grätzel, F.D. Angelis, J. Phys. Chem. C, 117 (2013) 13902.

[453] X. Chen, S. Shen, L. Guo, S. S. Mao, Chem. Rev., 110 (2010) 6503.

[454] D. Jing, Y. Zhang, L. Guo, Chem. Phys. Lett. , 415 (2005) 74.

[455] Y. Ebina, T. Sasaki, M. Harada, M. Watanabe, Chem. Mater. , 14 (2002) 4390.

[456] Y. Ikuma, H. Bessho, Int. J. Hydrogen Energy, 32 (2007) 2689.

[457] J. Kiwi, M. Gratzel, J. Phys. Chem. , 88 (1984) 1302.

[458] A. Iwase, H. Kato, A. Kudo, Catal. Lett., 108 (2006) 7.

[459] G. Wu, T. Chen, G. Zhou, X. Zong, C. Li, Sci. China, Ser. B, 51 (2008) 97.

[460] A. V. Korzhak, N. I. Ermokhina, A. L. Stroyuk, V. K. Bukhtiyarov, A.E. Raevskaya, V. I. Litvin, S. Y. Kuchmiy, V. G. Ilyin, P. A. Manorik, J. Photochem. Photobiol., A, 198 (2008) 126.

[461] K. Gurunathan, Int. J. Hydrogen Energy, 29 (2004) 933.

[462] Y. Mizukoshi, K. Sato, T. J. Konno, N. Masahashi, Appl. Catal. B, 94 (2010) 248.

[463] K. Teramura, K. Maeda, T. Saito, T. Takata, N. Saito, Y. Inoue, K. Domen, J. Phys. Chem. B 109 (2005) 21915.

[464] H. Tada, T. Mitsui, T. Kiyonaga, T. Akita, K. Tanaka, Nat. Mater., 5 (2006) 782.

[465] H. Park, W. Choi, M.R. Hoffmann, J. Mater. Chem., 18 (2008) 2379.

[466] Y. Ou, J. Lin, S. Fang, D. Liao, Chem. Phys. Lett., 429 (2006) 199.

[467] R. Brahimi, Y. Bessekhouad, A. Bouguelia, M. Trari, Catal. Today, 122 (2007) 62.

[468] F. Su, T. Wang, R. Lv, J. Zhang, P. Zhang, J. Lu, J. Gong, Nanoscale, 5 (2013) 9001.

[469] P. A. DeSario, J. J. Pietron, D. E. DeVantier, T. H. Brintlinger, R. M. Stroud, D.R. Rolison, Nanoscale, 5 (2013) 8073.

[470] W. H. Hung, T. M. Chien, C. M. Tseng, J. Phys. Chem. C, 118 (2014) 12676.

[471] C. Wang, Z. Chen, H. Jin, C. Cao, J. Lia, Z. Mi, J. Mater. Chem. A, 2 (2014) 17820.

[472] S. W. Shin, J. Y. Lee, K. S. Ahn, S. H. Kang, J. H. Kim, J. Phys. Chem. C, 119 (2015) 13375.

[473] M. Khatamian, M. S. Oskoui, M. Haghighi, M. Darbandi, Int. J. Energ. Res., 38 (2014) 1712.

[474] R. P. Cavalcante, R. F. Dantas, B. Bayarri, O. González, J. Giménez, S. Esplugas, A. M. Junior, Catal. Today, 252 (2015) 27. 
[475] Q. Zhang, G. Rao, J. Rogers, C. Zhao, L. Liu, Y. Li, Chem. Eng. J., 271 (2015) 180.

[476] E. M. Seftel, M. Niarchos, C. Mitropoulos, M. Mertens, E. F. Vansant, P. Cool, Cat. Today, 252 (2015) 120.

[477] M. A. N. Khan, M. Siddique, F. Wahid, R. Khan, Ultrason Sonochem., 26 (2015) 370.

[478] P. Dhatshanamurthi, B. Subash, M. Shanthi, Mater. Sci. Semicond. Process., 35 (2015) 22.

[479] M. J. Sampaio, C. G. Silva, A. M. T. Silva, L. M. Pastrana-Martínez, C. Han, S. Morales-Torres, J. L. Figueiredo, D. D. Dionysiou, J. L. Faria, Appl. Catal. B, 170-171 (2015) 74.

[480] V. Vaiano, O. Sacco, D. Sannino, P. Ciambelli, Appl. Catal. B, 170-171 (2015) 153.

[481] Z. Jiang, D. Jiang, Z. Yan, D. Liu, K. Qian, J. Xie, Appl. Catal. B, 170-171 (2015) 195.

[482] H. M. Ibrahim, World J. Microbiol. Biotechnol. , 7 (2015) 1049.

[483] F. Dong, Z. Wang, Y. Li, W. K. Ho, S. C. Lee, Environ. Sci. Technol., 48 (2014) 10345.

[484] J. Ma, H. He, F. Liu, Appl. Catal. B, 179 (2015) 21.

[485] C. C. Pei, W. W. F. Leung, Appl. Catal. B, 174-175 (2015) 515.

[486] G. Li, B. Jiang, S. Xiao, Z. Lian, D. Zhang, J. C. Yu, H. Li, Environ. Sci.: Processes Impacts, 16 (2014) 1975.

[487] S. O. Hay, T. Obee, Z. Luo, T. Jiang, Y. Meng, J. He, S. C. Murphy, S. Suib, Molecules, 20 (2015) 1319.

[488] Z. H. Lin, P. Roy, Z. Y. Shih, C. M. Ou, H. T. Chang, ChemPlusChem, 78 (2013) 302.

[489] H. M. Yadav, S. V. Otari, R. A. Bohara, S. S. Mali, S. H. Pawar, S. D. Delekar, J. Photochem. Photobiol A: Chem, 294 (2014) 130.

[490] J. Ananpattarachai, Y. Boonto, P. Kajitvichyanukul, Environ Sci Pollut Res Int., DOI: 10.1007/s11356-11015-14775-11351.

[491] J. W. Xu, Z. D. Gao, K. Han, Y. Liu, Y. Y. Song, ACS Appl. Mater. Interfaces 6(2014) 15122.

[492] O. Akhavan, R. Azimirad, S. Safa, M. M. Larijani, J. Mater. Chem., 20 (2010) 7386.

[493] K. Gupta, R. P. Singh, A. Pandey, A. Pandey, Beilstein J. Nanotechnol., 4 (2013) 345.

[494] H. Li, Q. Cui, B. Feng, J. Wang, X. Lu, J. Weng, Appl. Surf. Sci., 284 (2013) 179.

[495] W. S. Lee, Y. S. Park, Y. K. Cho, Analyst, 140 (2015) 616.

[496] M. Y. Lan, C. P. Liu, H. H. Huang, S. W. Lee, PLoS One, 8 (2013) 75364.

[497] V. Etacheri, G. Michlits, M. K. Seery, S. J. Hinder, S. C. Pillai, ACS Appl. Mater. Interfaces, 5 (2013) 1663.

[498] J. Z. Bloh, R. Dillert, D. W. Bahnemann, ChemCatChem, 5 (2013) 774.

[499] Z. B. Zhang, C. C. Wang, R. Zakaria, J. Y. Ying, J. Phy. Chem. B, 102 (1998) 10871.

[500] J. Z. Bloh, R. Dillert, D. W. Bahnemann, J. Phys. Chem. C, 116 (2012) 25558.

[501] D. Zhao, Y. Yu, C. Cao, J. Wanga, E. Wang, Y. Caoa, Appl. Surf. Sci. 345 (2015) 67.

[502] Y. Su, S. Han, X. Zhang, X. Chen, L. Lei, Mater. Chem. Phys. 110 (2008) 239.

[503] J. Cheng, J. Chen, W. Lin, Y. Liu, Y. Kong, Appl. Surf. Sci. 332 (2015) 573.

[504] N. Lu, H. Zhao, J. Li, X. Quan, S. Chen, Sep. Purif. Technol. 62 (2008) 668.

[505] V. Likodimos, C. Han, M. Pelaez, A. G. Kontos, G. Liu, D. Zhu, S. Liao, A. A. de la Cruz, K. O’Shea, P. S. M. Dunlop, J. A. Byrne, D. D. Dionysiou, P. Falaras, Ind. Eng. Chem. Res. 52 (2013) 13957.

[506] B. Li, Z. Zhao, F. Gao, X. Wang, J. Qiu, Appl. Catal. B 147 (2014) 958.

[507] R. Daghrir, P. Drogui, and D. Robert, Ind. Eng. Chem. Res., 52 (2013) 3581.

[508] S. Morales.-Torres, L. M. Pastrana-Martínez, J. L. Figueiredo, J. L. Faria, and A. M. T. Silva, Environmental Science and Pollution Research, 19 (2012) 3676.

[509] R. Fagan, D. E. McCormack, D. D. Dionysiou, and S. C. Pillai, Mater. Semi. Processing, 2015, 10.1016/j.mssp.2015.07.052 
Journal of Photochemistry and Photobiology C: Photochemistry Reviews, Volume 25, December 2015, Pages 1-29: doi:10.1016/j.jphotochemrev.2015.08.003

[510] D. Spasiano, R. Marotta, S. Malato, P.Fernandez-Ibañez, I. Di Somma, Appl. Catal B: Environ., 170-171 (2015) 90-123.

[511] O. Ola, M. M. Maroto-Valer, Photochem. Photobiol., R 24 (2015) 16-42.

[512] S. W. Verbruggen, Photochem. Photobiol., R 24 (2015) 64-84. 

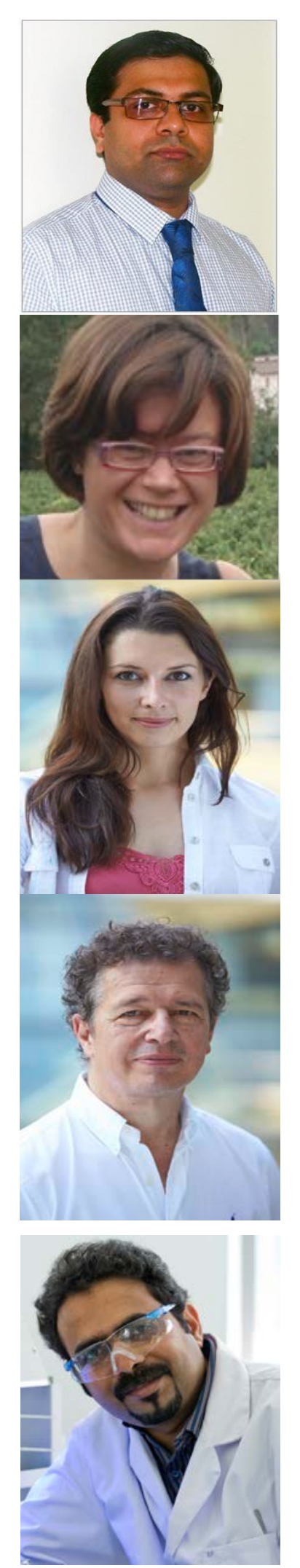

\section{Biographies}

Dr. Vinodkumar Etacheri obtained his PhD in Materials Chemistry from Dublin Institute of Technology (DIT), Ireland in 2011. This work under the guidance of Prof. Suresh C. Pillai involved the development of new generation visible-light active $\mathrm{TiO}_{2}$ nanomaterials. He then completed postdoctoral research at Bar Ilan University, Israel, and University of Michigan, USA in the area of $\mathrm{Li}$-ion and $\mathrm{Li}-\mathrm{O}_{2}$ batteries. Currently he is working as a research associate at Purdue University, USA, developing nanomaterials for a wide range of electrochemical energy storage systems. His research areas extent from semiconductor photocatalysis for environmental remediation, antibacterial applications, and water oxidation, to engineering of carbon and metal oxide based electrodes for rechargeable batteries and supercapacitors.

Prof. Cristiana Di Valentin was born in Maniago (PN) on 29/07/1973. She graduated in Chemistry in 1997 at the University of Pavia where she also received her Ph.D. degree in 2000 in collaboration with the Technische Universität München. She was appointed by the University of Milano-Bicocca as Assistant Professor in 2002 and as Associate Professor in 2012. She has been visiting scientist at the Technische Universität München, Universitat de Barcelona, Ecole Nationale Superieure de Paris and Princeton University. Her research activity spans from $a b$ initio computational study of reaction mechanisms in organic chemistry and homogeneous catalysis to heterogeneous catalysis, photocatalysis, doped and defective semiconducting oxides, graphene and carbon based materials for fuel cells.

Jenny Schneider received her M.Sc. degree in Material- and Nanochemistry in 2011 from the Gottfried Wilhelm Leibniz University Hannover. She is currently a Ph.D. student with Prof. Bahnemann at the Gottfried Wilhelm Leibniz University Hannover, investigating the reaction dynamics of photogenerated charge carriers in different photocatalysts by means of laser flash photolysis spectroscopy. Her research interests include the mechanism(s) of photocatalysis, the detailed understanding of photocatalytically induced chemical conversions as well as theoretical simulations of photocatalytic processes.

Prof. Dr. rer. nat. habil. Detlef Bahnemann has received his PhD in Chemistry from the Technical University Berlin in 1981 and his Habilitation in the area of Technical Chemistry from the Leibniz University Hannover in 2012. He is currently the Head of the Research Unit „Photocatalysis and Nanotechnology“ at the Institute of Technical Chemistry of the Leibniz University Hannover in Germany and also the Director of the Research Institute on Nanocomposite Materials for Photonic Applications at Saint Petersburg State University in Russia. His main research topics include photocatalysis, photoelectrochemistry, solar chemistry and photochemistry focussed on the synthesis and the detailed investigation of the physical-chemical properties of semiconductor and metal nanoparticles. He holds an Honorary Professorship at the Robert Gordon University in Aberdeen/Scotland (United Kingdom), an Honorary Professorship at the Xinjiang Technical Institute of Physics and Chemistry (Chinese Academy of Sciences) in Urumqi (China), the Erudite Professorship at the Mahatma Gandhi University in Kottayam (India), a Guest Professorship of Tianjin University (China), a Visiting Professorship under the Academic Icon Programme at the Universityof Malaya (Malaysia), and is DeTao Master of Photocatalysis, Nanomaterials and Energy Applications (China). Prof. Bahnemann is the lead author of more than 290 publications in peer reviewed journals that have been cited more than 24,000 times (h-index: 60 according to ISI, 68 according to Google Scholar Citations) and has edited 4 scientific books.

Prof. Suresh C. Pillai was born in Karukachal, Kottayam, Kerala, India. He has completed his BSc and MSc (with first rank) from Mahatma Gandhi University, Kottayam. Suresh has obtained his PhD in the area of Nanotechnology from Trinity College (TCD), The University of Dublin, Ireland and then performed a postdoctoral research at California Institute of Technology (Caltech), USA. He has then worked at CREST in DIT as a senior scientist responsible for nanotechnology research before moving to Institute of Technology Sligo as a senior lecturer in environmental nanotechnology. He is an elected fellow of the Royal Microscopical Society (FRMS) and the Institute of Materials, Minerals and Mining (FIMMM). $\mathrm{He}$ is responsible for acquiring more than $€ 3$ million direct $\mathrm{R} \& \mathrm{D}$ funding. Prof. Pillai is a recipient of a number of awards for research accomplishments including the 'Industrial Technologies Award 2011' from Enterprise Ireland for commercialising nanomaterials for industrial applications. He was also the recipient of the 'Hothouse Commercialisation Award 2009' from the Minister of Science, Technology and Innovation and also the recipient of the 'Enterprise Ireland Research Commercialization Award 2009'. He has also been nominated for the 'One to Watch' award 2009 for commercialising R\&D work (Enterprise Ireland). One of the nanomaterials based environmental technologies developed by his research team was selected to demonstrate as one of the fifty 'innovative technologies' (selected after screening over 450 nominations from EU) at the first Innovation Convention organised by the European Commission on 5- $6^{\text {th }}$ 
Journal of Photochemistry and Photobiology C: Photochemistry Reviews, Volume 25,

December 2015, Pages 1-29: doi:10.1016/j.jphotochemrev.2015.08.003

December 2011. He is the national delegate and technical expert for ISO standardization committee and European standardization (CEN) committee on photocatalytic materials. 